\title{
Interim Report: Manipulation of Natural Subsurface Processes: Field Research and Validation
}
J. S. Fruchter
D. J. Holford
F. A. Spane
L. E. Eary
J. E. Amonette
J. M. Zachara
J. K. Fredrickson
B. N. Bjornstad
C. R. Cole
G. D. Black
J. C. Templeton
V. R. Vermeul
T. O. Stevens
C. S. Simmons

November 1994

Prepared for

the Subsurface Science Program

Office of Health and Environmental Research and

In Situ Remediation Integrated Program

Office of Technology Development

U.S. Department of Energy

under Contract DE-AC06-76RLO 1830

Pacific Northwest Laboratory

Operated for the U.S. Department of Energy

by Battelle Memorial Institute 


\title{
DISCLAIMER
}

This report was prepared as an account of work sponsored by an agency of the United States Government. Neither the United States Government nor any agency thereof, nor Battelle Memorial Institute, nor any of their employees, makes any warranty, expressed or implied, or assumes any legal liability or responsibility for the accuracy, completeness, or usefulness of any information, apparatus, product, or process disclosed, or represents that its use would not infringe privately owned rights. Reference herein to any specific commercial product, process, or service by trade name, trademark, manufacturer, or otherwise does not necessarily constitute or imply its endorsement, recommendation, or favoring by the United States Government or any agency thereof, or Battelle Memorial Institute. The views and opinions of authors expressed herein do not necessarily state or reflect those of the United States Government or any agency thereof.

\author{
PACIFIC NORTHWEST LABORATORY \\ operated by \\ BATTELLE MEMORIAL INSTITUTE \\ for the \\ UNITED STATES DEPARTMENT OF ENERGY \\ under Contract DE-AC06-76RLO 1830
}

Printed in the United States of America

Available to DOE and DOE contractors from the

Office of Scientific and Technical Information, P.O. Box 62, Oak Ridge, TN 37831; prices available from (615) 576-8401. FTS 626-8401.

Available to the public from the National Technical Information Service,

U.S. Department of Commerce, 5285 Port Royal Rd., Springfield, VA 22161. 
PNL -10123

UC $-402,802$

INTERIM REPORT

MANIPULATION OF NATURAL SUBSURFACE

PROCESSES: FIELD RESEARCH AND VALIDATION
J. S. Fruchter
D. J. Holford
F. A. Spane
L. E. Eary
J. E. Amonette
J. M. Zachara
J. K. Fredrickson
B. N. Bjornstad
C. R. Cole
J. C. Templeton
G. D. Black
T. 0 . Stevens
V. R. Vermeul
C. S. Simmons

November 1994

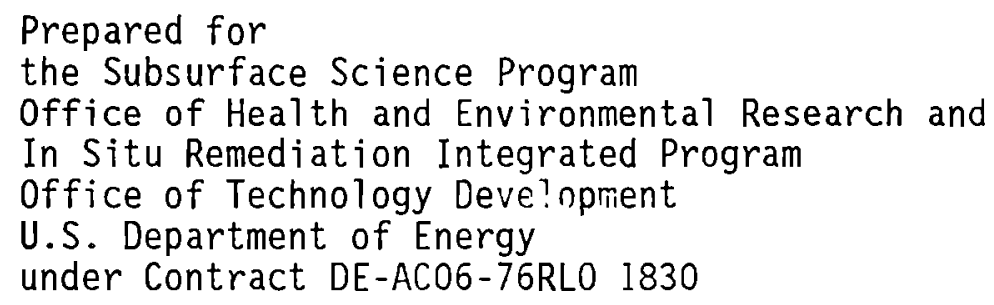

Pacific Northwest Laboratory

Richland, Washington 99352 



\section{EXECUTIVE SUMMARY}

Often the only alternative for treating deep subsurface contamination is in situ manipulation of natural processes to change the mobility or form of contaminants. However, the complex interactions of natural subsurface physical, chemical, and microbial processes limit the predictability of the system-wide impact of manipulation based on current knowledge.

This report is a summary of research conducted to examine the feasibility of controlling the oxidation-reduction (redox) potential of the unconfined aquifer at the Hanford Site in southeastern Washington State by introducing chemical reagents and microbial nutrients. The experiment would allow the testing of concepts and hypotheses developed from fundamental research in the U.S. Department of Energy's (DOE's) Subsurface Science Program. Furthermore, the achievement of such control is expected to have implications for in situ remediation of dispersed aqueous contaminants in the subsurface environment at DOE sites nationwide, and particularly at the Hanford Site.

This interim report summarizes initial research that was conducted between July 1990 and October 1991. The results of this research led to the transfer of the concept to the DOE In Situ Remediation Integrated Program, Office of Technology Development, in the Office of Environmental Restoration and Waste Management for further research leading to implementation.

The concept underlying the experiments is that the addition of chemical reagents and/or microbial nutrients to the aquifer through an injection well would create chemically reducing conditions in the aquifer, and thus create a geochemical or permeable treatment barrier. Such a geochemical barrier could be a powerful tool for future remediation of dispersed contaminants on DOE 1ands. The reagents and nutrients used were those previously found to result in on $1 y$ temporary changes to the aquifer chemistry.

A national workshop was conducted to guide initial experimental design, and a multidisciplinary team was assembled to conduct limited experimentation and modeling leading to field experimentation. This report reflects the Subsurface Science Program component of the research, summarizing efforts to 1) determine the effectiveness of abiotic reducing agents, 2) characterize 
microbial populations and nutrient requirements in the subsurface environment at Hanford, and 3) determine the sensitivity of the experiment to natural heterogeneity of the system and to experimental parameters, using hydrologic models and computer visualization methods.

Recommended future research includes 1) determination of the efficacy of additional chemical reagents and the impact of resulting dissimilatory ironreducing conditions on reduction of aquifer solids, 2) computer simulations to optimize reagent dispersal and recovery in the subsurface environment, and 3) evaluation of gradient control methods to increase reagent residence time in the subsurface environment.

Successful completion of the proposed field experiment also requires thorough characterization of the field site. Therefore, a three-phase plan is proposed for characterization of the hydrophysical, geochemical, and microbiological properties of the field site, which, in conjunction with the proposed future research, should provide the knowledge needed to initiate the field study. 


\section{CONTENTS}

EXECUTIVE SUMMARY ..............................

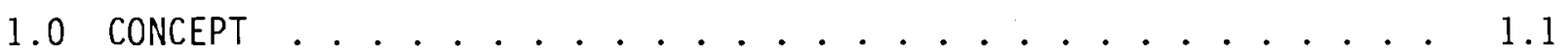

1.1 APPLICABILITY TO DOE CONTAMINANT REMEDIATION $\ldots \ldots \ldots . . . .4$

1.2 RATIONALE FOR FIELD STUDY . . . . . . . . . . . . 1.4

1.3 BACKGROUND . . . . . . . . . . . . . . . . . 1.5

1.4 PROJECT DESCRIPTION . . . . . . . . . . . . . . 1.8

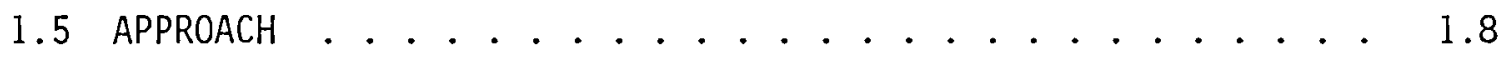

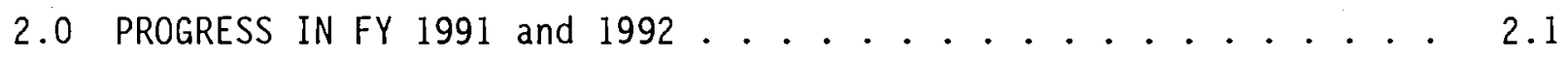

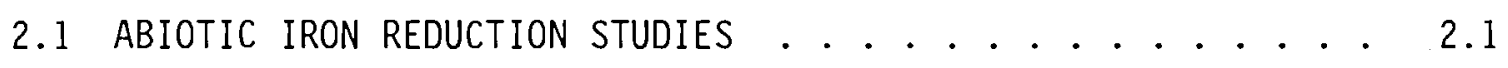

2.1 .1 Materials and Methods ........... 2.2

2.1 .2 Goethite Reduction........... 2.3

2.1.3 Smectite Reduction........... 2.5

2.1.4 Dithionite Stability.............. 2.6

2.2 CHARACTERIZATION OF MICROBIAL POPULATIONS . . . . . . 2.12

2.2.1 Functional-Group Enumeration ......... 2.12

2.2.2 Organic Substrate Utilization ......... 2.13

2.3 HYDROLOGIC SIMULATION AND VISUALIZATION ........ 2.16

2.3.1 Sensitivity Studies ........... . . . 2.17

2.3.2 Preliminary Simulations . . . . . . . . . 2.17

2.3.3 Visualization Studies ........... . . 2.25

2.3.4 Summary of Analysis and Visualization Activities . . 2.32

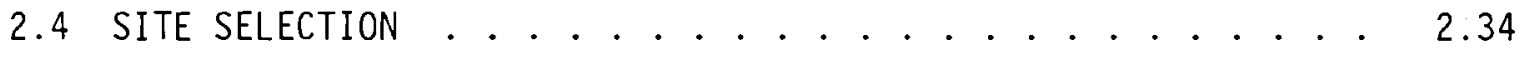

2.4.1 Site-Selection Criteria . . . . . . . . 2.34

2.4.2 Sample Collection in FY 1991 .......... 2.36

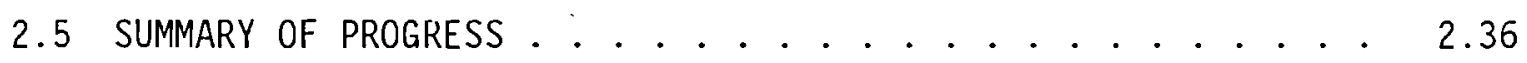

3.0 RECOMMENDED RESEARCH . . . . . . . . . . . . . . . . . . 3.1

3.1 RECOMMENDED SITE-CHARACTERIZATION ACTIVITIES . . . . . . 3.1

3.2 RECOMMENDED FUNDAMENTAL RESEARCH ACTIVITIES ....... 3.2

3.2 .1 Abiotic Reduction Experiment . . . . . . . 3.2

3.2.2 Requirements for In Situ Microbial Reduction .... 3.6 
3.2.3 Modeling to Improve Design and Investigate

Effects of Heterogeneity ........... . 3.9

3.3 SUMMARY OF RECOMMENDED RESEARCH ACTIVITIES . . . . . . . . . 3.15

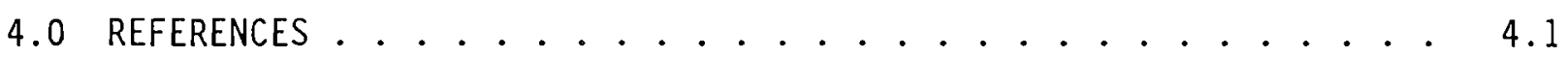

APPENDIX A - TEST PLANS . . . . . . . . . . . . . . . . A.1 


\section{FIGURES}

1.1 Possible Approaches to Redox Manipulation . . . . . . . . 1.2

1.2 Simplified Diagram of the Permeable Geochemical

Barrier Approach .................. 1... 1.3

1.3 Simplified Plan and Cross-Sectional Views of the

Single-Well Injection/Withdrawal Method ........... 1.10

1.4 Flow Chart for Proposed Manipulation of Natural

Subsurface Processes ................. 1.12

2.1 Reductive Dissolution of Natural Goethite in $12.6 \mathrm{mM} \mathrm{Na}_{2} \mathrm{SO}_{3}$
Solution at $25^{\circ} \mathrm{C}$ and Ionic Strength of $0.15 \mathrm{M} . . . . .2 .4$

2.2 Short-Wavelength Ultraviolet-Visible Spectra of

Dithionite Ion and Several of its Reaction Products . . . . . 2.7

2.3 Relative Stabilities of Dithionite, Sulfite, Sulfate,

and Thiosulfate Ions in Unbuffered Air-Saturated

Aqueous Solutions at $25^{\circ} \mathrm{C}$...............

2.4 Effect of Temperature on the Stability of Dithionite Ion in

Unbuffered Nitrogen-Saturated Aqueous Solutions with Time . . .

2.5 Effect of Initial Concentration on the Stability of

Dithionite Ion in Unbuffered Nitrogen-Saturated

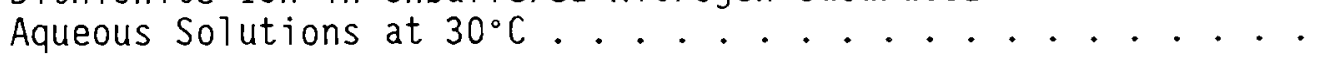

2.6 Effect of Sulfate Ion and Bentonite on the Rate of

Dithionite Decomposition in Unbuffered Nitrogen-Saturated

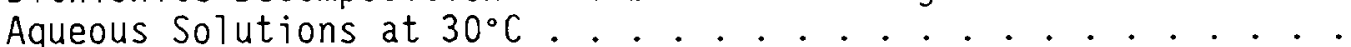

2.7 Respiratory Response of Sediment Samples from

15.0-m Depth Amended with Various Carbon Sources,

with and without Nitrogen

2.8 Respiratory Response of Sediment Samples fivin

22.4-m Depth Amended with Various Carbon Sources,

with and without Nitrogen . . . . . . . . . . . . . . .

2.9 Time Scale and Relationships among Driving Forces for the

Three Phases of the Injection-Withdrawal Experiment

2.10 Plumes for a Conservative Tracer for the Nominal System and Experiment at the End of the Injection Phase, at the End of the Residence Phase, and after 48 Hours of With-

drawa T-Phase Pumping 
2.11 Pumping Duration and Volume as a Function of the Percentage of Conservative Tracer Removed during the Withdrawal Phase for the Base Case and a Case with Half the Base Pumping Rate

2.12 Concentrations of Conservative Tracer and Nominal Reagent versus Time since the Start of the Experiment for the Base Case, and of the Conservative Tracer versus Time for the Halved-Injection-Rate Variation and the HalvedPumping-Rate Variation . . . . . . . . . . 2.22

2.13 Conceptual Diagram of the Injection-Withdrawal Experiment, Indicating How the Three Categories of Aquifer Material Exposure Arise ............

2.14 Relationship between Conceptual Understanding of the Phases of the Experiment and the Locations of the Injection/Withdrawal, Monitoring, and Coring Wells Relative to Expected Plume Movement . . . . . . . . . 2.24

2.15 Conceptual Differences between Fully and Partially Penetrating Injection/Withdrawal for Homogeneous and Heterugeneous Models of the InjectionWithdrawal Experiment ............. 2.26

2.16 Results of the Three-Dimensional, Heterogeneous Injection-Withdrawal Experiment during the Residence Phase . . . 2.29

2.17 Conceptual Diagram Illustrating the Relationships between Heterogeneity and the Various Phases of the Injection-Withdrawal Experiment

2.18 Proposed Location of the Subsurface Manipulation Field Site West of the Hanford 300 Area . . . . . . . . . . . 2.35

3.1 Plan View Illustrating Head Gradient Control with a Single Upstream Pumping Well and a Single Downstream

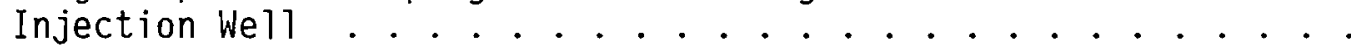

3.2 Plan View of a Weli Field for an Optimal Strategy to Control Drift within the Controlled Zone ...........

3.3 Conceptual Diagram of the Multiple-We11, Sequenced Injection-Withdrawal Experiment .

3.4 Digital Image of the Middle Ringold Outcrop, Illustrating Heterogeneity in the Form of a Typical of a Sand Lens 
3.5 Close-up Digital Image of the Middle Ringold Outcrop

Illustrating Its Bimodal Grain Size, as Well as

Heterogeneity in the Form of a Fine-Grained

Overbank Deposit, Rip-Up Clast ..............

3.6 Close-up Digital Image of the Middle Ringold Outcrop,

Illustrating a Typical Sand Lens Heterogeneity and

Smaller-Scale Heterogeneities in the Form of Weathered

Basalt Clasts in Various Stages of Disintegration . . . . . . .

\section{TABLES}

2.1 Elemental Composition of the Ca-Saturated, <2- $\mu$ m R-9

Isolate from Fine-Grained Sediments in the Ringold

Formation, Hanford Site...................

2.2 Fractions of the Total $\mathrm{Fe}$ in the R-9 Smectite Reduced by Successive Dithionite Treatments at $60^{\circ} \mathrm{C}$ in Bottles with Caps on and off ................. . . 2.6

2.3 Populations of Functional Groups of Bacteria in Core Samples Obtained from near the Hanford In Situ Redox-Manipulation

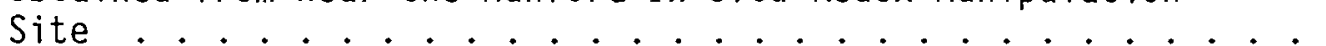




\subsection{CONCEPT}

The subsurface environment is a chemically and physically dynamic system in which naturally occurring processes control the mobility and form of chemical substances. These natural processes, which include precipitation/ dissolution, adsorption/desorption, and chemical degradation, may be mediated by microorganisms, by purely abiotic processes, or by a combination of both biotic and abiotic processes.

One of the system variables in the subsurface environment that has a considerable effect on these natural processes, and therefore on the persistence and mobility of chemical species, is the oxidation-reduction (redox) potential. Chemical species that are affected by changes in redox conditions include organic molecules (as a result of effects on both mobility and degradation) and a number of multivalent inorganic species, including iron, chromium, uranium, technetium, selenium, mercury, and arsenic. Thus, manipulation of the redox potential in the subsurface environment is a possible means of enhancing in situ remediation, by controlling the behavior of these species in groundwater aquifers and other subsurface environments.

Over long periods of time, the redox potential of subsurface environments is controlled by the flux of atmospheric oxygen into the system and the rate at which oxygen is consumed by subsurface reactions. However, short-term changes in the redox potential may be achieved by introducing chemical reagents or microbial nutrients, which in turn will facilitate degradation or precipitation of certain contaminants for periods that extend we11 beyond the manipulation period. Because most of the chemically reactive mass in the aquifer system resides in the nonaqueous components, particularly in the mineral solids, manipulation of redox phases must target these phases. Changes to the redox state of the aqueous component only will quickly be lost as a result of reequilibration with the solid phases.

There are several ways to approach in situ remediation, depending on the nature of the contaminant. Three possibilities are illustrated in Figure 1.1. 


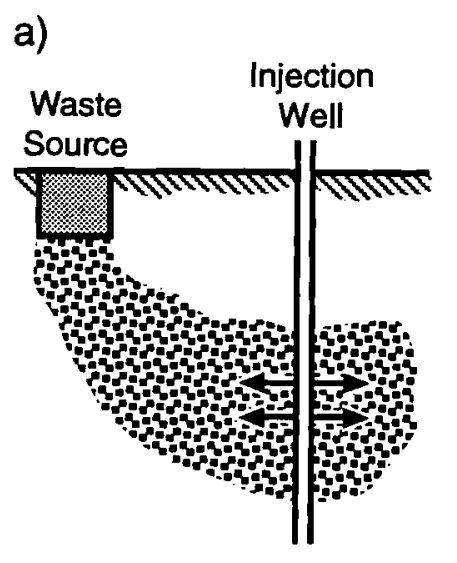

b)

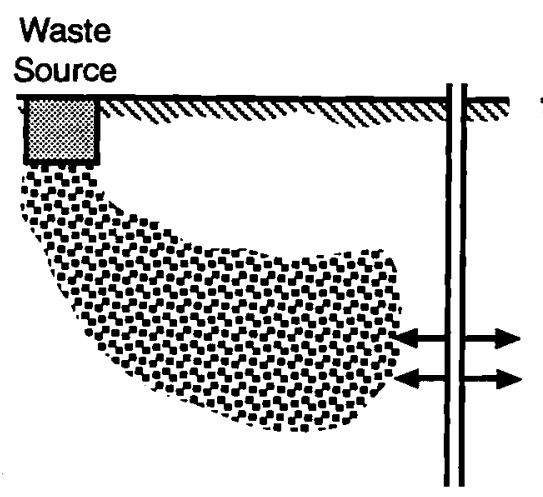

c)

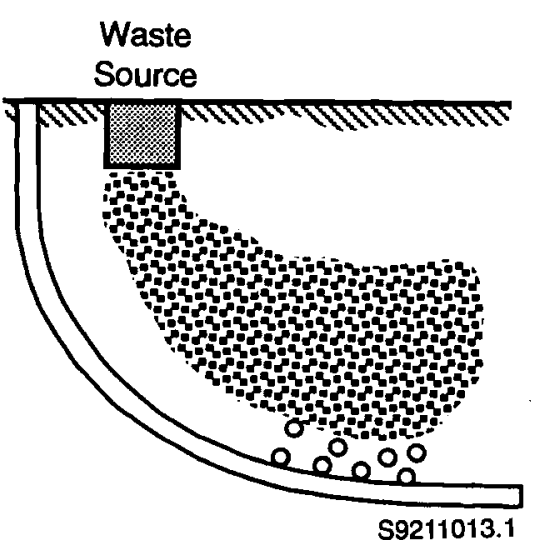

FIGURE 1.1. Possible Approaches to Redox Manipulation: a) Contaminant Bound to Solid Phase-Direct Injection; b) Aqueous ContaminantGeochemical Barrier; and c) Aqueous Contaminant-Injection of Gaseous Reagent from Horizontal We11

Alternative $A$, direct injection of the reagent or nutrient into the contaminant plume, requires some type of method to ensure in situ mixing of the reagent plume and the contaminant plume. If such mixing is not achieved, the reagent plume will merely move the contaminant plume ahead of it, with the result that there will be little contact between the reagent and contaminant. Because of the nature of the subsurface environment, in situ mixing is not easily achieved using currently available technology. Therefore, Alternatives $B$ and $C$ must be considered for circumventing the mixing problem. In Alternative $B$, the reagent or nutrient is injected ahead of the contaminant plume to form a permeable treatment barrier where reaction with the solid phases occurs. Then as the contaminant plume reaches the geochemical barrier, the plume and barrier react with each other. The permeable treatment barrier concept is illustrated in Figure 1.2. Alternative $C$ uses horizontal drilling technology to introduce a gaseous reagent to the contaminant plume. The first experiments proposed for this project will use the approach of Alternative B, the creation of a permeable treatment barrier.

Overa11, the experimental design selected on the basis of the initial assessment involves manipulation of aquifer chemistry through the use of abiotic and microbially mediated chemical reactions. Such manipulations could 


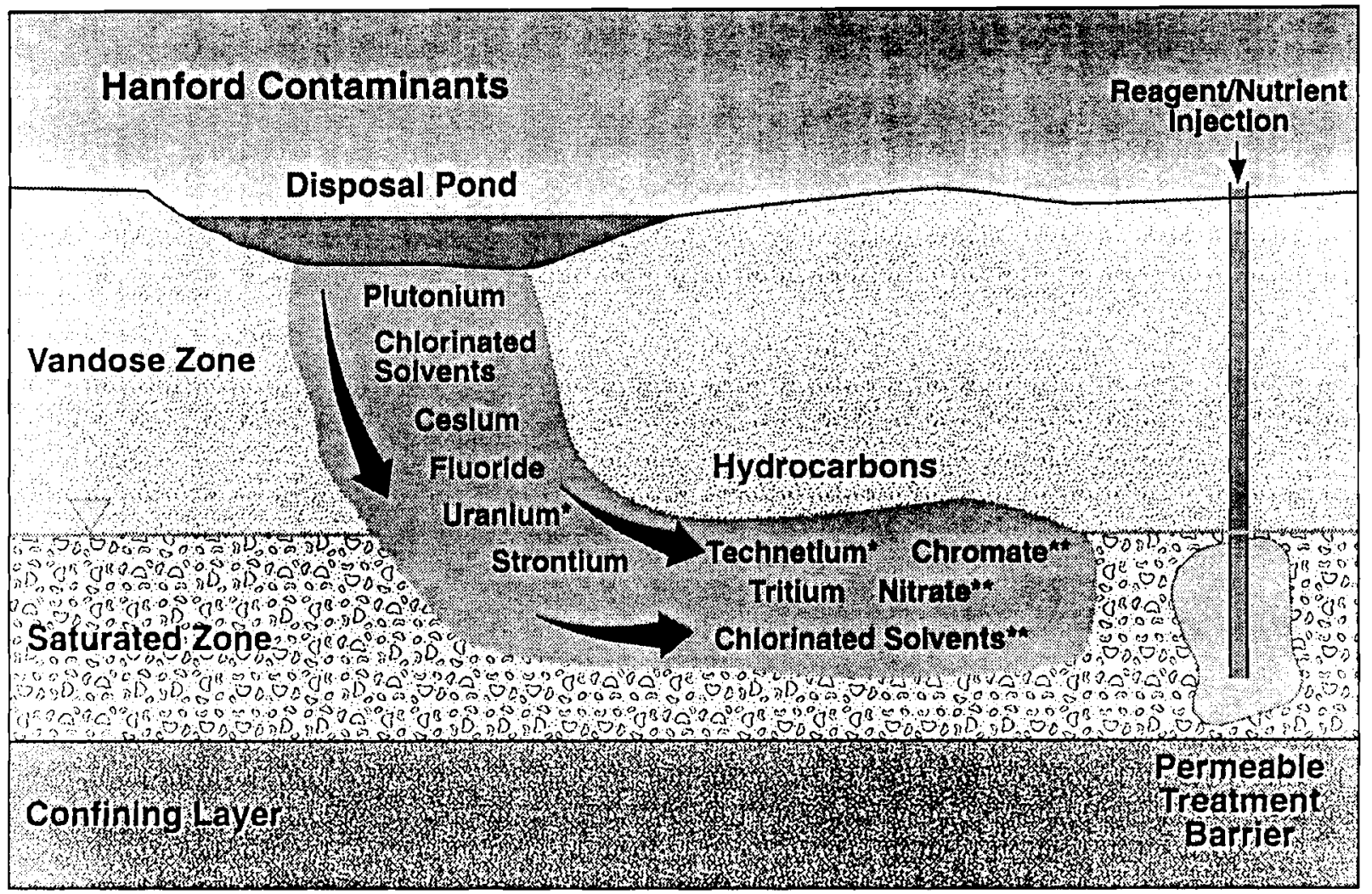

* Potential Candidate for Redox Treatment

$\$ 9409078.1$

** Favorable Candidate for Redox Treatment

FIGURE 1.2. Simplified Diagram of the Permeable Geochemical Barrier Approach

be a powerful tool for future remediation of dispersed contaminants at U.S. Department of Energy (DOE) sites, through the creation of geochemical barriers. The manipulation involves the use of reagents and microbial nutrients that cause only temporary changes to the aquifer chemistry and are themselves relatively short-lived in the subsurface system. This approach ensures that new contaminants are not introduced by the remediation process.

The subsurface biogeochemical processes that could be examined by manipulation include precipitation/dissolution, adsorption/desorption, and microbial degradation. These processes and their attendant reactions can be manipulated through control of key geochemical variables, such as pH, redox potential, and gas partial pressures. The initial focus of the project has been on redox manipulation, because of its broad potential for use in altering all of the subsurface biogeochemical processes described above. 


\subsection{APPLICABILITY TO DOE CONTAMINANT REMEDIATION}

The ability to manipulate subsurface conditions could provide a means to regulate key geochemical and microbial processes important to in situ remediation. If conditions in the aquifer could be made reducing, several contaminants in groundwater at DOE sites could be more easily treated. For instance, under chemically reducing conditions, chromate could be reduced to the trivalent chromic ion, which forms a highly insoluble iron-chromium hydroxide coprecipitate. In addition, carbon tetrachloride and other chlorinated solvents could be degraded microbially. Uranium and technetium could al so be transformed into less soluble forms. The reductive geochemical barrier concept is most applicable to contaminants in plumes that are dispersed over large volumes in the subsurface.

\subsection{RATIONALE FOR FIELD STUDY}

Contamination problems at DOE sites are fieid problems that extend over large spatial domains. Therefore, laboratory research alone is insufficient to allow prediction of geochemical behavior and establishment of effective remediation procedures. Although the chemical, microbial, and hydrologic phenomena that govern constituent behavior can be identified at the laboratory scale and selected coupled processes can be examined at the intermediate scale, the combined effects of multiple processes in three dimensions over length scales that are relevant to the environment cannot be readily investigated in any experimental system except the field. For example, in the case of redox reactions, spatial variation in the flux of atmospheric oxygen into an unconfined aquifer via flow and molecular diffusion will have a significant impact on the rates of a variety of abiotic and microbially mediated electrontransfer reactions. These spatial effects are caused by field-scale heterogeneities that are difficult to simulate in laboratory-scale or intermediatescale experiments.

Successful remediation of subsurface contamination on DOE 1 ands is limited by the fact that the in situ geochemical, microbiological, and hydrophysical processes controlling contaminant concentrations and migration are not sufficiently understood. Knowledge of the behavior of various 
contaminants in mixed waste that has been determined in laboratory studies rarely applies in a straightforward way to the subsurface environment. The complexity of interacting processes and the heterogeneous distribution of physical and chemical properties in the subsurface often confound the prediction of the behavior of contaminants in subsurface environments. It is therefore imperative that investigations be directed toward resolving those interactions and that potentially useful in situ remediation concepts be tested by field experimentation to prove their efficacy and reduce uncertainty regarding system complexity.

\subsection{BACKGROUND}

The Hanford Site in southeastern Washington State, like other DOE weapons-production waste sites, includes a broad variety of subsurface contamination situations (DOE 1989; Evans et al. 1988; U.S. General Accounting Office 1988a,b; Riley and Zachara 1992). Mixed wastes including transuranic elements, metals (e.g., chromium), nitrates, and organic chemicals are found in the subsurface. Some contaminants, such as carbon tetrachloride, trichloroethylene, nitrate, and tritium, are present as extensive plumes in the groundwater below several DOE sites. The size of these plumes makes it economically and technologically infeasible to remove them by pumping and treatment. In addition, various chemicals in the vadose zone occur in volumes and at depths that preclude excavation and treatment. As a result, there is a need to find effective ways to remediate subsurface contamination in situ by manipulating, when possible, the physical, chemical, and biological processes that control their migration and fate.

At present, the geosriences (soil physics and ciitilistr; , seohydro?ogy, geochemistry, and microbiology), taken collectively, have not advanced to a scientific level of quantification and modeling that is adequate to permit a systems-7evel predictive capability (Anderson 1987). In particular, the major interactive processes controlling contaminant transport (i.e., advection, dispersion, sorption, chemical transformation, and biodegradation) are not understood well enough to allow a priori establishment of effective in situ remediation techniques. 
Although the subsurface environment is now being subjected to various engineering approaches for remediation and restoration, the efficacy of these approaches under differing circumstances is rarely proven. This lack is partly due to the difficulty of predicting and measuring the complex interactions that occur in the deep subsurface environment. For example, biological reclamation methods have been used in some situations, but their efficacy is not adequately confirmed, nor are fundamental processes well understood. Many of the techniques that are currently being applied to remediate subsurface contamination leave residual contaminants that are still significantly above the levels that pose an environmental health hazard, as defined by regulatory limits or risk assessments. Therefore, a fundamental understanding of the limitations of these processes is also important.

The lack of certainty about subsurface processes is illustrated by the difficulty of explaining the time-dependent retardation and transformation behavior of five halogenated organic tracers encountered in a prior tracer experiment (Roberts et a1. 1986; Curtis et a1. 1986). During the three-year transport period, retardation of each organic tracer in the field experiment increased with time by a factor of 2 to 3 . Although laboratory experiments had indicated that retardation could be described by a 1 inear equilibrium isotherm with constant distribution coefficient, they also demonstrated that, as a result of slow interparticle diffusion, prolonged equilibration times were required to reach steady-state concentrations (Ball and Roberts 1991a,b). Moreover, although three of the organic tracers biodegraded as expected, carbon tetrachloride and tetrachloroethylene were refractory under anoxic conditions, even though previous laboratory-scale research had demonstrated their biodegradation. Dichlorobenzene degraded under aerobic conditions, whereas bromoform degraded under anoxic conditions. The conclusion to be reached is that the biodegradability of some chlorinated hydrocarbons in the subsurface is uncertain.

Mathematical coupled-process models generally reflect the current level of mechanistic understanding about process interactions, such as redoxcontrolled chemical reactions and microbial transformations. Models for such processes are limited by the availability of data for the parameters used by 
the particular mechanistic theory that describes the controlling processes. Data for important subsurface processes are still sparse. Appropriate models, both simple and complex, are needed to help design an experimental system to test the feasibility of manipulation concepts. This can be illustrated by examining the redox-dependent degradation of organic contaminants. A number of reactive transport models have been developed to describe biodegradation of an organic contaminant and microbial growth as a result of electron transfer reactions (Macquarrie and Sudicky 1990; Borden et al. 1986; Molz et al. 1986b).

One such recent biodegradation model uses a Monod decay rate equation coupled with three advection-dispersion transport equations that describe the simultaneous relations among organic solute utilization, electron acceptor availability, and microbial population growth (MacQuarrie and Sudicky 1990; Sudicky et al. 1990). With such a model, it is possible to examine the feasibility of biodegradation under specific aquifer conditions. Molz and Widdowson (1988) and Sudicky et al. (1990) studied the implications of spatially variable hydraulic conductivity on advective oxygen flux and the activity of aerobic heterotrophs. Sudicky et al. (1990) showed that a fieldscale representation of dispersion that is appropriate for a conservative solute is not necessarily appropriate for accurately describing the biodegradation of an organic substrate in a heterogeneous system. Representing transport with a field-scale dispersion coefficient causes biodegradation to be overestimated, because contact between the organic substrate and oxygen are overestimated. For this reason, Molz and Widdowson (1988) recommend that the detailed pattern of heterogeneity of hydraulic conductivity be taken into account.

The overestimation of biodegradation is just one of the problems encountered when processes identified at one scale are extrapolated to another scale. Scale-effect problems are a basic obstacle to estimating the dynamic behavior of interacting transport processes as needed to implement effective remediation approaches. Generally, the solution of this problem is higherresolution modeling, which in turn demands better statistical characterization of subsurface properties. 


\subsection{PROJECT DESCRIPTION}

A permeable in situ subsurface treatment barrier is being developed to immobilize or destroy target contaminants. The treatment barrier is a zone of favorable redox potential created by the addition of chemical and/or microbiological reducing agents. The goal is to design a barrier that will effectively transform metals, ions, and radionuclides to less soluble forms and promote the destruction of organics, especially chlorinated hydrocarbons.

A series of experiments is being performed to test different reagents or microbial nutrients for their efficiency in manipulating the redox conditions of an unconfined aquifer. Bench-scale testing is being used to determine the nature of the reactions that occur and the efficiency with which they are induced by the reagent or nutrient. This includes the kinetics of reduction and subsequent reequilibration of the reduced phases. Based on information from the bench-scale tests, field experiments will be designed to test the feasibility of in situ redox manipulation. The initial field experiment will involve reduction by a chemical reagent.

A key issue is the scaling-up of redox manipulation from the carefully controlled conditions of the bench-scale tests to the less certain conditions found in the field. The design methodology developed in this project includes tools to systematically analyze reagent and site chemistry in the context of field-scale transport. Once developed, the analytical tools and framework will also be applicable to the design and evaluation of other in situ chemical technologies.

\subsection{APPROACH}

A dense spatial array of multilevel sampling wells is necessary to adequately delineate the spatial distribution of an existing contaminant plume and to measure the hydraulic properties of the aquifer associated with the plume development (Thurman et al. 1986). On the other hand, forced-flow systems using one or two injection and withdrawal wells have proven quite effective in the measurement of hydraulic conductivity and dispersion (Molz et al. 1985, 1986a). Similar techniques should also be applicable to the 
field testing of remediation concepts. Closely spaced injection and withdrawal wells would also allow completion of a field experiment in less time than the years often required to track a contaminant plume under naturatgradient subsurface conditions. Such an experiment would involve the injection and withdrawal of water and chemical agents from a localized region around one or two wells to determine the occurrence and kinetics of certain chemical reactions or biological transformations in situ. Use of a forcedgradient experiment avoids the need to characterize a whole aquifer region in detail and reduces the uncertainty due to the influence of field-scale dispersion on transport behavior. Moreover, processes are still studied under dynamic flow conditions, in a realistic setting.

For these reasons, the approach proposed for the field experiment is to evaluate the extent to which redox chemistry in an aquifer can be manipulated by injecting and withdrawing specific reagents or nutrients. This forcedgradient approach allows examination of the response of the system to relatively rapid changes and has several additional advantages:

- Initial conditions are well-defined. Because the constituents to be studied are injected at the beginning of the experiment, the initial mass, volume, location, chemical, and hydraulic parameters are better defined than in most natural-gradient experiments using existing contaminant plumes.

- Characterization problems are minimized. Because a relatively short time elapses between injection and sampling, a relatively small volume will have to be sampled. Although even with a relatively small volume of natural material, significant variability in chemical and physical properties is likely, it should be more manageable than it would be in a larger volume.

- The movement of the solutes can be controlled. By forcing a hydraulic gradient by means of pumping and withdrawing, the patnway taken by the reactive solutes can be better controlled. This approach also simplifies the sampling design.

In view of these advantages, a forced-gradient field experimental facitity should be constructed to test hypotheses relating to manipulation of natural subsurface processes. Simplified cross-sectional and plan views of a conceptual site are shown in Figure 1.3. 

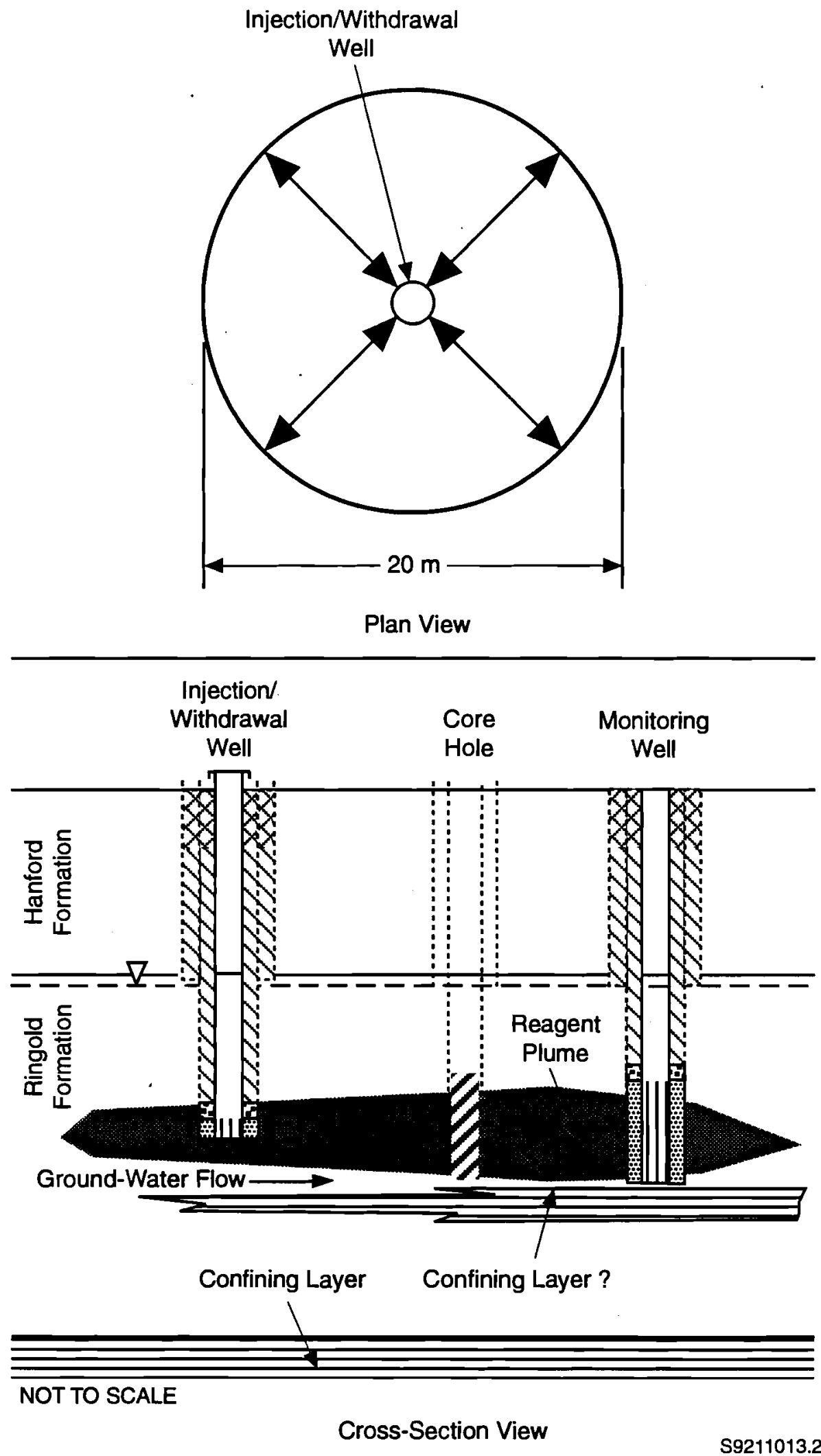

FIGURE 1.3. Simplified Plan and Cross-Sectional Views of the Single-Well Injection/Withdrawal Method 
Before final design, additional laboratory data on the efficacy of various reagents and nutrients for reduction of mineral phases in sediments at the Hanford Site are required. In addition, an appropriate site must be chosen and characterized hydraulically, geochemically, and microbiologically. Finally, the optimum approaches for injecting and withdrawing the reagents must be determined using computer modeling simulations. The major steps involved in the experiments are

Phase 1. Project Planning and Design.

1. Select and characterize a site

2. Select reagents/nutrients and design experiments

3. Conduct laboratory and modeling simulations to develop the scope of experimental conditions

4. Design injection and sampling well network

5. Obtain permits and carry out activities related to the National Environmental Policy Act (NEPA)

6. Conduct workshops with external participants to strengthen experimental approaches and design.

Phase 2. Field Experimentation.

7. Inject reagents and/or nutrients

8. Assess subsurface performance

a. Post-experiment sampling and characterization

b. Data interpretation - modeling and derivation of field reaction constants.

The initial activities are to be carried out in parallel, as illustrated in Figure 1.4. 


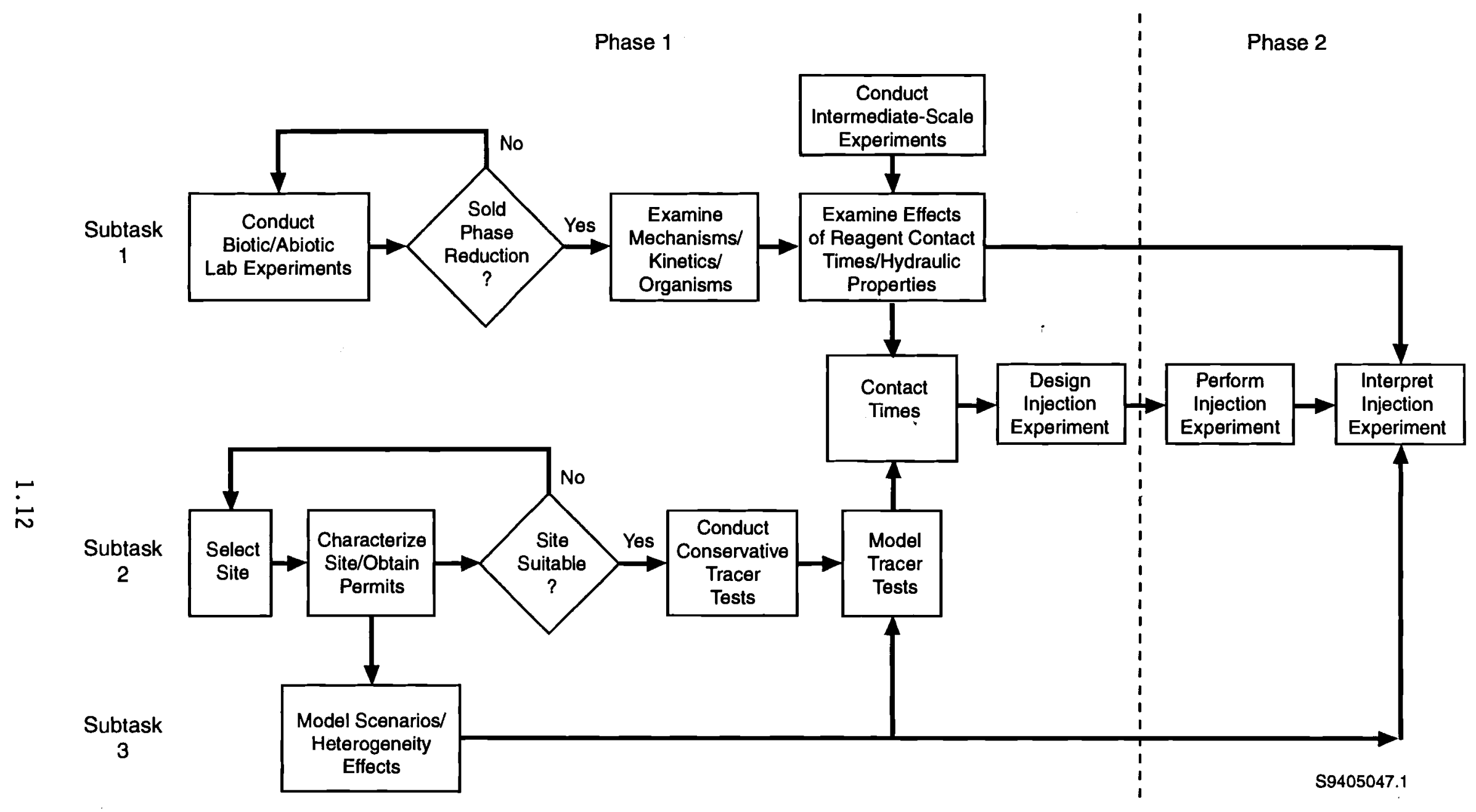

FIGURE 1.4. Flow Chart for Proposed Manipulation of Natural Subsurface Processes. 


\subsection{PROGRESS IN FY 1991 and 1992}

As discussed in Chapter 1.0 , there is a strong rationale for attempting in situ redox manipulation of contaminated aquifers on DOE 1ands. Although the concept is well understood, there are gaps in our knowledge of basic chemical, hydrophysical, and microbial processes that are key to the success of the in situ redox-manipulation experiment. Therefore, preliminary investigations were conducted during FY 1991 and 1992 in four areas: 1) abiotic iron reduction studies, 2) characterization of microbial population in Hanford subsurface sediments, 3) hydrologic simulation and visualization, and 4) site selection and preliminary geochemical characterization. In addition, preliminary site-selection and permitting activities began. These activities are described below.

\subsection{ABIOTIC IRON REDUCTION STUDIES}

As shown by Barcelona and Holm (1991) for a sand-and-gravel aquifer, nearly all of the oxidizing or reducing capacity of an aquifer system resides in the solid mineral phases that make up the aquifer matrix, rather than in the groundwater. However, even though the contribution of groundwater to the aquifer's redox capacity is sma11, the most practical and non-invasive way of altering an aquifer's redox status is to alter the chemistry of the groundwater that contacts the mineral solids. At Hanford, because groundwater flow velocities in the unconfined aquifer are relatively rapid, the use of this approach to alter the redox status in a particular zone requires that the kinetics of the reduction reaction also be rapid (i.e., on the order of days rather than weeks or months).

Abiotic iron-reduction experiments began by reacting suspensions of redox-buffering mineral solids (similar to those expected in the Hanford sediments) with aqueous reductants, in order to determine the most effective and rate-efficient reductant. Subsequent experiments focused on the factors controlling the stability and reactivity of this reductant under conditions more like those in the unconfined aquifer at Hanford. 


\subsubsection{Materials and Methods}

The redox-buffering capacity of mineral solids is largely determined by their Fe content. Two types of oxidized Fe(III)-bearing minerals, goethite (a crystalline $\mathrm{Fe}$ oxyhydroxide with the stoichiometry of $\mathrm{FeOOH}$ ) and smectite [a layer silicate of approximately the stoichiometry $\mathrm{X}_{0.1}(\mathrm{~A} 1, \mathrm{Fe}, \mathrm{Mg})_{2}$ $(\mathrm{Si}, \mathrm{Al}, \mathrm{Fe})_{4} \mathrm{O}_{10}(\mathrm{OH})_{2}$, where $X$ is an exchangeable cation such as $\mathrm{Ca}^{2+}$ or $\left.\mathrm{Na}^{+}\right]$, were selected to represent the redox-buffering minerals in the Hanford unconfined aquifer. Both goethite and smectite were used because they were expected to behave quite different7y in a reducing environment. Once reduced, the goethite was expected to dissolve, whereas the smectite, which contains other structural cations in addition to $\mathrm{Fe}$, was expected to retain its structural integrity, albeit with a more negative layer charge and additional exchangeable cations (i.e., $\mathrm{Ca}, \mathrm{Na}$ ) to balance this charge.

The reductants tested were sulfite $\left(\mathrm{SO}_{3}^{2-}\right)$, dithionite $\left(\mathrm{S}_{2} \mathrm{O}_{4}^{2-}\right)$, and hydrox$y$ lamine $\left(\mathrm{NH}_{2} \mathrm{OH}\right)$; these reductants were viewed as plausible candidates for injection into the saturated zone. Separate studies estimated the rate of reductive dissolution of goethite by sulfite ion and determined the feasibility of reduction of structural $\mathrm{Fe}$ in smectite by sulfite ion, dithionite ion, and hydroxylamine.

Studies with both a natural specimen of goethite from Biwabik, Minnesota, which may have contained $\mathrm{Fe}(\mathrm{II}), \mathrm{Mn}, \mathrm{AT}, \mathrm{Ti}$, and Si impurities, and a pure synthetic goethite were performed in sealed reaction vessels at $25 \pm 1^{\circ} \mathrm{C}$. The procedure involved adding an aliquot of a concentrated $\mathrm{Na}_{2} \mathrm{SO}_{3}$

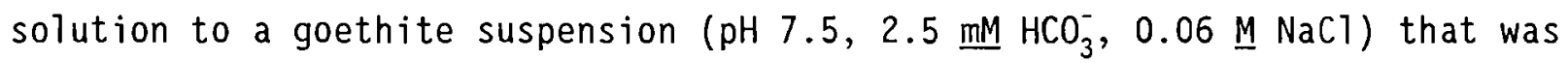
initially saturated with dissolved oxygen, and then following the changes in concentrations of $\mathrm{O}_{2}(\mathrm{aq}), \mathrm{Fe}(\mathrm{II})$, tota? $\mathrm{Fe}$, $\mathrm{Eh}$, and $\mathrm{pH}$ with time.

The smectite samples studied were R-9, a beidellite isolated from an exposed fine-grained lens in the Ringold Formation on the Hanford Site, and BB-90-14, a well core sample from the Yakima Barricade test well on the northwest side of the Hanford Site. The $<2-\mu \mathrm{m}$ fraction of each sample was used and was shown to be at 1east $95 \%$ smectite by $X$-ray diffraction. The elemental analysis of BB-90-14 was very similar to that for R-9 shown in Table 2.1. 
TABLE 2.1. ETemental Composition of the Ca-Saturated, <2- $\mu$ m R-9 Isolate from Fine-Grained Sediments in the Ringold Formation, Hanford Site

\begin{tabular}{|c|c|c|c|}
\hline Oxide & $\begin{array}{c}\text { Weight } \\
\%\end{array}$ & Oxide & $\begin{array}{l}\text { Weight } \\
\%\end{array}$ \\
\hline $\mathrm{Na}_{2} \mathrm{O}$ & 0.63 & $\mathrm{CaO}$ & 1.43 \\
\hline $\mathrm{MgO}$ & 1.86 & $\mathrm{TiO}_{2}$ & 0.65 \\
\hline $\mathrm{AT}_{2} \mathrm{O}_{3}$ & 22.18 & $\mathrm{Fe} 0$ & 0.11 \\
\hline $\mathrm{SiO}_{2}$ & 57.97 & $\mathrm{Fe}_{2} \mathrm{O}_{3}$ & 7.12 \\
\hline $\mathrm{K}_{2} \mathrm{O}$ & 1.31 & & \\
\hline
\end{tabular}

For the smectite experiments, $50 \mathrm{mg}$ of the smectite was measured into a $125-\mathrm{ml}$ polypropylene bott7e, and $10 \mathrm{ml}$ of a $0.9 \mathrm{M} \mathrm{NaHCO}_{3}^{-} \mathrm{l} \% \mathrm{Na}$-citrate solution was added to buffer the $\mathrm{pH}$ at about 7.5. Next, $20 \mathrm{ml}$ of $\mathrm{H}_{2} \mathrm{O}$ containing the reductant was added (except for dithionite, which was added as a solid in 500 -mg portions), and the bottle was capped tightiy; the samples were incubated at $60^{\circ} \mathrm{C}$ for various lengths of time. At the end of the prescribed period, the bottles were removed, the smectite was separated from the solution by centrifugation, and the $\mathrm{Fe}(\mathrm{II})$ and totai $\mathrm{Fe}$ contents were determined by the complexometric method of Komadel and Stucki (1988). For the treatments with hydroxylamine, total reductive capacity was determined by the oxidimetric method of Amonette and Scott (1991). Because the main purpose of the smectite experiments was to compare the efficiency of different reductants, the higher temperature of $60^{\circ} \mathrm{C}$ was used to increase the rate of the process.

\subsubsection{Goethite Reduction}

Typical results for the goethite reductive dissollition experiments are shown in Figure 2.1. After a sight initial drop, the $\mathrm{pH}$ initially rose to a stable value because of the protonation of $\mathrm{SO}_{3}^{2-}\left(\mathrm{SO}_{3}^{2-}+\mathrm{H}^{+}=\mathrm{HSO}_{3}^{-}\right)$, while the Eh decreased rapidly because of the consumption of dissolved oxygen by reaction with the $\mathrm{HSO}_{3}^{-}\left[\mathrm{HSO}_{3}^{-}+0.5 \mathrm{O}_{2}(\mathrm{aq}) \rightarrow \mathrm{SO}_{4}^{2-}+\mathrm{H}^{+}\right]$(Figure 2.1a). The $\mathrm{O}_{2}(\mathrm{aq})$ concentrations decreased rapidly during the first 15 minutes of the reaction and stayed at 70 watues for the remainder of the experiments (Figure 2.1b). The concentration of $\mathrm{Fe}(\mathrm{II})$ rose to slight7y above the 

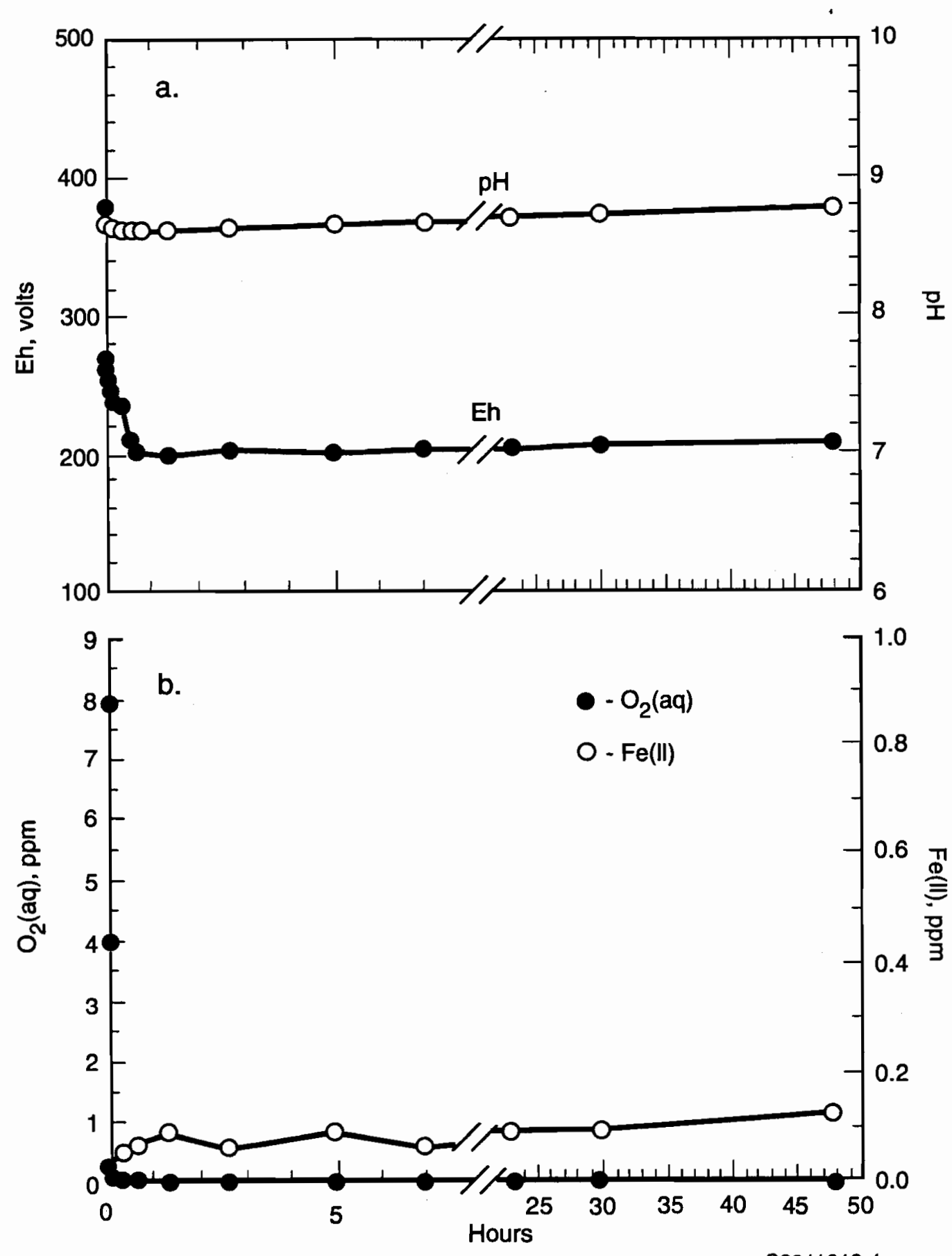

FIGURE 2.1. Reductive Dissolution of Natural Goethite (Biwabik, Minnesota; $0.5 \mathrm{~g} / \mathrm{L}^{3}$ ) in $12.6 \mathrm{mM} \mathrm{Na}{ }_{2} \mathrm{SO}_{3}$ Solution at $25^{\circ} \mathrm{C}$ and Ionic Strength of $0.15 \mathrm{M}$ 
detection limit of $50 \mathrm{ppb}$ after about 1 to 2 hours and increased at very slow rates thereafter but never reached concentrations greater than $125 \mathrm{ppb}$ (Figure 2.1b). All dissolved Fe was determined to be $\mathrm{Fe}(\mathrm{II})$, indicating that some reductive dissolution of the goethite had occurred but at a very slow rate. Increasing the initial ratio of $\mathrm{SO}_{3}^{2-}$ to $\mathrm{O}_{2}(\mathrm{aq})$ produced a slightly. greater rate of reductive dissolution of the goethite, as indicated by higher Fe(II) concentrations, but the effect was small and was not investigated in detail.

\subsubsection{Smectite Reduction}

Results similar to those described for goethite were obtained for reduction of $\mathrm{Fe}$ in smectites by $0.07 \mathrm{M}$ sulfite solutions for periods of 48 hours at $60^{\circ} \mathrm{C}$ (data not shown). Saturation of the cation exchange sites on the smectite with $\mathrm{Zn}^{2+}$ ions (to promote electron transfer between the solution and the structural $\mathrm{Fe}$ ) had no effect on the reaction. Attempts to reduce structural Fe in smectites with hydroxylamine were inconclusive, inasmuch as only the total reductive capacity of the system was measured and it was not clear whether all of the hydroxylamine had been removed from the clay surfaces prior to analysis.

In contrast to the inconclusive results with sulfite and hydroxylamine, dithionite successfully reduced large amounts of the structural $\mathrm{Fe}$ in smectite (Table 2.2). Successive treatments with dithionite increased the amount of structural Fe reduced, up to a limit of about $60 \%$ of the total Fe present in the clay. Whether this represents a fundamental limit to structural Fe reduction or is simply an indication that $40 \%$ of the $\mathrm{Fe}$ is reoxidized during the $\mathrm{Fe}$ (II) analysis remains to be determined. At temperatures of $70^{\circ} \mathrm{C}$, Stucki et a1. (1984) were able to reduce only $73 \%$ of the total iron in a high-iron smectite using dithionite, even after treatments under an inert atmosphere for periods as long as 1 week.

Although the present experiments were performed at temperatures that exceed groundwater temperatures, there seems little doubt that, of the three reductants tested, dithionite would be the most efficient and aggressive reductant of structural $\mathrm{Fe}$ in smectite under groundwater conditions. 
TABLE 2.2. Fractions of the Total $\mathrm{Fe}$ in the R-9 Smectite Reduced by Successive Dithionite Treatments at $60^{\circ} \mathrm{C}$ in Bottles with Caps on and $0 \mathrm{ff}$

\begin{tabular}{cccc} 
& & \multicolumn{2}{c}{$\begin{array}{c}\text { Structural Fe } \\
\text { Reduced, \% }\end{array}$} \\
\cline { 4 - 4 } $\begin{array}{c}\text { Treatment } \\
\text { Number }\end{array}$ & & Cap On & Cap Off \\
1 & & 47 & 25 \\
2 & & 56 & 35 \\
3 & & 57 & 27 \\
4 & & 61 & 36
\end{tabular}

To gauge the sensitivity of the reduction reaction in the presence of air, one set of samples was reduced without capping the bottles (Table 2.2). Only about half as much reduction occurred as when the caps were left on. It seems clear then, that reduction is diminished by the reaction of dissolved oxygen, which diffuses into the solution from the air, with dithionite and the reduced smectite. Although it is well known that reduced smectite suspensions can be reoxidized in a matter of a few hours by contact with air, it is not clear to what extent the decrease in structural Fe reduction in this experiment stems from reaction of reduced smectite with air versus that from the oxidation of the dithionite by air before the dithionite can reduce the smectite.

\subsubsection{Dithionite Stability}

Because of the initial success with dithionite, further experiments were perficmed to iulentify and quantify parameters affecting its longevity in groundwater. This information was needed to optimize injection-well spacing and reductant injection rates for the in situ redox-manipulation experiment. Absorption spectrophotometry was used to monitor the concentration of dithionite and its reaction products in dilute aqueous solutions and suspensions. Experiments were conducted using 1-cm-path-length cells in the temperature-controlled cell block of a Beckman 5270 ultraviolet/visible wavelength spectrometer. 
The short-wavelength visible spectrum of dithionite has a 'large peak at $315 \mathrm{~nm}$ that is completely isolated from peaks produced by its various decomposition and oxidation products (shaded area in Figure 2.2). This fortunate circumstance allows the straightforward collection of kinetic data based on the concentration of dithionite in the range for which the Beer-Lambert 1 aw is valid. Measurement of the concentration of the various products of reaction with dithionite, however, is difficult at best because of the overlapping absorption peaks of the product species.

Initially, we examined the stabilities of dithionite and several of the reaction products in pure aqueous solutions that were in contact with air at room temperature (Figure 2.3). The results of these studies showed that the half-time of dithionite in oxygenated solutions is on the order of a few

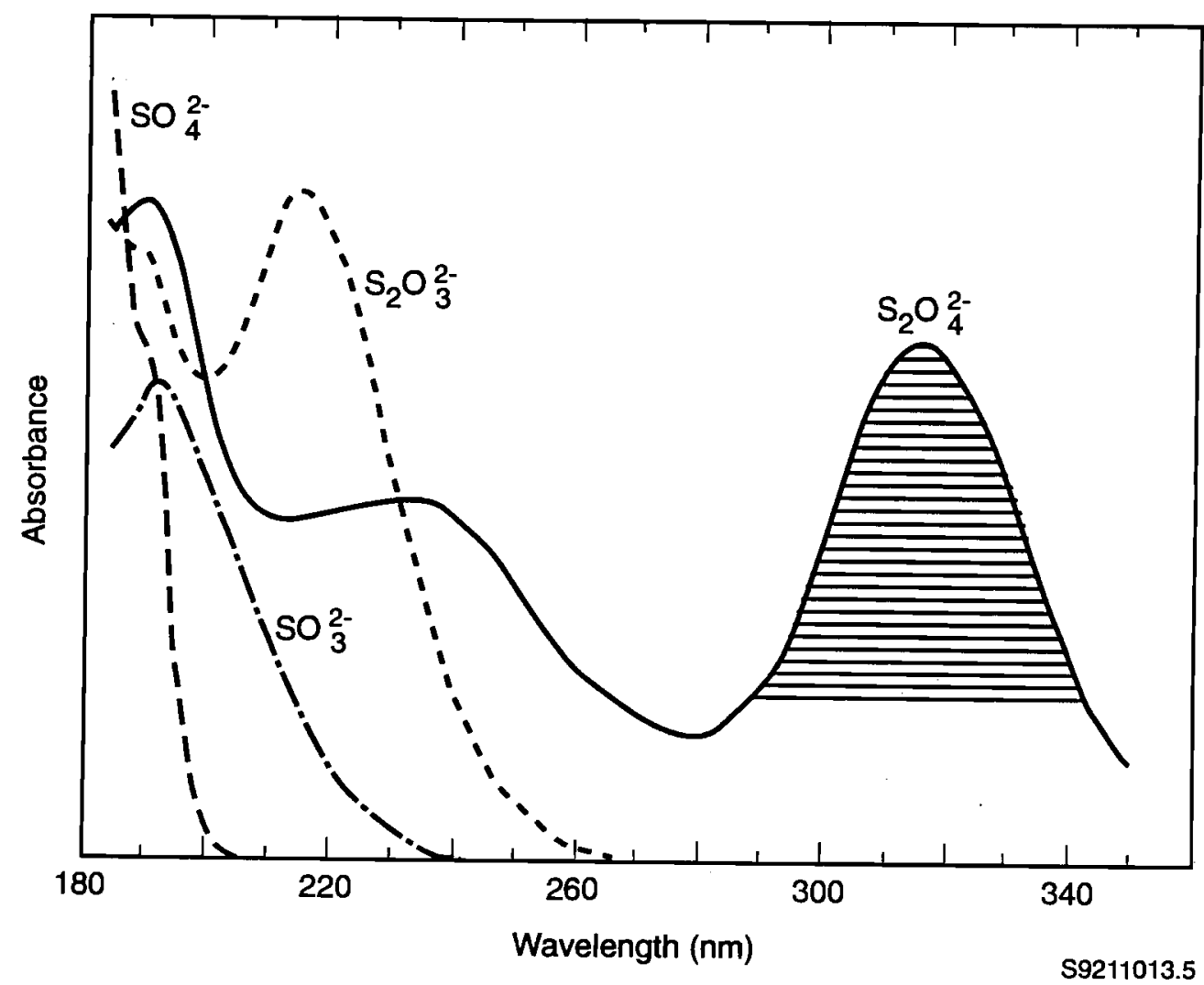

FIGURE 2.2. Short-Wavelength U1traviolet-Visible Spectra of Dithionite Ion and Several of its Reaction Products 


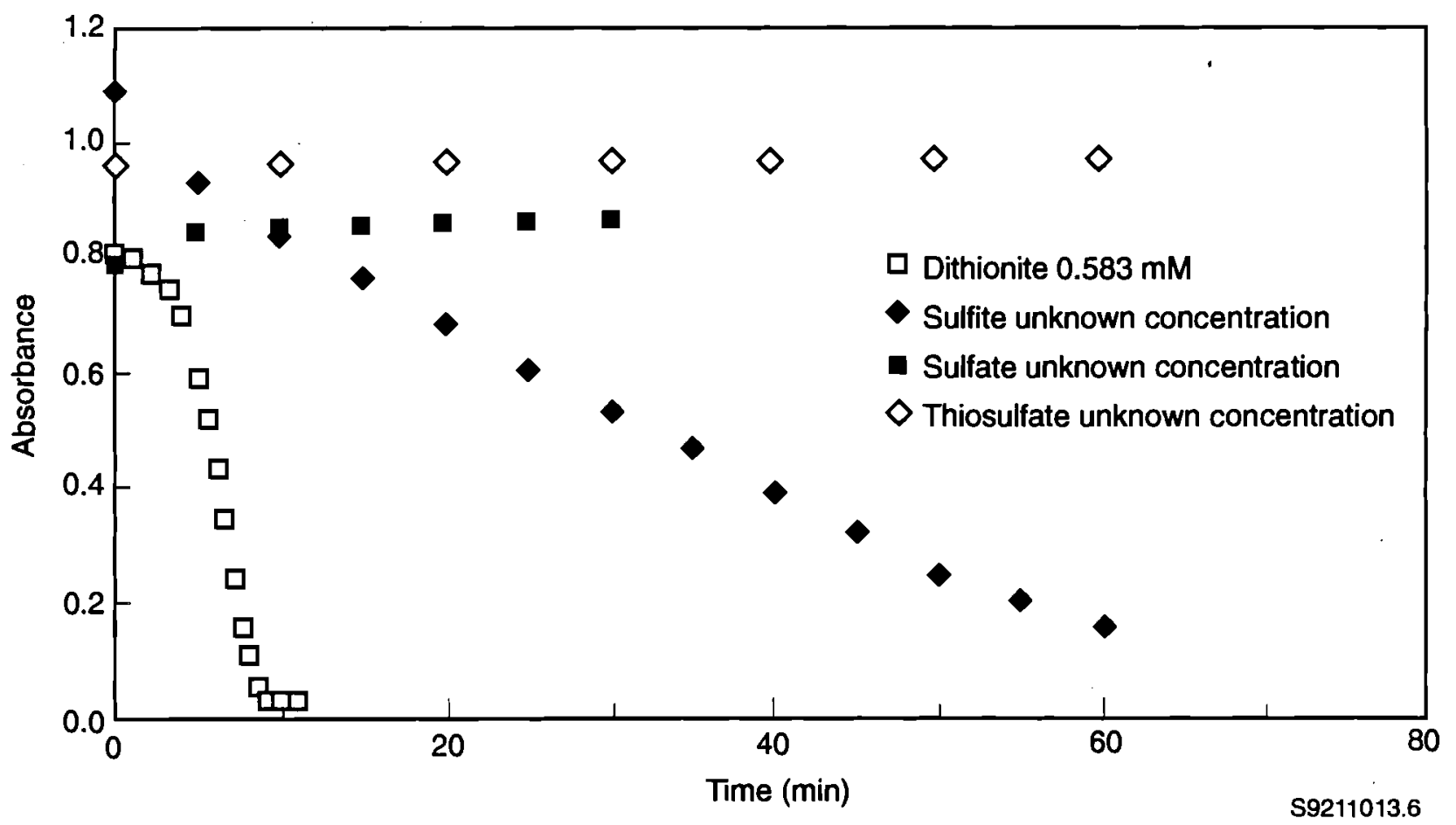

FIGURE 2.3. Relative Stabilities of Dithionite, Sulfite, Sulfate, and Thiosulfate Ions in Unbuffered Air-Saturated Aqueous Solutions at $25^{\circ} \mathrm{C}$

minutes; the reaction would probably be much faster if diffusion of oxygen into the solution were not limiting. The stability of sulfite was several times greater than that of dithionite (i.e., on the order of an hour), whereas sulfate and thiosulfate species were stable. The relative stabilities that we observed for these oxygenated sulfur compounds agree with those reported by other investigators (e.g., Rinker et al. 1960).

Dithionite, however, is unique among these species in that it undergoes a disproportionation reaction in aqueous solutions to yield bisulfite and thiosulfate ions (Cotton and Wilkinson 1988, p. 522):

$$
2 \mathrm{~S}_{2} \mathrm{O}_{4}^{2-}+\mathrm{H}_{2} \mathrm{O} \rightarrow 2 \mathrm{HSO}_{3}^{-}+\mathrm{S}_{2} \mathrm{O}_{3}^{2-}
$$

That is, two dithionite ions, in which sulfur is in the +3 oxidation state, react with water to yield a single thiosulfate ion [S(II)] and two bisulfite ions [S(IV)]. Also, dithionite reversibly dissociates to yield two $\mathrm{SO}_{2}^{-}$ radical ions that are extremely reactive [e.g., the electron paramagnetic 
resonance data of Gan et al. (1992)] and account for kinetic rate laws for dithionite oxidation that are half-order:

$$
\mathrm{S}_{2} \mathrm{O}_{4}^{2-}=2 \mathrm{SO}_{2}^{-}
$$

Thus, dithionite can be removed from solution not only by reaction with an oxidant, but also by disproportionation into other oxo sulfur species of higher and lower oxidation states. A thorough study of the stability of dithionite, therefore, must take into account the kinetics of the disproportionation reaction, as well as any oxidation reaction that might occur.

Accordingly, we conducted several studies of dithionite stability under a nitrogen atmosphere to eliminate the oxidation reaction and focus on the kinetics of the disproportionation reaction. The results of these studies suggest that the disproportionation reaction is quite sensitive to temperature (Figure 2.4) and to the initial concentration of dithionite (Figure 2.5). An increase in either of these parameters results in an increase in the rate of dithionite decomposition. Because these studies were conducted in unbuffered solutions, changes in $\mathrm{pH}$, which can have significant effects on dithionite stability, also occurred. Consequently, the results with different concentrations of dithionite, in particular, are confounded by presumed lower $\mathrm{pH}$ levels that result from the disproportionation of dithionite [reaction (2.1)] and suggest the need to buffer solution $\mathrm{pH}$ at slightly alkaline levels to prolong the lifetime of dithionite in solution and thereby enhance its efficiency as reductant.

Lastly, a series of experiments under nitrogen were run in which the sffects of an oxidizing so?id (an iron-containing smectite) arid an inert ion that would compete with dithionite for surface sites on the solid (i.e., sulfate) were examined (Figure 2.6). The results of this study were surprising in one respect: dithionite stability was lowest in the absence of the solid and the inert ion. As might be expected, the effect of the sulfate ion on decomposition rate masked any effect of the solid. The presence of the solid in suspension without the inert ion, however, resulted in faster decomposition 


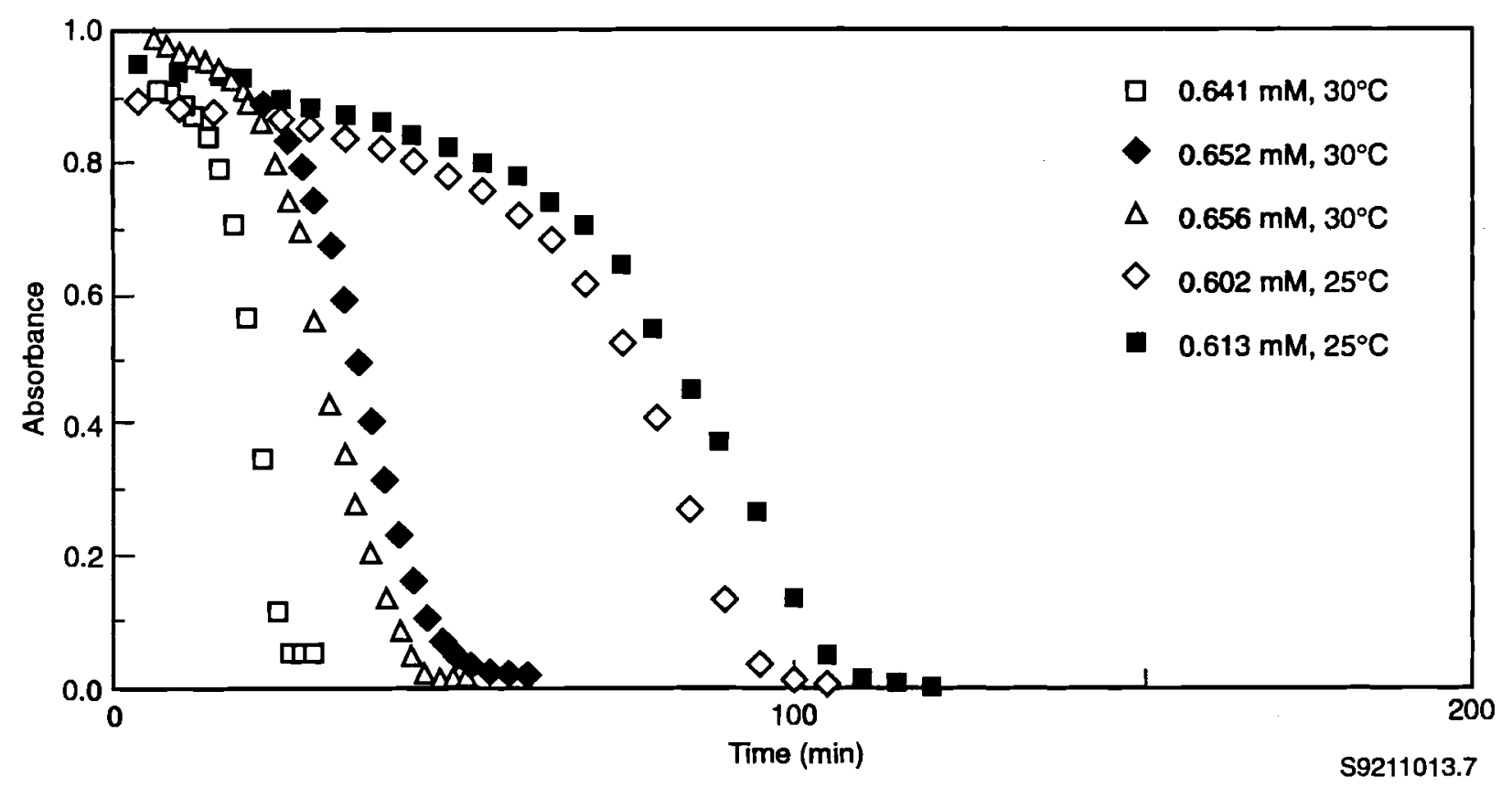

FIGURE 2.4. Effect of Temperature on the Stability of Dithionite Ion in Unbuffered Nitrogen-Saturated Aqueous Solutions with Time

than when the inert ion was present, but still had a stabilizing effect on the dithionite ion relative to the pure dithionite solution. We concluded from this series of tests that the presence of sulfate ion in solution and the adsorption of dithionite to mineral surfaces may actually prolong the survival time of dithionite relative to the pure solution.

In the course of these preliminary experiments, it became evident that a continuous-flow system that would eliminate the settling of the solid phase and minimize the effects of diffusion by promoting adequate mixing while maintaining a controlled atmosphere was needed. Such a system was designed and constructed and will allow us to obtain more precise data and make a quantitative analysis of the reaction kinetics feasible. Future work (see Chapter 3.0 of this report) will include quantitative definition of the kinetics of dithionite disproportionation and oxidation reactions using data obtained with this continuous-flow system. 


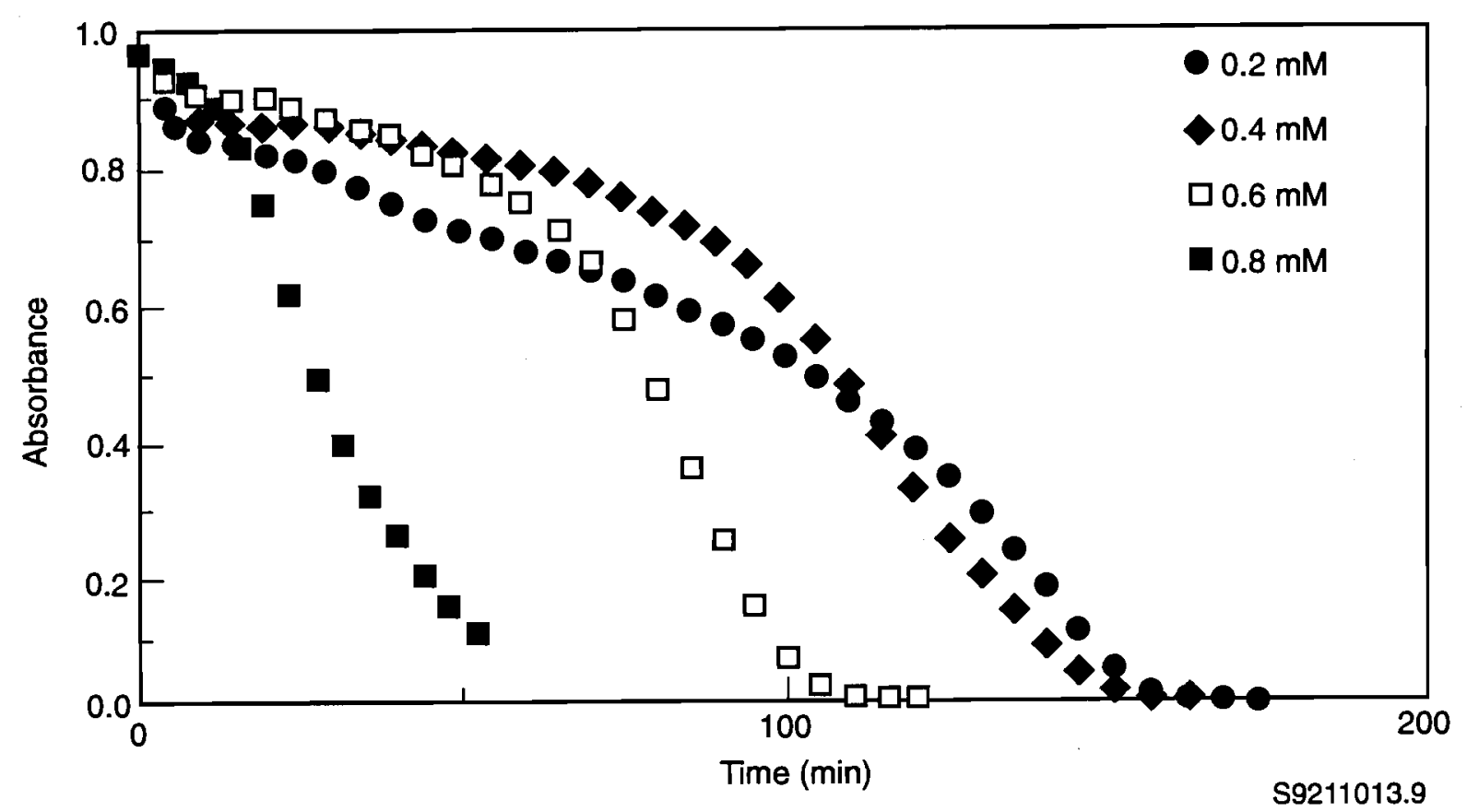

FIGURE 2.5. Effect of Initial Concentration on the Stability of Dithionite Ion in Unbuffered Nitrogen-Saturated Aqueous Solutions at $30^{\circ} \mathrm{C}$

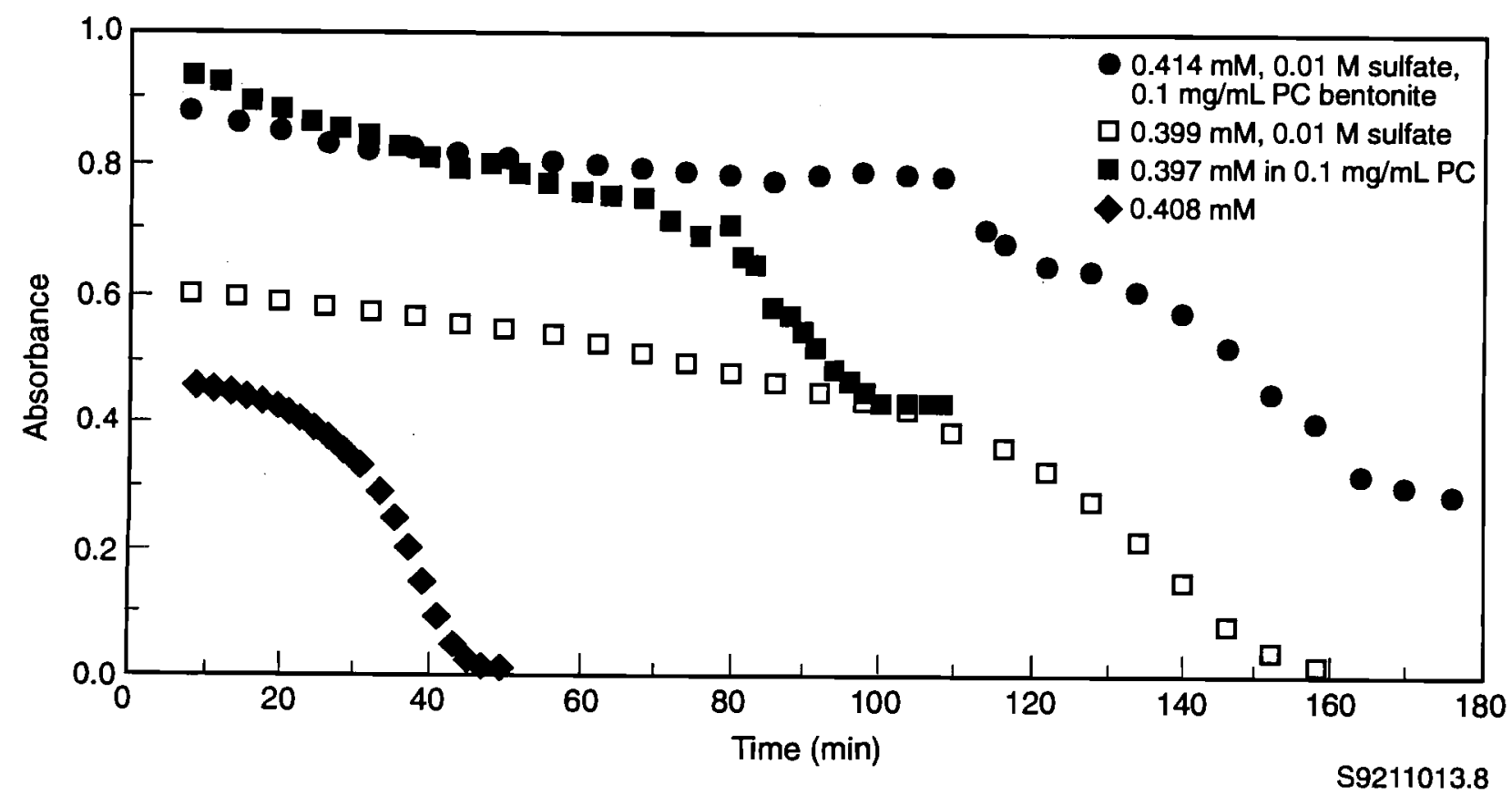

FIGURE 2.6. Effect of Sulfate Ion $(0.01 \mathrm{M})$ and Bentonite $(0.1 \mathrm{mg} / \mathrm{ml})$ on the Rate of Dithionite Decomposition in Unbuffered Nitrogen-Saturated Aqueous Solutions at $30^{\circ} \mathrm{C}$ 


\subsection{CHARACTERIZATION OF MICROBIAL POPULATIONS}

Before design and implementation of a field experiment that included the in situ manipulation of microbial activity, information on the types of indigenous microorganisms present and the types of carbon sources they can metabolize must be obtained.

Core samples for microbial and geochemical analysis were collected from a borehole (300-FF-5, \#4C) drilled near the 300 Area on the Hanford Site, in proximity to the proposed field test site. The samples were an opportunity provided by a regulatory compliance project being conducted near the planned study site. Five core samples were obtained. The first was an intact finegrained sediment with little apparent disturbance. The other four samples were physically disturbed (e.g., fractured gravels, cobbles, and mixing of sediments), thus presenting the possibility that their geochemical integrity had been compromised. However, because no water had been added to the borel.ole, we decided to proceed under the assumption that the samples were at least microbially representative.

\subsubsection{Functional-Group Enumeration}

The functional groups that were analyzed for included 1) aerobic heterotrophs; 2) fermentors; 3) denitrifiers; 4) Fe(III)-reducers; 5) sulfatereducers; and 6) methanogens. Given that the upper portion of the unconfined (uppermost) aquifer on the Hanford Site is oxic, it was expected that there would be few if any strictly anaerobic bacteria. The results agreed with this prediction. The most numerous functional group in all samples were the aerobic heterotrophic bacteria, which ranged between $10^{4}$ and $10^{7}$ colony-forming units (CFU) per gram of sediment (Table 2.3). Bacteria that can ferment glucose were also present in every sample, albeit at lower populations than the aerobic heterotrophs. Denitrifiers, bacteria that can grow anaerobically and reduce nitrate, were also abundant. Fe(III)-reducing bacteria were above detection in only one sample, but the analyses were confounded by the presence of high aqueous concentrations of $\mathrm{Fe}$ (II) in the samples that were physically disturbed. The source of the excess $F e(I I)$ was probably dissolution of mafic minerals exposed by the fracturing of gravels and cobbles in the disturbed 
TABLE 2.3. Populations of Functional Groups of Bacteria in Core Samples obtained from near the Hanford In Situ Redox-Manipulation Site

\begin{tabular}{|c|c|c|c|c|c|c|}
\hline \multirow[b]{2}{*}{$\begin{array}{l}\text { Sample } \\
\text { Depth, } \\
\mathbf{m}\end{array}$} & \multirow[b]{2}{*}{$\begin{array}{c}\text { Aerobes, } \\
\log \\
\text { CFU/g } \\
\end{array}$} & \multicolumn{5}{|c|}{$\log M P N / g^{(a)}$} \\
\hline & & Fermentors & Denitrifiers & $\begin{array}{l}\text { Fe(III) - } \\
\text { Reducers } \\
\end{array}$ & $\begin{array}{c}\mathrm{SO}_{4}^{-} \\
\text {Reducers } \\
\end{array}$ & Methanogens \\
\hline 15.0 & 4.9 & $>1.0$ & 3 & $\mathrm{BD}^{(\mathrm{b})}$ & $\mathrm{BD}$ & $\mathrm{BD}$ \\
\hline 22.4 & 5.7 & 0.7 & $<4$ & $>1$ & $\mathrm{BD}$ & $\mathrm{BD}$ \\
\hline 27.6 & 5.8 & 0.5 & $<5$ & $\mathrm{BD}$ & $\mathrm{BD}$ & $\mathrm{BD}$ \\
\hline 30.0 & 6.9 & 0.7 & $<4$ & $\mathrm{BD}$ & $\mathrm{BD}$ & $\mathrm{BD}$ \\
\hline 38.1 & 3.6 & 1.2 & 3.3 & $\mathrm{BD}$ & $\mathrm{BD}$ & $\mathrm{BD}$ \\
\hline
\end{tabular}

(a) $M P N=$ most probable number.

(b) $\mathrm{BD}=$ below detection.

samples. Enrichments are currently being repeated with a different culture medium. Neither sulfate-reducing bacteria nor methanogens were detected in any of the samples.

\subsubsection{Organic Substrate Utilization}

Microbial utilization of organic substrates was analyzed using an automated respirometer that measures both $\mathrm{O}_{2}$ consumption and $\mathrm{CO}_{2}$ evolution. Measuring the aerobic respiration that occurred with the various substrates was rationalized on the basis that, before fermentation reactions can proceed, the dissolved $\mathrm{O}_{2}$ in the groundwater must first be removed by aerobic respiration. Little aerobic respiration occurred with any of the substrates in the fine-textured sediment from $15.0 \mathrm{~m}$, except for oxalate (Figure 2 7). However, when sediments were amended with nitrogen, a respiration response was observed for most of the substrates. Samples were preincubated with substrate for a minimum of $24 \mathrm{~h}$ to stimulate microbial activity, so some of the more readily metabolizable substrates may already have been depleted prior to respiration measurements. These results indicate that microbial activity in the unconfined aquifer is $\mathrm{N}$-limited and that the addition of $\mathrm{N}$ is likely to be required to stimulate microbial activity and reduction. The probable reason 


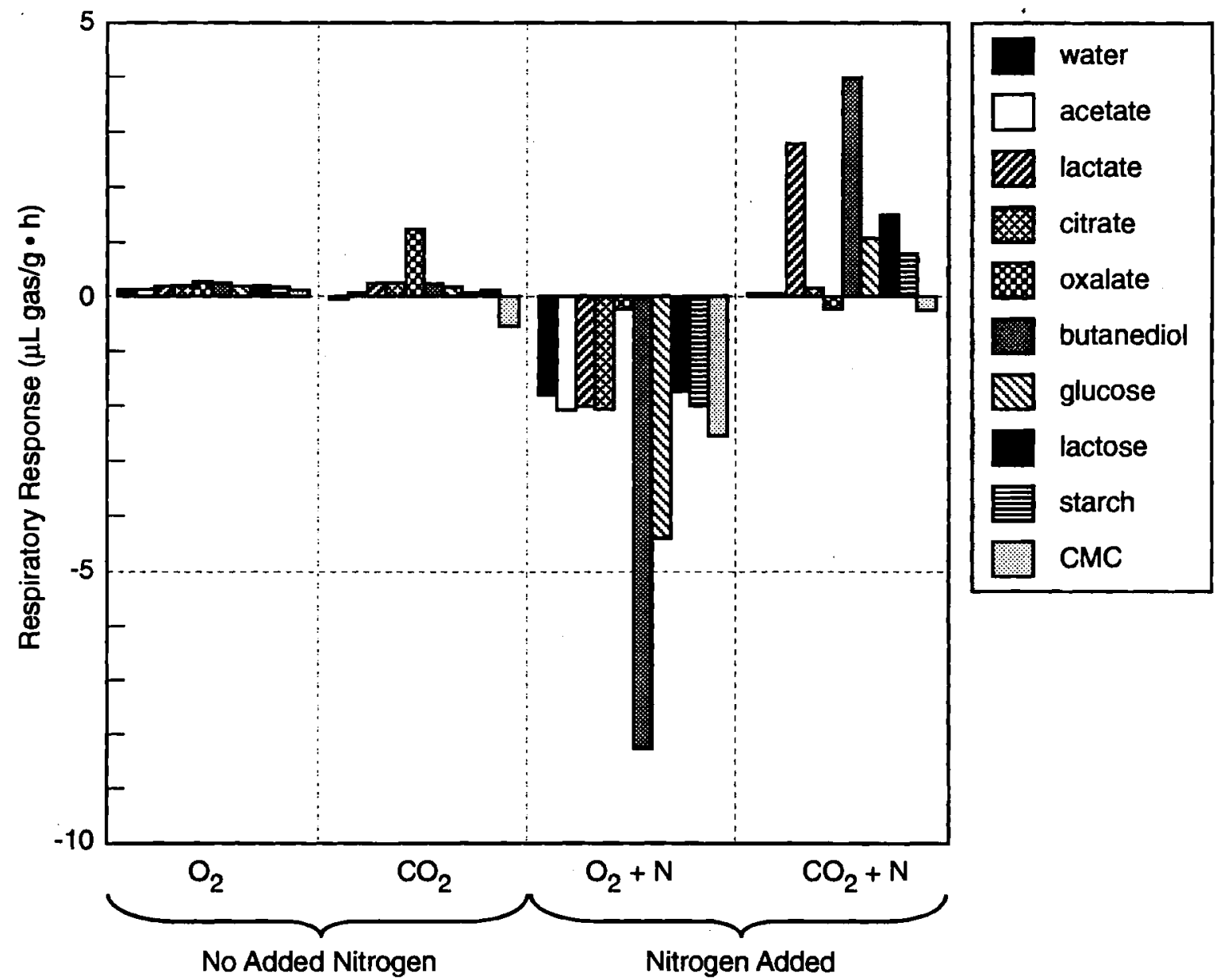

S9111073.8

FIGURE 2.7. Respiratory $\left(\mathrm{O}_{2}\right.$ consumption and $\mathrm{CO}_{2}$ evolution) Response of Sediment Samples from 15.0-m Depth Amended with Various Carbon Sources, with and without Nitrogen (CMC = carboxymethyl cellulose)

that oxalate promoted respiration in the sediment that had not been amended with $\mathrm{N}$ was because the oxalate was added as the ammonium salt.

In the samples that were physically disturbed by drilling, consumption of $\mathrm{O}_{2}$ was significant but there was little accompanying $\mathrm{CO}_{2}$ evolution (Figure 2.8). This was probably due to the exposure of surfaces of gravels and cobbles crushed by the hard tool where $\mathrm{Fe}$ (II) could act as a reductant. Although this abiotic reduction complicated interpretation of the results, there was clearly still a stimulation of $\mathrm{CO}_{2}$ evolution by the addition of $\mathrm{N}$. 


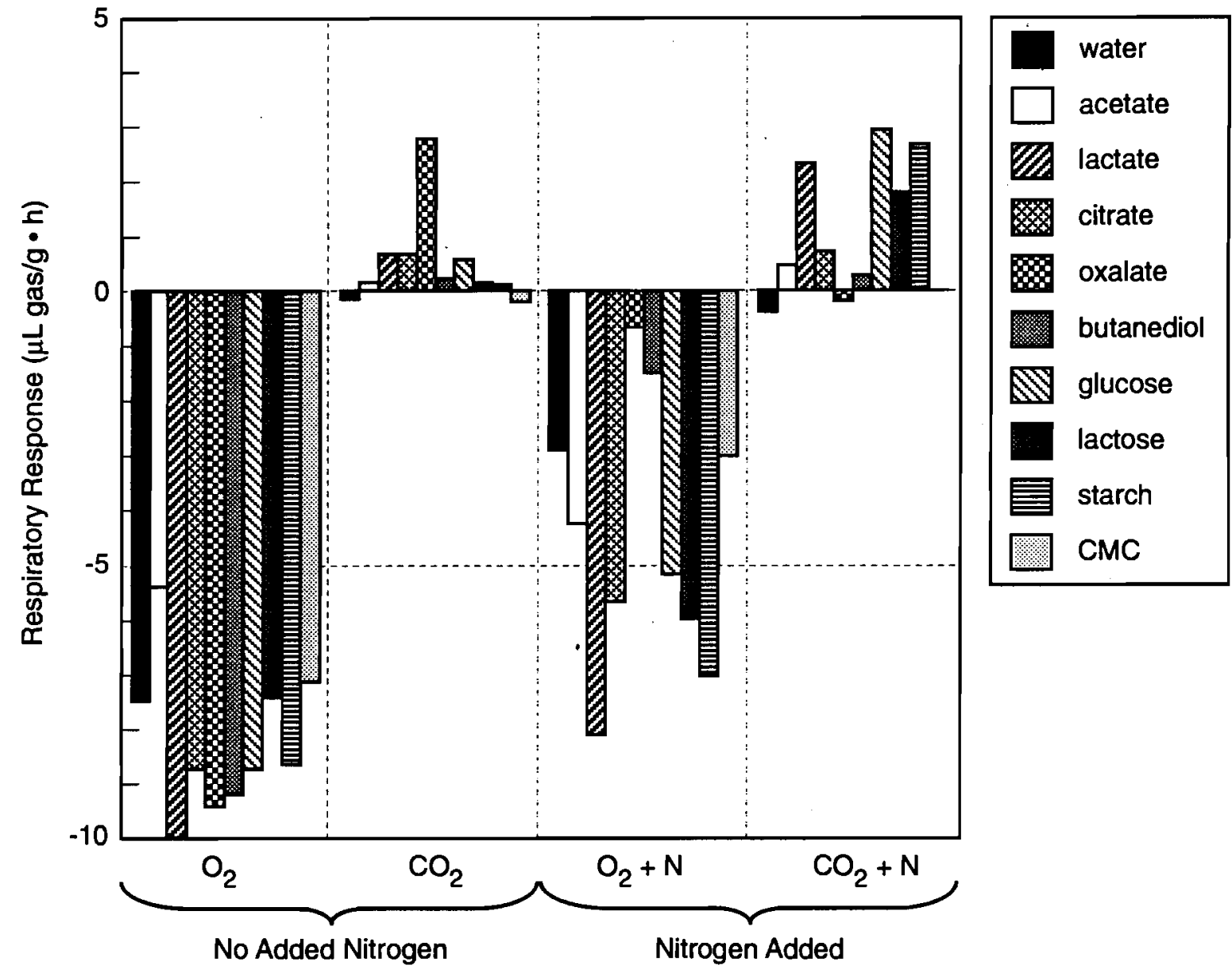

S9111073.9

FIGURE 2.8. Respiratory $\left(\mathrm{O}_{2}\right.$ consumption and $\mathrm{CO}_{2}$ evolution) Response of Sediment Samples from 22.4-m Depth Amended with Various Carbon Sources, with and without Nitrogen (CMC = carboxymethyl cellulose)

The results and their implications to the objectives of this project can be summarized as follows:

- Active aerobic and facultative anaerobic bacterial populations are present in the subsurface sediments in the vicinity of the proposed field site; in situ stimulation of the indigenous microbiota to reduce $\mathrm{O}_{2}$ and $\mathrm{NO}_{3}$ is feasible.

- The native microbial populations can utilize a variety of carbon sources but are nitrogen-limited; any attempt at in situ stimulation of the microbiota will require addition of a nitrogen source. 
- Strict anaerobic bacteria were not detected; it is unlikely that the addition of electron donor in stoichiometric excess of $\mathrm{O}_{2}$ and $\mathrm{NO}_{3}$ would lead to rapid reduction of sulfate.

These results indicate that reduction of the aqueous phase in the aquifer should be straightforward, but they are inconclusive with regard to our ability to reduce iron in the solid phases. Reduction of $\mathrm{Fe}$ (III) in sediments may require inoculation with Fe-reducing bacteria cultured from other sources. Future work that would determine the ability of indigenous and exogenous bacteria to reduce solid-phase $\mathrm{Fe}$ (III) in Hanford sediments is discussed in Chapter 3.0.

\subsection{HYDROLOGIC SIMULATION AND VISUALIZATION}

Analysis and visualization activities in FY 1991 examined a variety of factors important to the design and interpretation of the in situ redoxmanipulation experiments:

- Practical factors related to the time and cost of carrying out the experiment (e.g., volume of reagent, volume of recovered waste fluids, number and kind of sampling boreholes and their construction)

- Technical factors related to the various interacting mechanisms that cause the change in redox state (e.g., time required for the chemical reactions and microbial processes that affect the change, the stability of the changed system when subjected to ambient geochemical conditions during the different phases of the experiment)

- Factors related to site characteristics (e.g., target geology and facies, nature and scales of heterogeneity, location of confining and injection layers, injection zone size, mean hydraulic conductivity, ambient hydraulic gradient)

- Factors related to the methodology used to interpret the results of the in situ redox-manipulation experiments (e.g., how the field measurements are interpreted to obtain model-equivalent parameters or observations, how models are calibrated and validated, characteristics of the models used to describe the important physical, chemical, and microbial mechanisms).

Activities were undertaken in two separate areas: 1) sensitivity studies with simple models to evaluate site-selection criteria and develop a 
better understanding of the experiment and 2) high-resolution modeling and visualization studies to examine effects of various scales of heterogeneity on the experiment and thus its design.

\subsubsection{Sensitivity Studies}

Sensitivity analysis studies were performed with a two-dimensional homogeneous hydrologic flow and transport model using the CFEST code (Gupta et a1. 1987). Once a tentative site location was selected, a base case (i.e., a nominal experiment) was defined based on assumed site characteristics (estimated from nearby boreholes), a preliminary reagent selection with assumed reactivity parameters, and such other factors as costs of drilling boreholes, obtaining reagent, and disposal of the withdrawn fluids. The sensitivity studies were conducted to develop a better conceptual model of the experiment and to aid preliminary design efforts. These studies were performed by examining the effects of varying site characteristics, reagent reactivity, and experimental design parameters over a range around their nominal values. We examined the effects of changes in these variables on predicted plume shape, volume of aquifer affected, mass of reagent required, conservative tracer recovery, and the resulting volumes of waste fluids.

\subsubsection{Preliminary Simulations}

Figure 2.9 illustrates, in a conceptual manner, the plume shapes expected in a homogeneous system as a function of time during the three phases of the injection-withdrawal experiment. The figure also illustrates how these shapes are related to the time scales associated with the experimental phases and the magnitude and direction of the advective driving forces during the injection, drift, and withdrawal phases. Injection and withdrawal times for the nominal experiment correspond to hours (ca. 12) and days (7), respectively, but residence times are measured in tens of days (30). The 22.5-gpm rates for injection and withdrawal induce advective driving forces that result in radially converging and diverging groundwater velocities ranging from tens to hundreds of feet per day during the associated phases. However, residence phase velocities, in the form of average linear velocities, are much smaller and directed toward the Columbia River. They amount to only $1.3 \mathrm{ft} / \mathrm{day}$ and are induced in the nominal system, which has a mean hydraulic conductivity of 

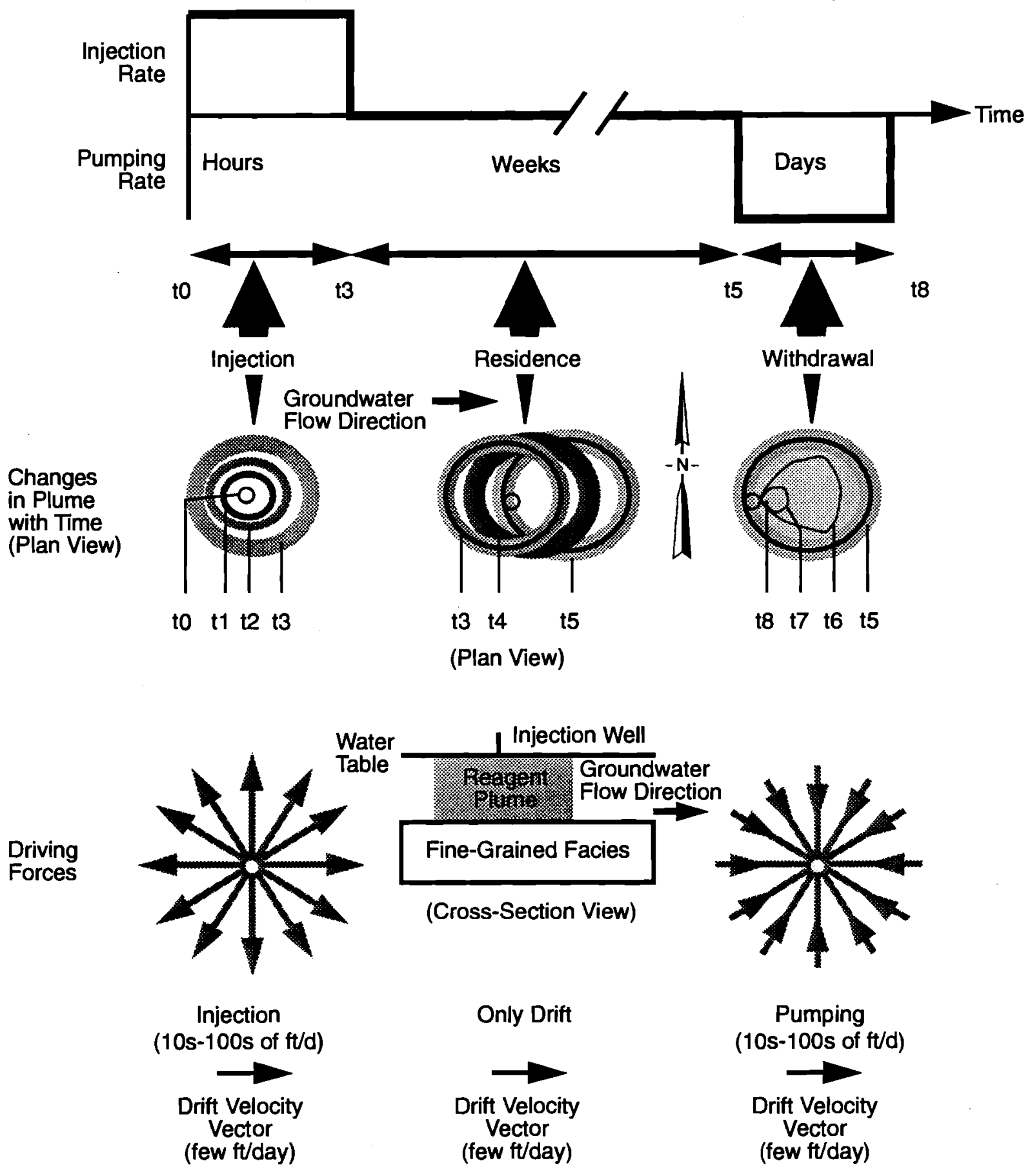

S9211013.19

FIGURE 2.9. Time Scale and Relationships among Driving Forces for the Three Phases of the Injection-Withdrawal Experiment 
$200 \mathrm{ft} /$ day and an effective porosity of $0.3 \mathrm{ft}^{3} / \mathrm{ft}^{3}$, as a result of a natural groundwater system gradient of $0.002 \mathrm{ft} / \mathrm{ft}$ resulting from topographic and recharge factors. The differences in velocities and time scales between the three phases of the experiment can create additional difficulties in heterogeneous porous media, as is discussed later.

Figure 2.10 shows model results for a nominal experiment involving a conservative tracer. These results were calculated based on a two-dimensional homogeneous conceptual model using the CFEST code (Gupta et a1. 1987). The plume, which was compact, nearly circular, and centered on the injection/ withdrawal well at the end of the injection phase (Figure 2.10a) is transformed into a more diffuse elliptical shape by dispersive forces (hydrodynamic

a)

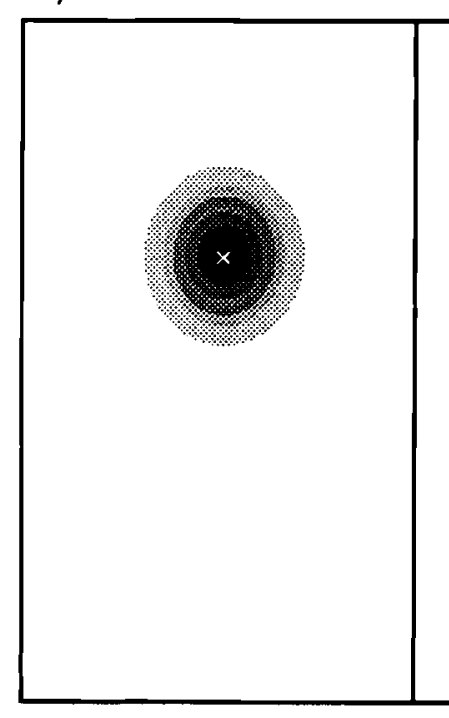

End of Injection b) c)

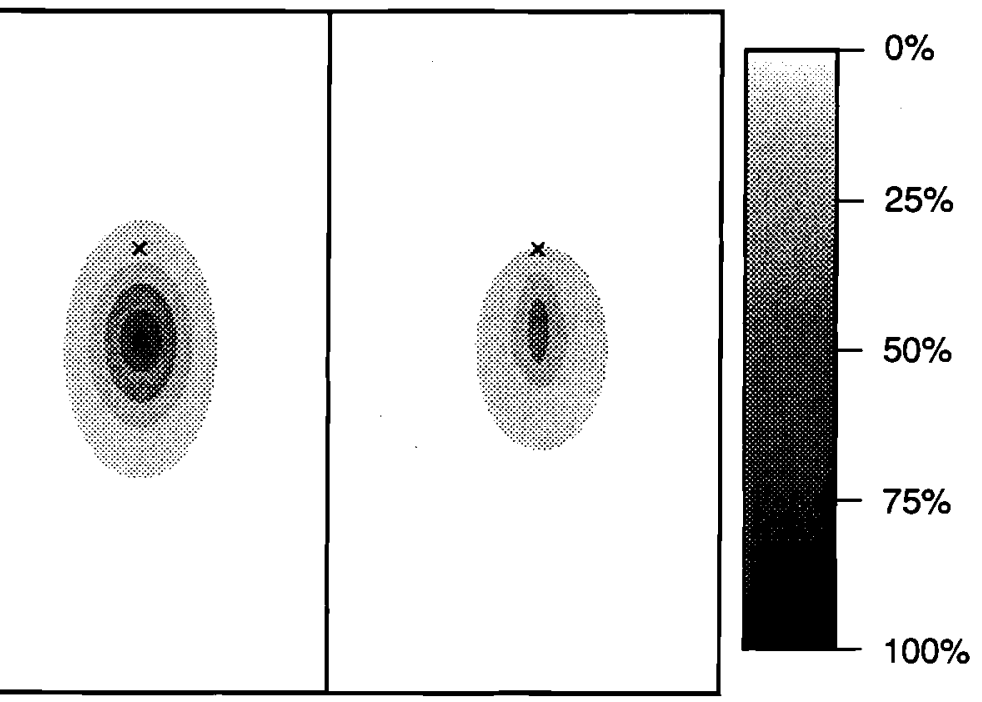

End of Drift

$48 \mathrm{~h}$ of Pumping

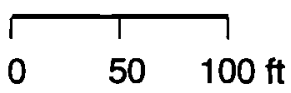

S9111073.6

FIGURE 2.10. Plumes for a Conservative Tracer for the Nominal System and Experiment a) at the End of the Injection Phase, b) at the End of the Residence Phase, and c) after 48 Hours of Withdrawa1-Phase Pumping 
dispersion and molecular diffusion) that moves nearly past the injection/ withdrawal well as a result of 30 days of advection during the residence phase (Figure 2.10b). Nominal values for the longitudinal and lateral dispersivity are $2.5 \mathrm{ft}$ and $0.5 \mathrm{ft}$, respectively. Pumping during the withdrawal phase induces a radially convergent flow field that transforms the receding tracer plume into a teardrop shape as the tracer is diluted with ambient groundwaters in the injection/withdrawal well.

The sensitivity of withdrawal-phase pumping duration and volume to withdrawal-phase pumping rate is illustrated in Figure 2.11. Results indicate that halving the withdrawal pumping rate more than doubles the pumping time required to achieve 90 or $95 \%$ recovery of the conservative tracer. However, the pumped volume increases only $19 \%$.

Calculated concentrations at the injection/withdrawal well versus time from the start of the experiment are illustrated in Figure 2.12. I1lustrated are three variations involving a conservative tracer and one involving the nominal reactive reagent, which is characterized by a 15-day first-order reaction rate time constant. The variation for the nominal reagent uses base-case injection and withdrawal pumping rates. Comparison of conservative and reactive results (Figure $2.12 \mathrm{a}, \mathrm{b}$ ) indicates a distinct difference in the shapes of the predicted concentration versus time curves as a result of the reactivity of the reagent. Results for the conservative tracer variations indicate that halving the injection rate had little effect on predicted concentrations versus time, but that halving the withdrawal rate resulted in less dilution and thus higher injection/withdrawal well concentrations during the withdrawal phase. This latter effect may be important for those reagents and tracers that are harder to detect at low concentrations. 
a)

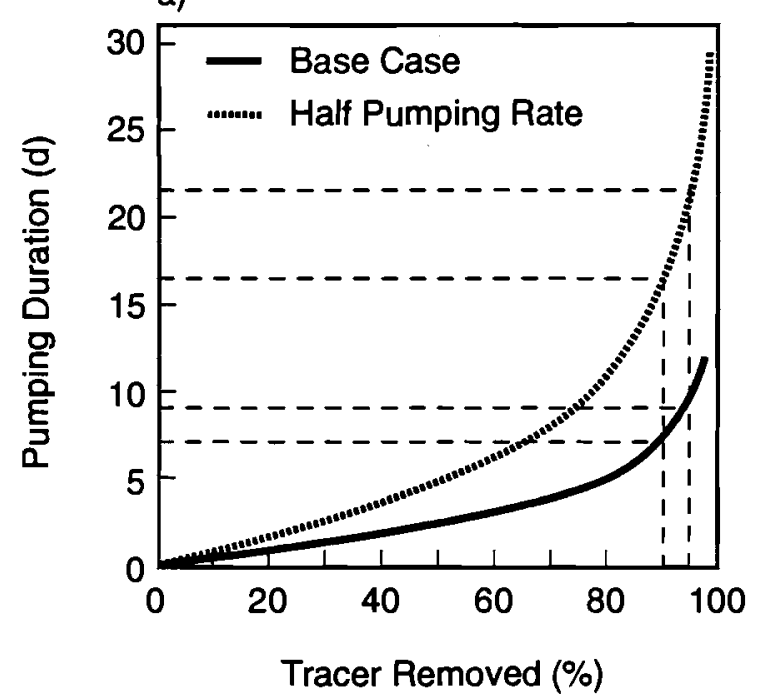

Base Case

Injection:

Injection Rate $=22.5 \mathrm{gal} / \mathrm{min}$

Injection Duration $=12 \mathrm{~h}$

Volume Injected $=16,000 \mathrm{gal}$

Pumping:

Pumping Rate $=22.5 \mathrm{gal} / \mathrm{min}$

For $95 \%$ Recovery

Pumping Duration $=9.1 \mathrm{~d}$

Volume Pumped $=293,900 \mathrm{gal}$

For $90 \%$ Recovery

Pumping Duration $=7.1 \mathrm{~d}$

Volume Pumped $=229,300 \mathrm{gal}$ b)

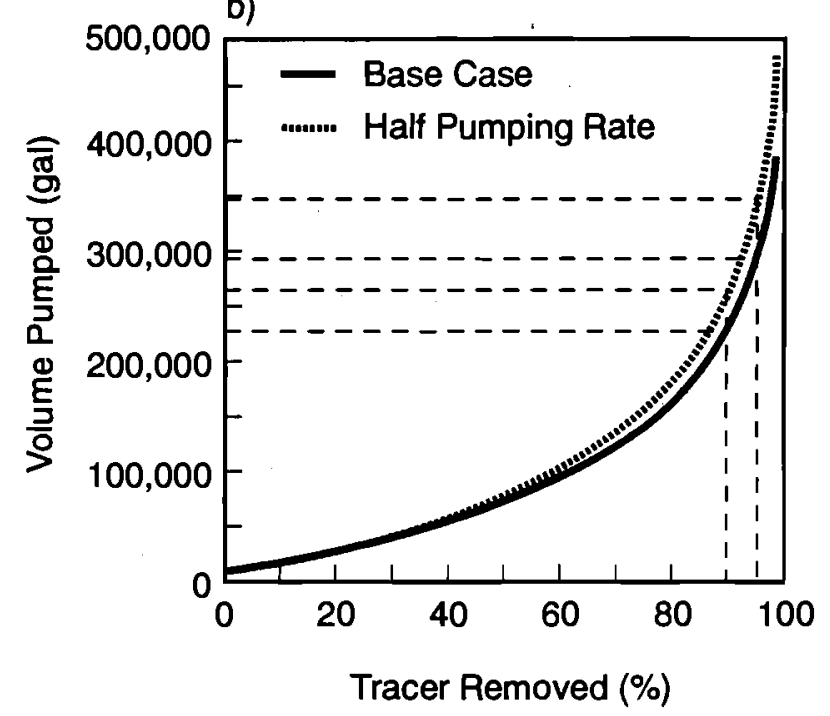

Half Pumping Rate

Injection:

Injection Rate $=22.5 \mathrm{gal} / \mathrm{min}$

Injection Duration $=12 \mathrm{~h}$

Volume Injected $=16,000 \mathrm{gal}$

Pumping:

Pumping Rate $=11.25 \mathrm{gal} / \mathrm{min}$

For $95 \%$ Recovery

Pumping Duration $=21.6 \mathrm{~d}$

Volume Pumped $=348,800 \mathrm{gal}$

For $90 \%$ Recovery

Pumping Duration $=16.5 \mathrm{~d}$

Volume Pumped $=266,500 \mathrm{gal}$

S9111073.11

FIGURE 2.11. Pumping a) Duration and b) Volume as a Function of the Percentage of Conservative Tracer Removed during the Withdrawal Phase for the Base Case and a Case with Half the Base Pumping Rate 


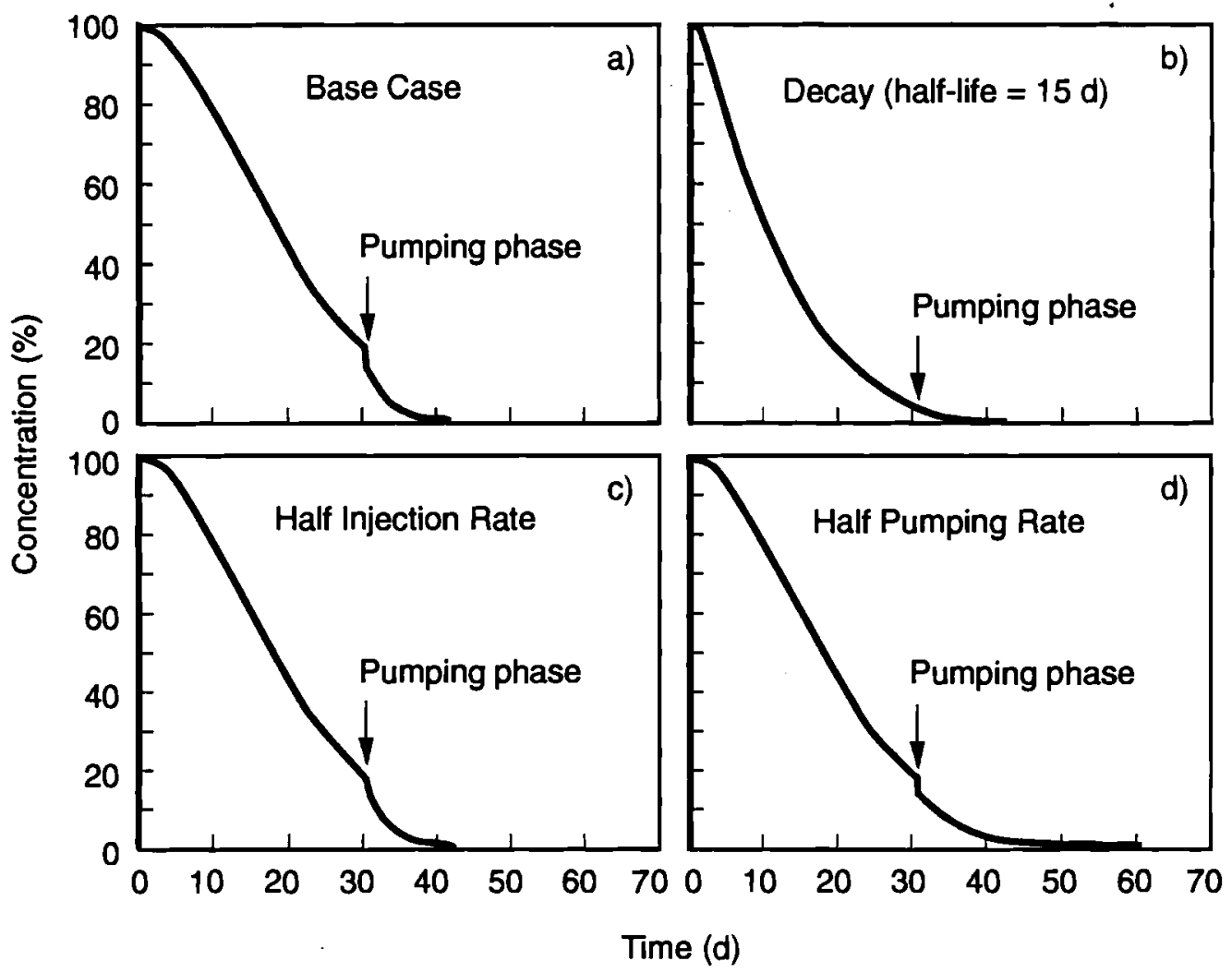

S9111073.10

FIGURE 2.12. Concentrations of a) Conservative Tracer and b) Nominal Reagent versus Time since the Start of the Experiment for the Base Case, and of the Conservative Tracer versus Time for $c$ ) the Halved-Injection-Rate Variation and d) the Halved-Pumping-Rate Variation

Aspects of the injection-withdrawal experiment that are important to reagent selection, final design, and interpretation of results elucidated by sensitivity analysis are shown in Figure 2.13. The combination of time mon:ired for reagent reaction (residence tima), other desigil parameters, and site characteristics define three volumes of aquifer material that are exposed: a) that initially exposed to reagent and subject to re-equilibration before the withdrawal phase, b) that continuously exposed to reagent, and c) that exposed to reagent only during the residence phase as a result of plume movement. The sensitivity calculations clearly demonstrated that the 


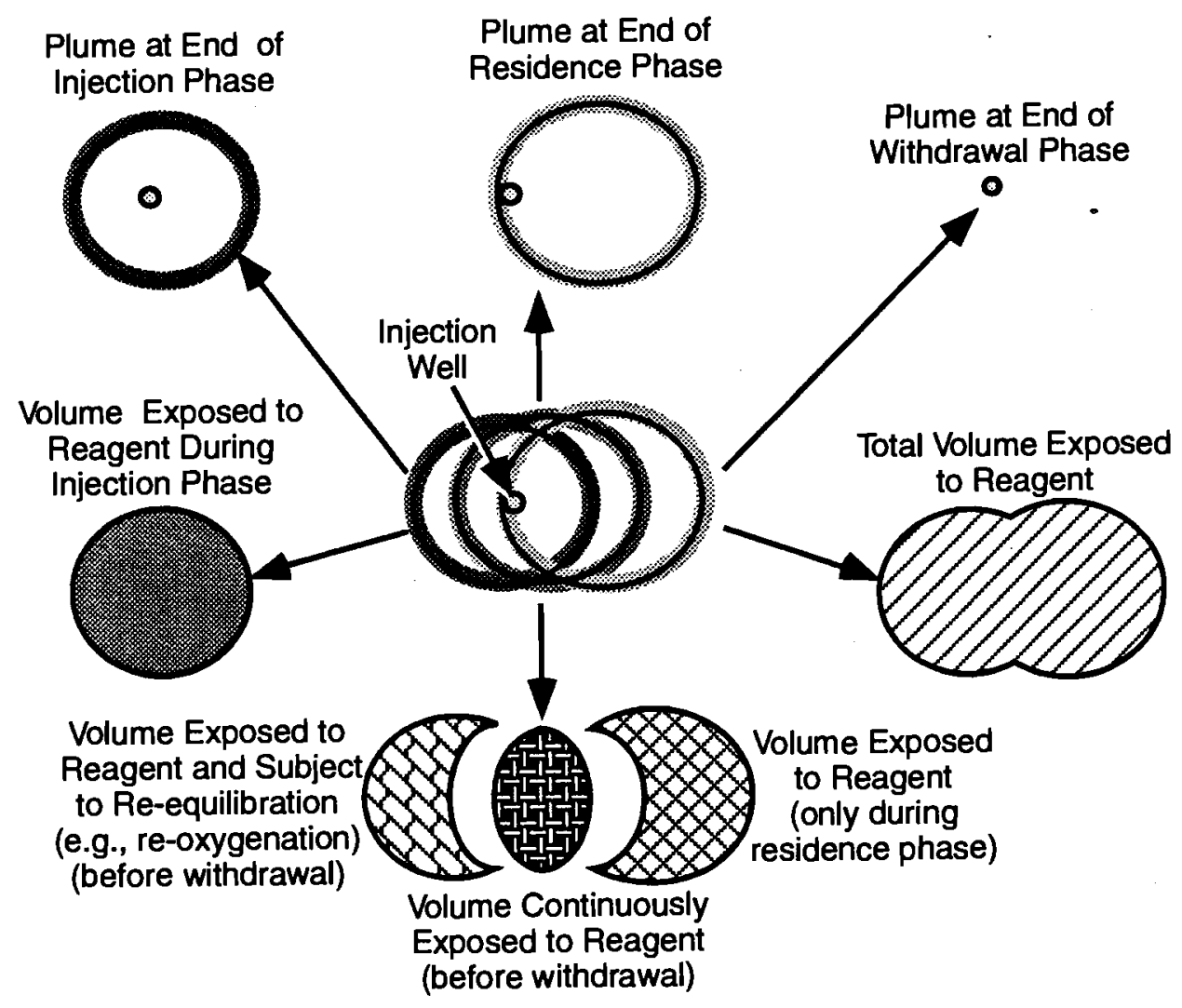

S9211013.12

FIGURE 2.13. Conceptual Diagram of the Injection-Withdrawal Experiment, Indicating How the Three Categories of Aquifer Material Exposure Arise. Groundwater flow is from left to right

volume of the aquifer continuously exposed to redox-altering conditions is inversely related to the residence-phase groundwater velocity and reagent reaction rate time constant (either biotic or abiotic).

The improved conceptuai understariuing of the experiment derived from the sensitivity calculations influenced where the injection, monitoring, and coring boreholes should be drilled (Figure 2.14). In this conceptual diagram, the majority of the boreholes are located along a line passing through the injection/withdrawal well in the expected direction of ambient groundwater flow and longitudinal spreading. Some of the boreholes along this plume center line are located to monitor the leading and trailing edges of the plume and to sample the re-equilibration and residence-phase zones; a majority 


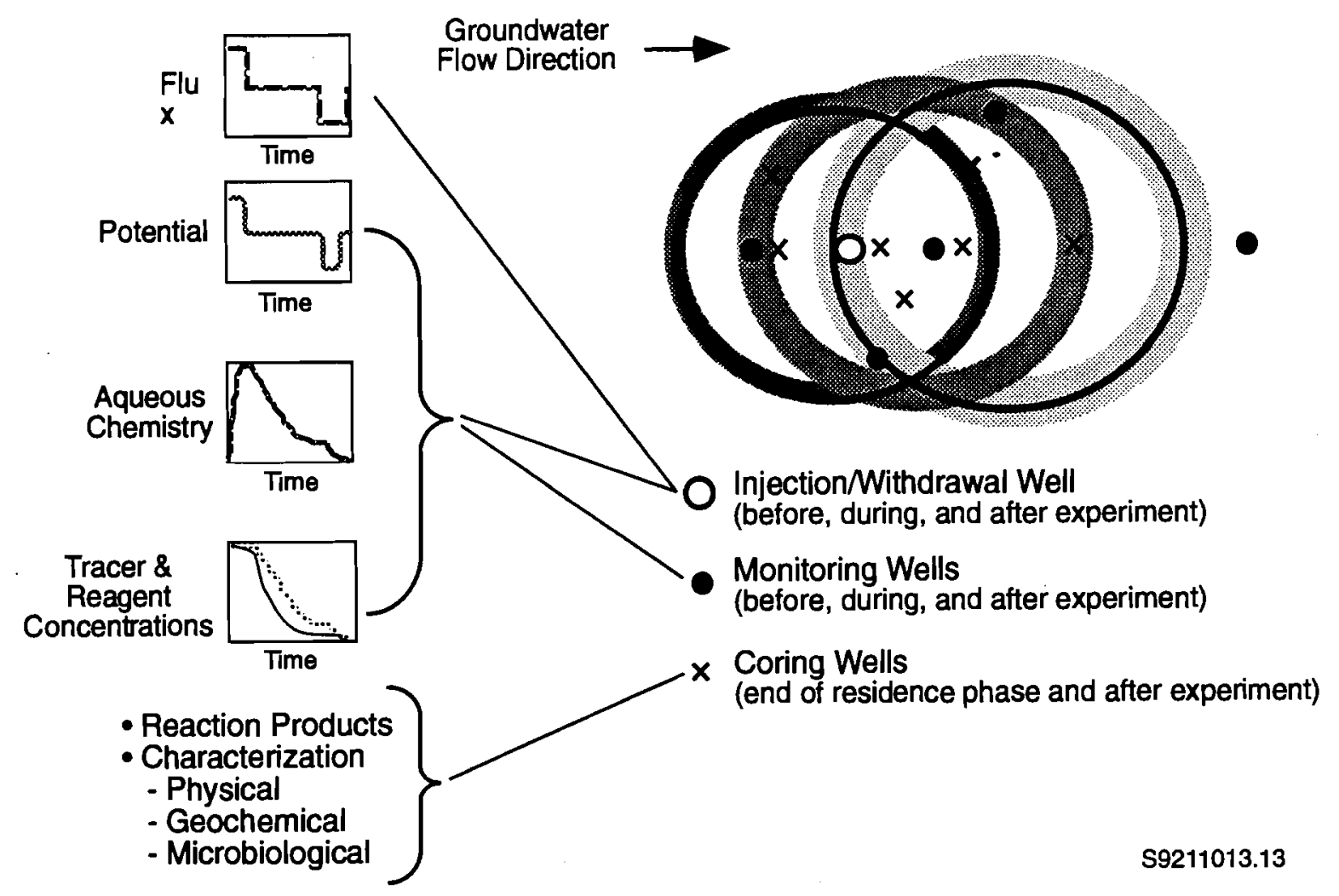

FIGURE 2.14. Relationship between Conceptual Understanding of the Phases of the Experiment and the Locations of the Injection/Withdrawal, Monitoring, and Coring Wells Relative to Expected Plume Movement

sample the continuously exposed zone. The other boreholes (those not located along the expected plume centerline) accommodate the uncertainty of the actual direction of plume advective movement and/or heterogeneity effects that would cause deviations from expected behavior.

Estimates of a 15-day time constant for the reactivity of the nominal reagent, which resulted in the 30 -day nominal residence phase, now appear overly optimistic for both the abiotic and biotic experiments, given the slow rates of geochemical reactivity noted in laboratory experiments and the low counts of Fe-reducing bacteria in Hanford aquifer sediments. In reality, residence times of 60 days may be needed. Sensitivity studies performed thus far indicate that a residence time longer than 30 days decreases the volume of 
the aquifer materials exposed continuously to chemical reduction or stimulated microbial activity. Consequently, modifications to the nominal design for the single injection/withdrawal well experiment must be examined. Two possible modifications are discussed in later sections. One involves placement of a series of gradient-controlling pumping and injection wells around the injection/withdrawal wel1. The second uses a sequence of injection and withdrawal pulses through either one or several centrally located wells. These and other modifications must be investigated through hydrologic calculations to determine ways to attain the longer residence phase required by both the abiotic and biotic experiments.

\subsubsection{Visualization Studies}

After the initial sensitivity studies, it was apparent that the twodimensional, homogeneous modeling approach was unable to simulate either

1) the various scales of heterogeneities known to exist in the Ringold Formation or

2) the vertical gradients induced by the high rates of injection and withdrawal pumping.

Figure 2.15 illustrates basic conceptual differences between homogeneous and heterogeneous models for both fully and partially penetrating injection/withdrawal wells. The spatially distributed low- and highhydraulic-conductivity zones of a heterogeneous system are expected to result in an irregular tracer front and plume, instead of the regularly shaped plume expected in a homogeneous system. A partially penetrating injection well will give rise to vertical as well as horizontal gradients, as illustrated in Figure 2.15. These vertical gradients result in additional vertical spreading of the contaminant plurie for both the homogeneous and heterogeneous cases (Figure 2.15).

An advanced visualization system was used with a high-resolution computer code to demonstrate and examine the effect of heterogeneity of porous media on plume development. A three-dimensional injection-withdrawal experiment was simulated by coupling the output of the three-dimensional 
a)

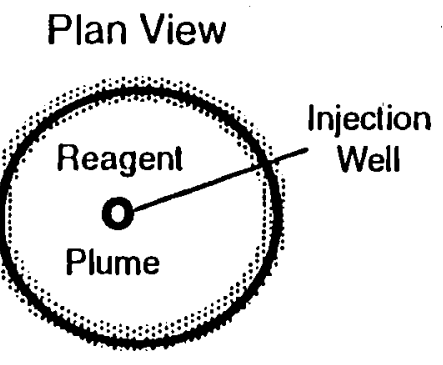

Cross Section with Full Well Screening

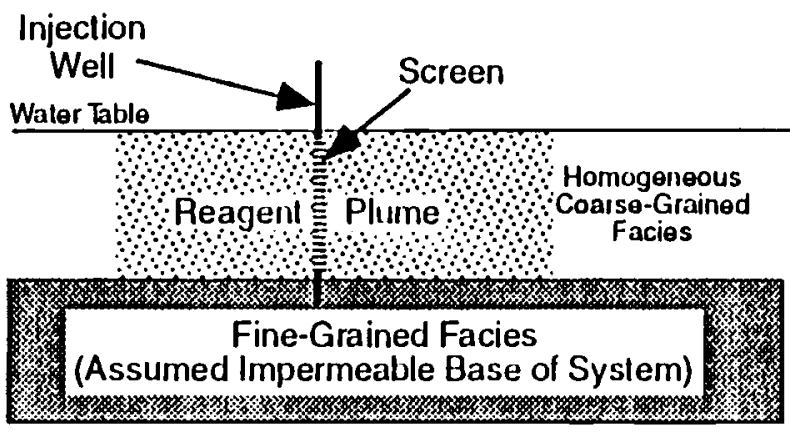

Cross Section with Partial Well Screening

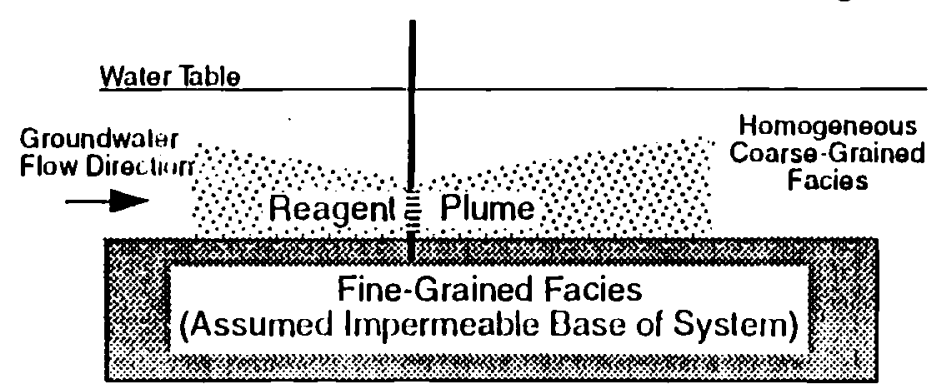

S9211013.17 b)

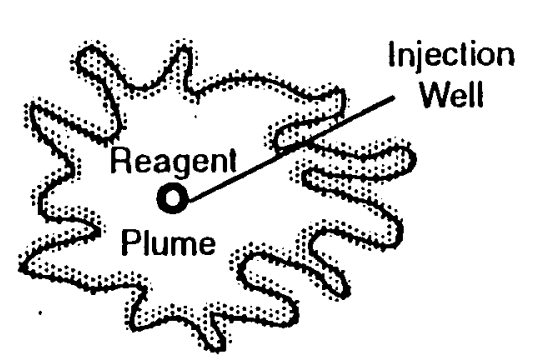

Cross Section with Full Well Screening

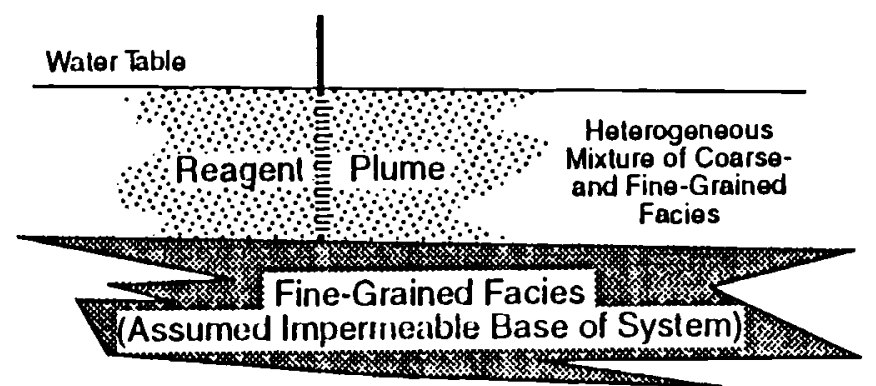

Cross Section with Partial Well Screening

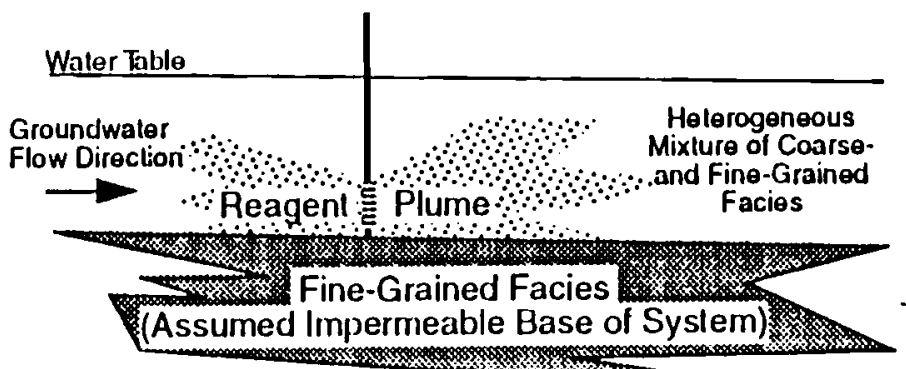

S9211013.20

FIGURE 2.15. Conceptual Differences between Fully and Partially Penetrating Injection/Withdrawal for a) Homogeneous and b) Heterogeneous Models of the Injection-Withdrawal Experiment 
finite-difference hydrologic flow code MGRID3D, which uses the multigrid solution method (Cole and Foote 1990), to a PNL-modified version of the AVSTM particle tracker to simulate transport. The coupling was accomplished through the use of a PNL-developed AVST velocity field calculation module that reads three-dimensional hydraulic conductivity, porosity, and potential scalar data. sets and calculates the three-dimensional vector field of pore-water velocities.

The heterogeneous hydraulic conductivity distribution used to simulate the three-dimensional injection-withdrawal experiment was generated through the use of a simple convolution filtering technique. With this convolution filtering technique, a uniformly spaced three-dimensional grid of normally or lognormally distributed hydraulic conductivity values having the desired mean, variance, and spatial correlation length can be generated. Site data were not available on actual hydraulic conductivity variability (e.g., correlation lengths, hydraulic conductivity variance). As a result, values were selected somewhat arbitrarily, but so that the heterogeneity would not be extreme and so that the mean value would be in the same range as that used in the nominal homogeneous experiment. A 33 by 33 by 33 grid was selected for this heterogeneity study and a lognormally distributed hydraulic conductivity data set was generated with a mean of $100 \mathrm{ft} /$ day (half the nominal value) and a small standard deviation (49 ft/day). These values were chosen to represent the middle unit of the Ringold Formation, a heterogeneous conglomerate zone consisting of stringers and lenses of sand and silt at various scales, interspersed throughout a rather uniform clast-supported, imbricated gravel with poorly defined horizontal bedding. The correlation length was arbitrarily set at approximately $1 / 10$ of the grid dimensions selected for the synthetic heterogeneous data set. The steps in this convolution filtering process were as follows:

- A random-number generator was used to develop a 33 by 33 by 33 grid of hydraulic conductivity values between 1 and 1000 with a uniform distribution (NOTE: The selection of 1 and 1000 is arbitrary, since the whole distribution is rescaled during a subsequent step) 
- This grid of values was then filtered three times with a 3 by 3 by 3 box filter to create a lognormal (or Gaussian) distribution of hydraulic conductivity values with a spatial correlation scale of approximately four grid blocks ( $-1 / 10$ of the grid dimensions)

- This 33 by 33 by 33 grid was then scaled to have the desired mean hydraulic conductivity of $100 \mathrm{ft} /$ day and a standard deviation of $49 \mathrm{ft} /$ day.

Results of this heterogeneous injection-withdrawal simulation during the residence phase of the experiment are shown in Figure 2.16. The color-coded visualization contains the following:

- An outline of the 33 by 33 by 33 cube of heterogeneous aquifer surrounding the injection/withdrawal well

- A color-coded plot of the hydraulic conductivity distribution for a 33 by 33 horizontal slice along the base of the system. The colors ranging from red (through yellow and green) to blue represent the hydraulic conductivity highs through hydraulic conductivity lows, respectively

- Rendered three-dimensional contour- or iso-surfaces (the white three-dimensional surfaces) that essentially display shells that surround the blue (i.e., low-hydraulic-conductivity) zones illustrated on the base slice

- Flow visualization lines in a horizontal slice near the top of the system. The flow visualization lines in this slice have a length proportional to the velocity magnitude and a direction oriented along the direction of flow

- Rendered tracer particles that are color coded according to their velocity magnitude. Color coding for these particles ranges from red (through yellow and green) to blue as the velocity ranges from the highest through the lowest values, respectively.

This visualization illustrates an association between the slow-moving particles and the conductivity lows [i.e., the blue (or slower) particles are near the white shells of lower hydraulic conductivity]. The flow visualization lines indicate that the main part of the flow moves, for the most part, around the low-conductivity zones. 


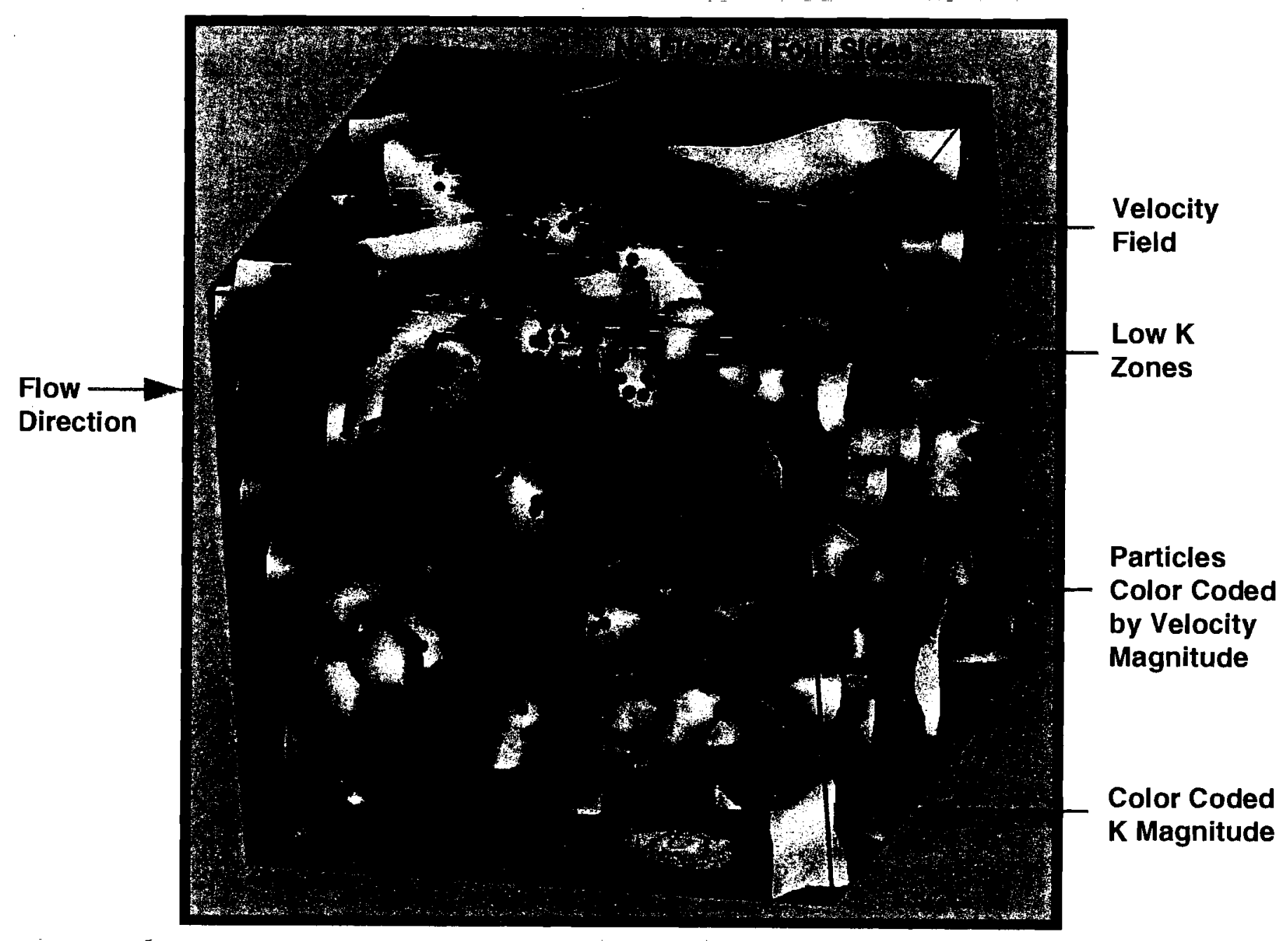

FIGURE 2.16. Results of the Three-Dimensional, Heterogeneous Injection-Withdrawal Experiment during the Residence Phase

These observations of simulated tracer behavior, even for this only sight $l_{j}$ heterogereuus simulation of the injection-withdrawai experillent, confirm the importance of the concerns regarding the importance of field-scale heterogeneity that were raised by participants during (and in written communications after) the DOE Field Experimentation Workshop held in Richland, Washington, in July 1991. It was suggested that small-scale spatial variations in hydraulic conductivity, which can span several orders of magnitude even in simple depositional systems, could give rise to preferential flow of conservative and reactive tracers through the high-conductivity zones and 
bypass the zones of low hydraulic conductivity. Because fine-grained sediments generally contain more reactive mineral phases, with higher surface area and more grain coatings, and also exhibit lower hydraulic conductivity, such preferential flow could allow reductant to bypass the very zones that contain most of the redox-buffering capacity of the aquifer. This effect will be further exacerbated by. the large differences in both magnitude and direction of the groundwater velocities during the various phases of the experiment, as illustrated in Figure 2.9.

Figure 2.17 illustrates postulated effects of the heterogeneity of porous media on reactant and tracer distribution in the in situ redoxmanipulation experiment. The aquifer in this diagram is composed of interconnected zones of higher and lower hydraulic conductivity $(k)$. The low-k zones (i.e., the outlined areas) are of various shapes, scales, hydraulic conductivity, and facies compositions. The shaded areas represent areas of high and or low conductivity that have been invaded by injected tracer.

The high gradients and short duration of the injection phase result in primarily the connected high-k zones being invaded (Figure 2.17b). The zones of lowest conductivity are bypassed (e.g., zones 4 through 8 ). Zones of intermediate hydraulic conductivity (1-3) are invaded to varying degrees during the injection phase, as illustrated by their shading. However, the degree to which these intermediate-k zones are invaded is dependent on their size, shape, and orientation (relative to the gradients), as well as their differences in conductivity. It is apparent that the effective porosity for this system, as estimated from the extent of invasion of the tracer at the end of the injection period, will be lower than the actual porosity. This disparity occurs because 1) the low-k zones are bypassed advectively and 2) the time scale of the injection is too short for these low-k zones to come into dispersive equilibrium with the tracer in the connected high-k zones. It is also apparent that, if the reducible species were located in either the larger low-k zones or those smaller low-k zones having the lowest conductivity, the injected reagent would not be in contact with the reducible species for quite some time (if at a11) during the experiment. 

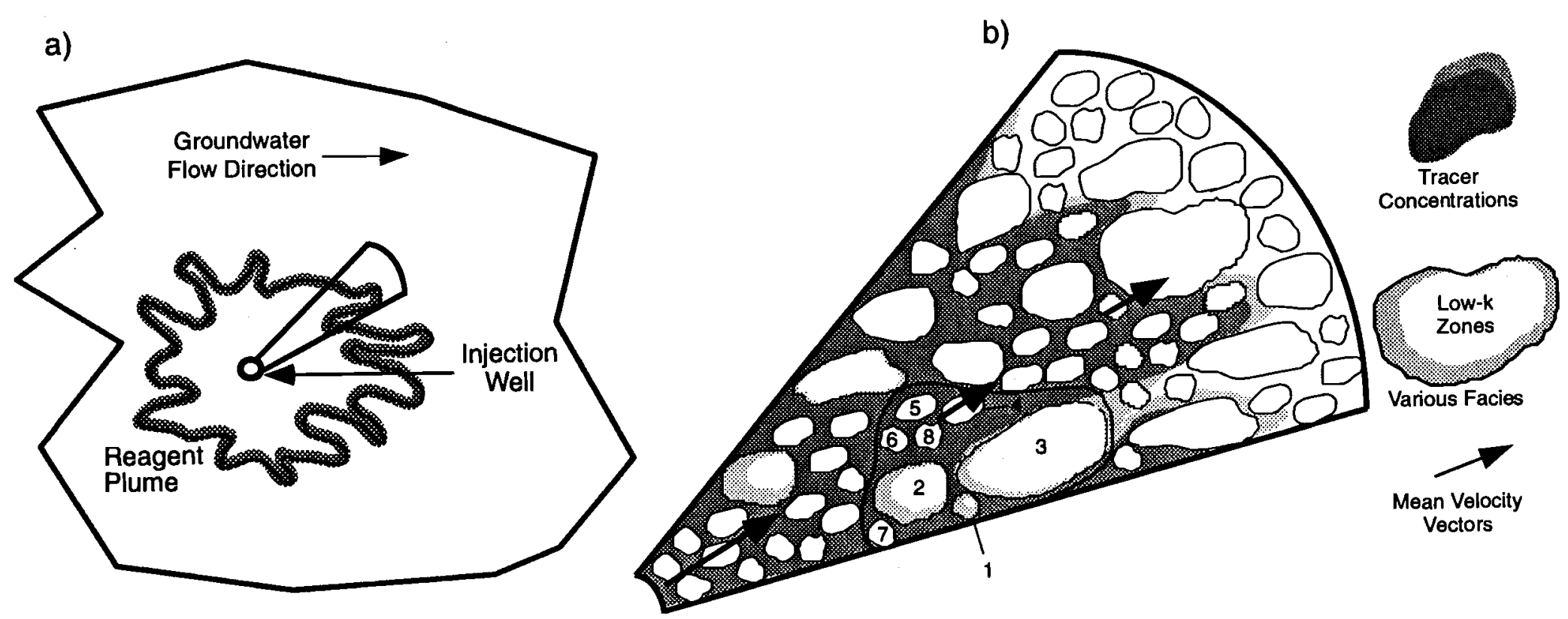

$\stackrel{\sim}{\omega}$
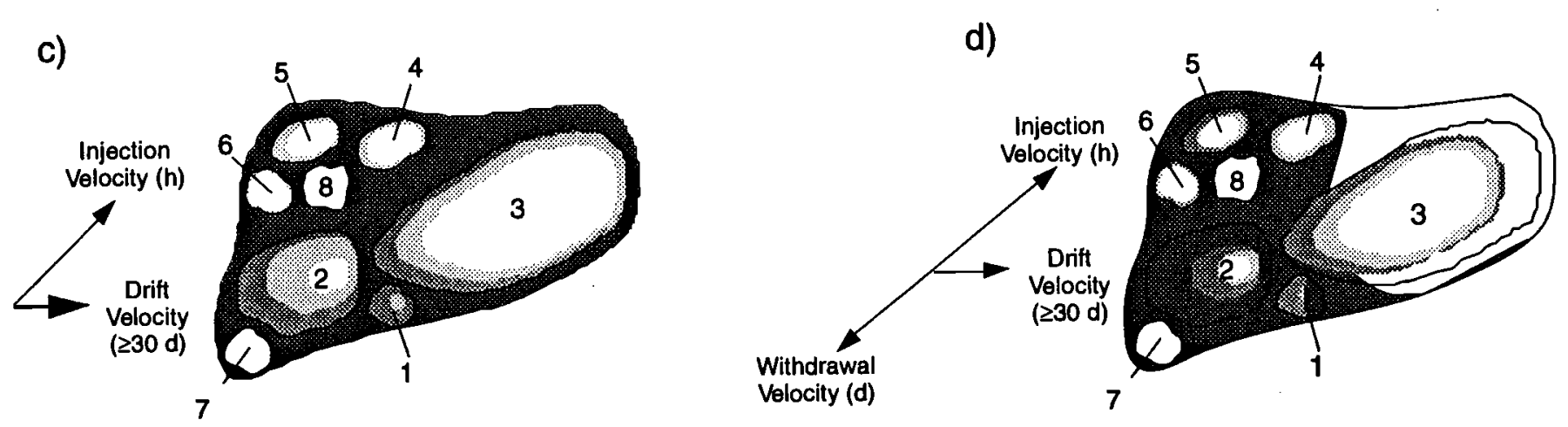

S9211013.18

FIGURE 2.17. Conceptual Diagram Illustrating the Relationships between Heterogeneity and the Various Phases of the Injection-Withdrawal Experiment: a) plan view of the whole plume near the end of the injection phase of the experiment, b) an expanded-scale plan view of the plume at this same time, c) a detailed-scale plan view near the end of the residence phase, and d) a detailed-scale plan view at the midpoint of the withdrawal phase 
During the residence phase (Figure 2.17c), the velocity is reduced in magnitude and the velocity field changes from a radial field to an ambient unidirectional field moving toward the Columbia River. The significant decrease in the magnitude of advective velocity results in a corresponding increase in the ratio of diffusive to advective movement. The increase in this ratio, coupled with the much longer period of this phase (30 or more days versus 12 hours), results in a more significant invasion of the low-k zones (zones $1-8$ ) as the system changes to one that is more dominated by diffusion. The effective porosity of the system (i.e., that portion of the system reached by the reagent or tracer) may be directly dependent on the ratio of diffusive to advective movement and inversely dependent on the scale (i.e., size) of the low-k zones.

The withdrawal phase (Figure 2.17d) illustrates the concern that all of the tracer (and/or unreacted reagent) will not be recovered. The first reason for this concern is simply related to the shorter time scale of the withdrawal phase. However, a second possible reason is illustrated by low-k zone 3 . It is postulated that the interaction between shape, size, and orientation of the low-k zones relative to the injection, residence, and magnitudes and directions of withdrawal velocity results in hysteresis. Because of these interactions, the withdrawal driving forces do not reverse the loading driving forces of the residence phase, as illustrated for low-k zone 3 . Contaminant that was loaded by advection during the injection and residence phases must take a different (and in this case a new and much slower) path before it again reaches the well-connected high-k zones.

\subsubsection{Summary of Analysis and Visualization Activities}

To develop a better conceptual model of the experiment and to aid preliminary design efforts, sensitivity analysis studies were performed with a two-dimensional flow and transport model based on

- a homogeneous description of the proposed site characteristics estimated from wells near the proposed location for the experiment, and

- preliminary reagent selection, assumed reactivity parameters, and other nominal experimental design parameters. 
These studies examined the changes in a variety of response functions (e.g., volume of aquifer affected, changes in predicted plume shape, mass of reagent required, volume of waste fluids recovered, and conservative tracer recovery) as a function of experimental phase, variations in site characterization parameters, reagent reactivity, and experimental design parameters (e.g., pumping and injection rates).

Homogeneous model sensitivity study results indicate that

- the character of the concentration versus time curve at the injection/withdrawal well is significantly affected by reagent reactivity and affected very little by changes in the injection rate

- halving the withdrawal rate nearly doubled the concentrations observed during the withdrawal phase (this point is important for hard-to-detect reagents and tracers), with on $7 y$ a $19 \%$ increase in the total amount of waste or purge water that would have to be disposed of

- for nominal site characteristics, a residence phase longer than 30 days requires either some form of gradient control (to limit plume migration from ambient groundwater flow) or a modification to the experimental design.

The homogeneous modeling studies also improved the conceptual understanding that served as the basis for the strategy used to select locations for injection, monitoring, and boreholes (Figure 2.14).

Three-dimensional transport visualization studies were performed to develop an initial understanding of how formation heterogeneity would cause differences from predictions made with the homogeneous model and how vertical gradients induced by the high rates of injection and withdrawal pumping in partially screened wells wolitu affect the concilisions that had been reached under the assumption of a fully screened well. Dynamic three-dimensional visualization of the three phases of this experiment through particle transport simulations suggested a very complex model for the transport of reagent or tracer (Figure 2.17) in highly heterogenous media. The main part of the flow is expected to move preferentially along radially divergent flow paths through the highly conductive zones during the short duration of the injection phase. The low-hydraulic-conductivity zones, which generally contain more 
reactive mineral phases with higher surface area and grain coatings (and thus contain the bulk of the redox-buffering capacity of the aquifer), are bypassed. This preferential flow is repeated during the withdrawal phase. However, the process is further complicated by the differences in duration as well as changes in flow direction and magnitude of the final two experimental phases. The differences in flow direction and magnitude during the different experimental phases result in movement along distinct preferential pathways and with ratios between advective and diffusive forces that are vastly different, as was discussed in conjunction with Figure 2.17. These behaviors will complicate delivery of the reagent and recovery of the tracers and reaction products during the in situ redox-manipulation experiment.

\subsection{SITE SELECTION}

\subsubsection{Site-Selection Criteria}

Several criteria were used to select a preferred site for the in situ redox-manipulation experiment within the saturated zone at Hanford:

- lack of contamination, to reduce complications and restrictions (and resultant increased costs) associated with discharge of purgewater and with handling and disposing of hazardous wastes

- favorable geohydrologic conditions (e.g., hydraulic conductivity, porosity, gradient), to maximize control over geochemical reaction rates and recovery of reagent

- shallow depth to groundwater, to reduce drilling and wellinstallation costs

- stable ground-water surface (e.g., away from bank storage effects), to minimize perturbations in groundwater movement

- adequate geohydrologic database to minimize the amounts of uncertainty and of additional site characterization needed.

Based on these criteria, the most favorable place for the experiment on the Hanford Site appears to be the area west of the 300 Area (Figure 2.18). However, the size of the preferred site is 1 imited by the boundaries of the 300-FF-5 operable unit to the east and a bullet impact area associated with a target range controlled by Hanford Patrol to the west. Depths to groundwater 


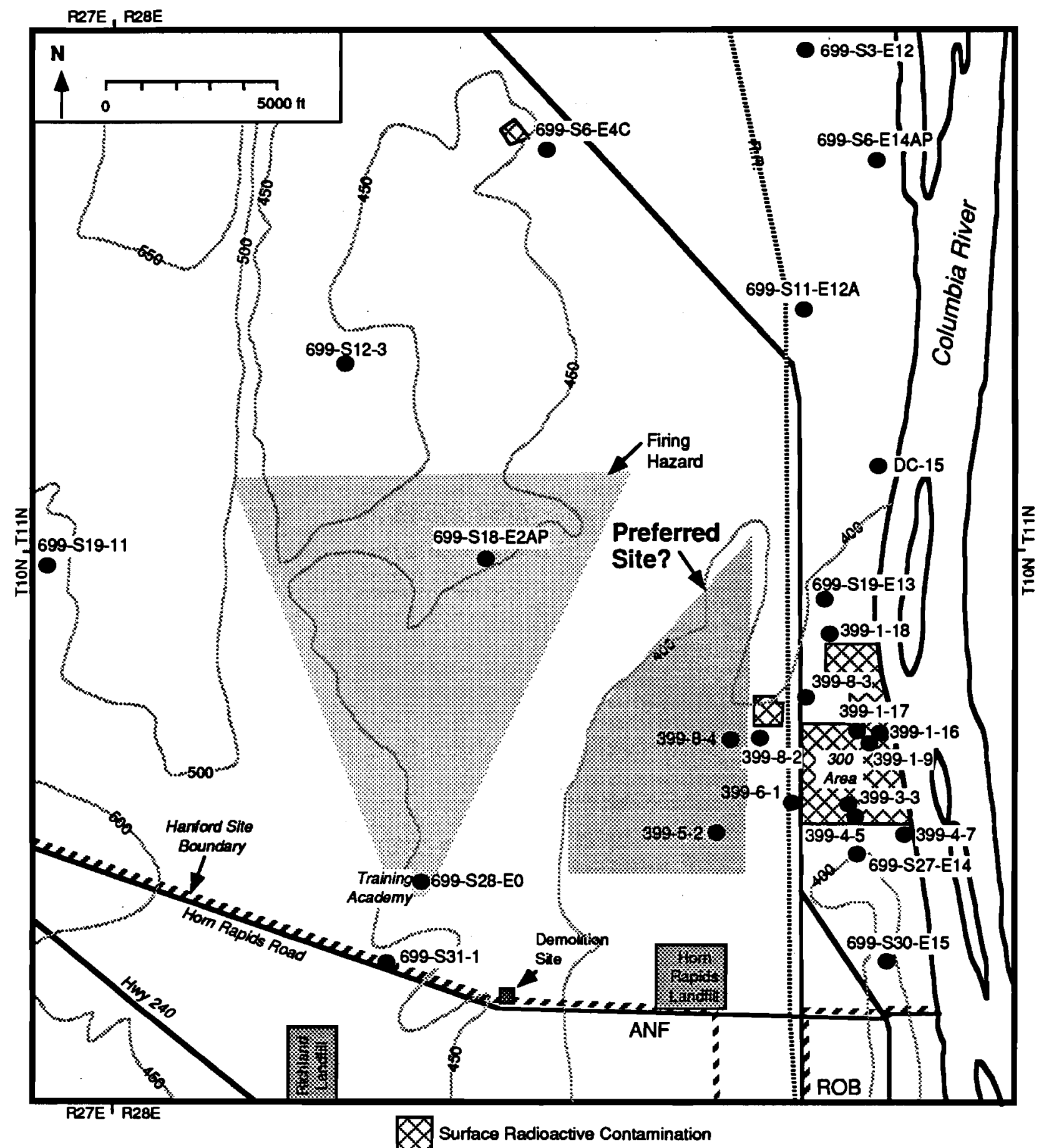

FIGURE 2.18. Proposed Location of the Subsurface Manipulation Field Site West of the Hanford 300 Area 
are as little $25 \mathrm{ft}$ in this area, and Ringold Formation sediments with favorable hydraulic conductivities (hundreds of feet per day) form a major portion of the unconfined aquifer in this region. The area lies upgradient of any hazardous, radioactive, or mixed waste contamination associated with the 300 Area and lies outside any plumes of groundwater contamination associated with other activities on the Hanford Site.

\subsubsection{Sample Collection in FY 1991}

During the spring of 1991, drilling of several groundwater monitoring well clusters began as part of a regulatory compliance program in the vicinity of the proposed in situ redox-manipulation experiment site (Figure 2.18). Five core samples for microbial and chemical characterization were obtained from the well cluster closest to the proposed in situ redox-manipulation experiment site (cluster 4). The samples were collected from depths ranging from 48 to $125 \mathrm{ft}$; all came from the saturated portion of the Ringold Formaiion. In addition, bulk sediment samples for chemicai characterization were collected from wells \#7C (43-45 ft) and \#7A (53-56 ft). These wells, which are not shown on the map, are located just southeast of the proposed field site (Figure 2.18).

Only the shallowest core sample (48-50 ft), collected from a sandy mud layer, appeared to be physically undisturbed. The microbial and geochemical properties of the deeper core samples appeared to have been compromised by hard-tool drilling, which occurred prior to core sampling.

\subsection{SUMMARY OF PROGRESS}

Progress was made in three areas of research relating to determination of the feasibility of the in situ redox manipulation approach.

In the first area, abiotic reduction, it was determined that sulfite is not sufficiently reactive with iron in the solid phases to be useful under physical and chemical conditions similar to those expected in the uppermost Hanford aquifer. Therefore, sulfite was dropped from further consideration. On the other hand, dithionite was found to be capable of reducing a significant fraction of the ferric iron in clay minerals in Hanford sediments. How- 
ever, there is the concern that, because of its inherent instability in water, dithionite might not remain in the groundwater for a sufficient period to accomplish reduction of the aquifer solids. Therefore, experimental studies focussed on dithionite stability. Extrapolation of preliminary results showed that, under temperature conditions expected in the aquifer, a 48- to 72-hour half-life can be expected for the dithionite ion. This length of time should be sufficient to accomplish a significant reduction of iron in aquifer solid, and there is the additional advantage that unreacted dithionite in the aquifer should decay naturally in a relatively brief period, leaving no residual environmental hazard.

The second area of progress involved characterization of the potential for microbial reduction of the aquifer solids by indigenous organisms. The investigations found active populations of both aerobic and facultative anaerobic bacteria in sediments from near the proposed field site. No strict anaerobes were detected by the methods used. The native populations are capable of using a variety of carbon sources, and thus could be usable.

Progress in the third area included sensitivity studies based on a twodimensional representation of the in situ redox-manipulation experiment and visualization studies based on a simple three-dimensional heterogeneous representation of the experiment. The two-dimensional studies found that the character of the concentration versus time curve at the injection/withdrawa 1 well is significantly affected by reagent reactivity but affected very little by changes in the injection rate. These studies also found that a reagent residence phase longer than 30 days requires some form of gradient control (to limit plume migration from ambient groundwater flow). The three-dimensional studies show that in hishly het irogenesus media, the main part of the fiow moves preferentially along radially divergent flow paths through the highly conductive zones during the short duration of the injection phase. The lowhydraulic-conductivity zones, which generally contain more reactive mineral phases with higher surface area and grain coatings (and thus contain the bulk of the redox-buffering capacity of the aquifer), are bypassed, thus complicating reagent delivery and recovery. 


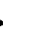




\subsection{RECOMMENDED RESEARCH}

As of FY 1992, DOE Office of Health and Environmental Research (OHER) support for this project has been terminated. However, the concepts outlined in this report remain viable, novel, and scientifically credible, and as such. they warrant further investigation. Therefore, support has been obtained from DOE's In Situ Remediation Integrated Program, Office of Technology Development. This chapter outlines the research that is recommended for the continuation of this project. This research falls into two basic categories: 1) site-characterization studies to obtain an understanding of the distribution of physical, chemical, and microbial characteristics at the chosen site, and 2) laboratory studies to obtain quantitative information on the mechanisms of both abiotic and microbially mediated iron reduction in the subsurface environment, and the expected rates of these processes under the conditions in the unconfined aquifer at Hanford. The information from these laboratory studies is essential for choosing the most suitable reagents and/or nutrients.

\subsection{RECOMMENDED SITE-CHARACTERIZATION ACTIVITIES}

Site characterization should be conducted in three phases. The first phase is a detailed areal hydrogeologic characterization of the site, including determination of the lateral and vertical distribution of hydrogeologic properties for the unconfined (uppermost) aquifer within the designated field test site. These results will be used to select the depth interval for the redox-manipulation experiment, as well as the specific location within the general characterization area. Test wells used for subsurface characterization will be completed with multilevel monitorina systems that will be used to monitor the far-field physical and hydrochemical responses during the in situ redox-manipulation experiment.

The second phase will include the installation and characterization of wells that will be used specifically for the in situ redox-manipulation experiment. Test facilities installed during this phase include the central injection well and the network of monitoring wells used for observing the effects of the reagent injection(s). Characterization activities in this 
phase will be limited to the target depth interval for the experiment. Characterization will focus on tracer tests to determine the flow transport characteristics of the test interval prior to performing the reagent injection test(s) during the third phase.

The third phase will include test activities directly pertaining to the performance of the in situ redox-manipulation experiment. These test activities include injecting redox-controlling reagent(s), monitoring the effects of the reagents in the immediate test control area (i.e., within the monitoring wel1 network), and assessing any physical and geochemical changes within the target depth interval that can be attributed to the injected reagents. The assessment of possible physical and geochemical changes caused by the reagents will require the repetition of selected characterization tests from the second phase, as well as additional geologic and hydrochemical sampling within the target depth interval.

\subsection{RECOMMENDED FUNDAMENTAL RESEARCH ACTIVITIES}

The recommended fundamental research activities include experiments to provide information on both abiotic and microbially mediated iron reduction processes that are directly relevant to the conditions expected in situ in the uppermost aquifer at Hanford. A more complete understanding of both types of processes will allow optimization of field experimental designs and greater flexibility in potential remediation scenarios.

\subsubsection{Abiotic Reduction Experiment}

\subsubsection{Reagent Selection}

Research in IY 1992 established that dithionite ion $\left(\mathrm{S}_{2} \mathrm{O}_{4}^{2-}\right)$ was effective and efficient in reducing structural Fe in Ringold Formation samples. Although dithionite is a very strong reductant, its decomposition products, both from disproportionation and from oxidation, are benign (bisulfite and thiosulfate ions). Thus, the question as to its use as an environmental reductant centers on its stability under the expected experimental conditions. Recent work by Gan et a1. (1992) has shown that even in the absence of oxidants, dithionite in near-neutral solutions decomposes through disproportionation in 
48 hours or 1ess. This observation suggests that dithionite will persist only long enough to reduce structural Fe in sediments, but is not likely to be an environmental hazard, even in the absence of oxidants.

The kinetics of dithionite reactions with such oxidants as dioxygen and peroxo species have been studied (Creutz and Sutin 1974; Rinker et a1. 1960). At $25^{\circ} \mathrm{C}$, Creutz and Sutin (1974) observed a first-order reaction with dioxygen; the formation of the $\mathrm{SO}_{2}^{-}$radical as the rate-determining step, and a rate constant of a few seconds. Their study of reaction with peroxo species $\left(\mathrm{H}_{2} \mathrm{O}_{2}\right.$, $\mathrm{HO}_{2}^{-}$) showed a half-order dependence on dithionite and somewhat slower kinetics. For all three oxidants, the $\mathrm{SO}_{2}^{-}$radical was the most reactive species, not the parent ion dithionite. The results of these experiments, however, do not incorporate information about the rates of electron transfer across the aqueous:solid interface, rates that are critical to the success of any aquifer reduction experiment.

Thus, despite the qualitative work of Stucki and coworkers, there is not any work reported in the 1 iterature that quantitatively addresses either 1) the reduction of sediments by dithionite or 2) the stability of dithionite in a reduced sediment system. Therefore future work must focus on these two aspects of dithionite chemistry, in addition to exploring other possible reductants (e.g., ascorbate ion, hydroxylamine, phosphinate ion).

\subsubsection{Kinetic and Mechanistic Experiments}

Reductant chemistry will be studied under controlled atmospheres and temperatures using a jacketed reaction vessel. When possible, reaction progress will be monitored spectroscopically in either the ultraviolet-visible (UV-Vis) or the infrared portion of the spectrum. These studies will involve either discrete subsamples taken by syringe or a continuous-flow system in which fluid from the reaction vessel is circulated through a special cell in the spectrometer. Studies involving Fe-bearing sediment materials (e.g., clay isolates, reference clays) will also involve analysis of the $\mathrm{Fe}$ (II) content of the solids at selected points during the experiments. 
Specific experiments using this approach will include

1) monitoring the stability of dithionite at several temperatures between 0 and $40^{\circ} \mathrm{C}$, at $\mathrm{pH} 6.5,7.5$, and 8.5 , with and without citrate in a closed bicarbonate buffer system;

2) monitoring the reaction of dithionite with reference smectites and Hanford sediments at temperatures between 0 and $40^{\circ} \mathrm{C}$, at $\mathrm{pH} 6.5,7.5$, and 8.5, with and without citrate in a closed bicarbonate buffer system;

3) monitoring the stability and reactions of hydroxylamine with reference clays and Hanford sediments at $25^{\circ} \mathrm{C}$ and at $\mathrm{pH}$ 6-8 in bicarbonatebuffered systems;

4) monitoring the stability and reactions of ascorbate with reference clays and Hanford sediments at $25^{\circ} \mathrm{C}$ and at $\mathrm{pH}$ 6.5-8.5 in bicarbonate-buffered systems; and

5) monitoring the stability and reactions of phosphinates with reference $\mathrm{cl}$ ays and Hanford sediments at $25^{\circ} \mathrm{C}$ and at $\mathrm{pH}$ 6.5-8.5 in bicarbonatebuffered systems.

\subsubsection{Laboratory Simulations to Scope Experimental Conditions}

Abiotic scoping experiments will be conducted using samples of a natural sediment from the Hanford Site and a synthetic groundwater having a composition similar to that expected near the proposed field site. Before the experiments, the sediment will be characterized for bulk chemistry, mineralogy, proportions of redox-sensitive elements, and amounts of reactive solid oxidants to obtain the initial chemical conditions.

The experiments will be conducted under controlled $\mathrm{pH}$ and $\mathrm{pO}_{2}$ conditions for both homogeneous (groundwater + reductant) and heterogeneous (groundwater + reductant + sediment) systems so that the changes in redox state can be measured with and without reactive solids present. In the heterogeneous systems, the relative ratio of the masses of aqueous reductant to solid oxidant will be varied by adjusting the solid-to-solution ratio. The experiments using bulk sediment samples will most closely simulate the conditions expected in the field. Changes in the redox state during the laboratory experiment (as well as during the field test) can be monitored only by measuring the progress of the chemical reaction in the aqueous phase. Progress will be monitored with time by measuring complete water chemistries, including the redox states of the redox-sensitive species (i.e., Fe, Mn, N, and S). At the conclusion of 
the experiments, the sediment will again be completely characterized to measure changes in the composition and redox state of the solid phase assemblage. In this way, our ability to measure the changes in redox status of both aqueous and solid phases will be tested before the actual in situ redoxmanipulation experiment.

Because the reactive phases and solid oxidants in sediments are generally not the most abundant solids present, it is often difficult to detect them or to obtain a reasonable quantitative analysis of bulk sediments. For this reason, it is reasonable to assume that analytical difficulties may be encountered in measuring changes in the redox state of the bulk sediment used in the abiotic experiments. Therefore, rather than rely on our ability to measure potentially small changes in sediment chemistry and mineralogy of bulk samples, additional experiments will be performed on heterogeneous systems, using silt and clay fractions separated from the bulk sediment. The fractions can be treated separately before each experiment, using selective extraction techniques to remove specific reactive phases from each fraction. A comparison of the results from this suite of experiments in heterogeneous systems may allow us to identify which solid oxidants are involved in the overall redox process and what magnitude of change in redox status of the sediment should be expected in the field.

\subsubsection{Geochemical Modeling}

Proposed future research includes the following: 1) a review of the algorithms used to describe mineral dissolution kinetics in the EQ3/EQ6 code, 2) a review of redox kinetic rate expressions, and 3) model development. The review of the EQ3/EQ6 code will focus on evaluating both its approach to performing calculations that include ooth kinetic and equilibrium speciation/ solubility constraints and the algorithm it uses to solve problems involving several kinetic rate expressions simultaneously. The review of redox kinetic rate expressions for the reactions important to the abiotic experiment will ensure that the model developed can be adapted to the various types of rate expressions that might be determined from the laboratory experiments.

Model development will involve 1) developing an algorithm that can calculate the equilibrium pe for an aqueous system and the equilibrium 
concentrations of the species given the initial concentrations for several aqueous redox couples, 2) incorporating this algorithm into an equilibrium speciation/solubility code, 3) addressing the need to handle heterogeneous redox reactions, and 4 ) writing an algorithm to describe reaction progress using kinetic rate laws.

\subsubsection{Requirements for In Situ Microbial Reduction}

To date, most bioremediation approaches employed for the in situ degradation of organic contaminants in the subsurface have employed $0_{2}$ as the terminal electron acceptor. In many cases $0_{2}$ availability is the primary factor limiting in situ microbial metabolism and therefore $0_{2}$ is added by sparging injection water with air or by adding hydrogen peroxide (Thomas and Ward 1989; Wilson and Ward 1987). Few published studies have attempted to achieve anaerobic biotransformation of contaminants in situ in the subsurface. Although in situ degradation of organic contaminants is currently used in the bioremediation industry, the determination of the combination of nutrients and electron donors required is based on feasibility studies (at best) or on past experience, which is not always transferrable from site to site.

The objectives of this research are to determine 1) the requirements for in situ stimulation of the subsurface microflora to achieve reduction of the aqueous phase; 2) changes in the geochemical, hydrological, and microbial properties of the system associated with in situ manipulation; and 3) the rate of change of the system properties after cessation of nutrient injection.

\subsubsection{Characterization of Iron-Reducing Organisms}

Investigation of microbial subsurface reduction processes for the in situ iadrix-manipulation experiment will focus on the activities of dissimilatory iron-reducing bacteria (DIRB). This group of organisms was chosen for several reasons, including their potential to transform or degrade mixed and complexed radioactive contaminants, their ability to function in anaerobic environments, and their ability to use an electron acceptor [Fe(III)] that is abundant in subsurface sediments at Hanford. As microorganisms metabolize organic or inorganic compounds in a closed or diffusion-limited environment, they use up all available oxygen, producing anaerobic conditions. Under these 
conditions, anaerobic microorganisms use alternative compounds, such as nitrate, sulfate, and ferric iron, as electron acceptors. Dissimilatory ironreducing bacteria are a little-studied group of organisms that reduce ferric iron to ferrous forms as a result of the terminal electron-accepting reaction in their metabolism (Lovley and Phillips 1987). The resulting soluble ferrous iron can diffuse through an environment, carrying out reduction reactions that may in turn help to immobilize other metals. In addition, recent studies have shown that DIRB can directly reduce other metals, including uranium, to less soluble forms (Lovley et a1. 1991). Studies in our laboratory also suggest that some DIRB can couple Fe(III) reduction to degradation of complexing agents, such as citrate and oxalate.

It may be necessary to introduce DIRB from laboratory cultures for some field manipulations to succeed. In addition, little is known about the mineral forms of ferric iron that DIRB can utilize (Nealson and Myers 1992), or by which mechanisms this insoluble substrate is liberated. This lack of knowledge is due, in part, to the limited number of isolates that have been studied. We have now isolated a number of DIRB in our laboratory, some of which appear to have preferences for different forms of ferric iron. The proposed research will focus on

- the ability of known DIRB to reduce solid-phase Fe(III), and

- confirmation of whether DIRB are present naturally in sediments from the proposed field site.

\subsubsection{Nutrient Requirements}

To effect subsurface manipulation of DIRB in Hanford sediments, a number of factors must be determined, including the limiting nutrients and the boundary conditions for Fe(III) reduction. Although laboratory experiments almost always overestimate the rates of in situ processes, they can provide valuable information on limiting conditions. Flow-through columns containing subsurface materials from Hanford will be used for such studies. The ability of DIRB to function in Hanford-specific environments, as well as their interaction with other microbial groups, will be determined. This intergroup interaction is important because aerobic microorganisms will provide the initial reducing conditions for DIRB, while other groups of anaerobes, such as 
fermentors and sulfate-reducing bacteria, may act synergistically or competitively with DIRB, depending on environmental conditions.

Another crucial question that can be addressed by laboratory experiments is the long-term fate of a manipulated environment. That is, after manipulation hás ceased and normal groundwater flow resumes, how fast are reduced species reoxidized? Are immobilized species remobilized? If so, what minimum input would maintain reduced conditions? Preliminary qual itative answers to these questions can be determined in column experiments.

A chronological outline of the experiments follows:

A. Determine distribution and abundance of DIRB in Hanford sediments

1) Enumerate DIRB in selected Hanford sediment samples

2) Select isolates with known iron-reducing capability and substrate range

3) Characterize ability of DIRB cultures and enrichments to utilize different mineral forms of Fe(III)

B. Determine geochemical controls on DIRB activity using recirculating bioreactors

1) Availability of microbially reducible iron in Hanford sediment samples

2) Effect of inoculation with 1aboratory isolates

3) Extent of stimulation by addition of nutrients, including $\mathrm{N}, \mathrm{P}, \mathrm{SO}_{4}$, and carbon substrates

4) Effect of treatments on redox state, and effect of reoxygenation at end of treatment

C. Model results of experiments $A$ and $B$

D. Characterize core samples from field site

1) Enumerate DIRB, as above

2) Determine availability of microbially reducible $\mathrm{Fe}($ III), as above 
E. Conduct intermediate-scale experiments to test the most likely treatment scenario as indicated by the previous work, including effects of expected heterogeneities in physical and chemical properties

F. Refine the models.

\subsubsection{Modeling to Improve Design and Investigate Effects of Heterogeneity}

The purpose of the modeling activities is to investigate important design and heterogeneity issues. Design and analysis activities must be undertaken to determine

- plausible methods (e.g., gradient control) for minimizing the effect of natural advective movement during the residence phase of the experiment, and

- the characteristics of hydraulic conductivity and geochemical heterogeneity that would make interpretation of the manipulation experiment difficult.

\subsubsection{Methods for Achieving a Longer Residence Phase}

The sensitivity analysis and modeling studies discussed in Chapter 2.0 elucidated aspects of the single-well injection/withdrawal experiment that are important to reagent selection, final design, and interpretation of results. The studies indicated that residence phase times longer than 30 days decreased significantly the volume of the aquifer materials that were continuously exposed to chemical reduction or stimulated microbiological activity (Figures 2.9 and 2.13). These studies confirmed the need to investigate, through hydrologic calculations, modifications of the single-well injection/ withdrawal design to attain the longer residence time required by both the abiotic and biotic experiments. Two possible modifications would allow the longer residence phase to be attained: gradient control and sequenced multiple-well injection/withdrawal.

\subsubsection{Gradient Control}

In view of the current concern for controlling the migration of contaminant plumes (Aral 1989; Shafer and Vail 1987) and earlier concerns for head gradient control in aquifers used for fluid storage (Molz and Bell 1977), a variety of analytical and numerical methods are available for assessing gradient-control schemes. 
Gradient control involves reducing gradients by some type of pumping upstream of the area where gradient control is desired to reduce heads and injection downstream to increase heads. Gradient control can be achieved by either single- or multiple-we11 methods. The process is illustrated conceptually for a two-well control scheme in Figure 3.1 .

Other well field designs would control the velocity at selected points within the gradient-controlled zone by selection of appropriate pumping/ injection rates at a series of control wel1s (see Figure 3.2 for a conceptual illustration). The design methods use numerical and analytical models of the aquifer in conjunction with linear programming methods to minimize the quantity

$$
\delta_{1} \sum_{1}^{N} Q_{k}^{\pi}+\delta_{2} V_{\max }
$$

where

$$
\begin{aligned}
\delta_{1}, \delta_{2} & =\text { tradeoff weights } \\
Q_{k}^{\pi} & =\text { pumping/injection rate at control well } \mathrm{k} \\
V_{\max } & =\text { maximum velocity at any control point. }
\end{aligned}
$$

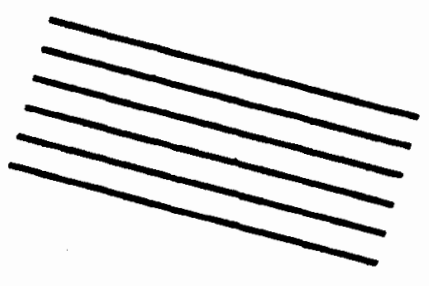

Potential Distribution in Uncontrolled System

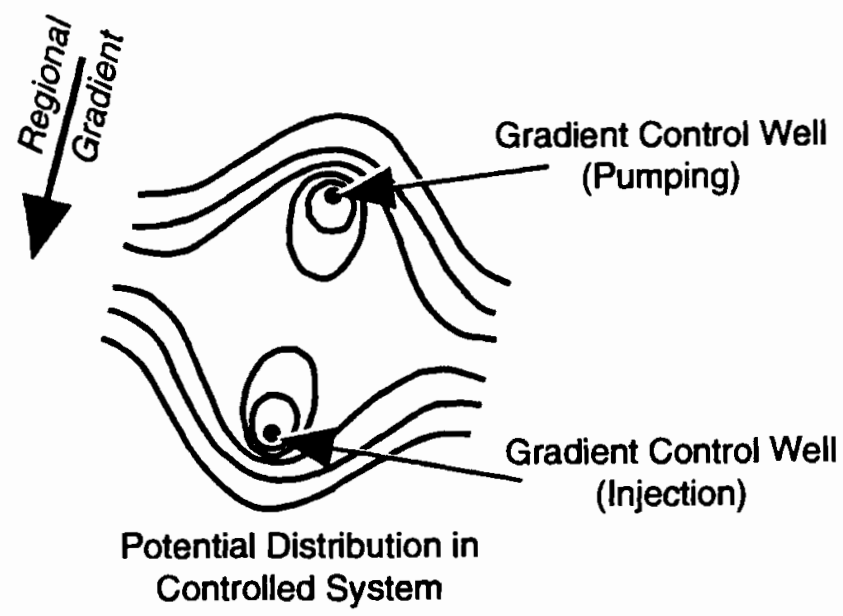

S9211013.14

FIGURE 3.1. Plan View Illustrating Head Gradient Control with a Single Upstream Pumping We11 and a Single Downstream Injection We11 


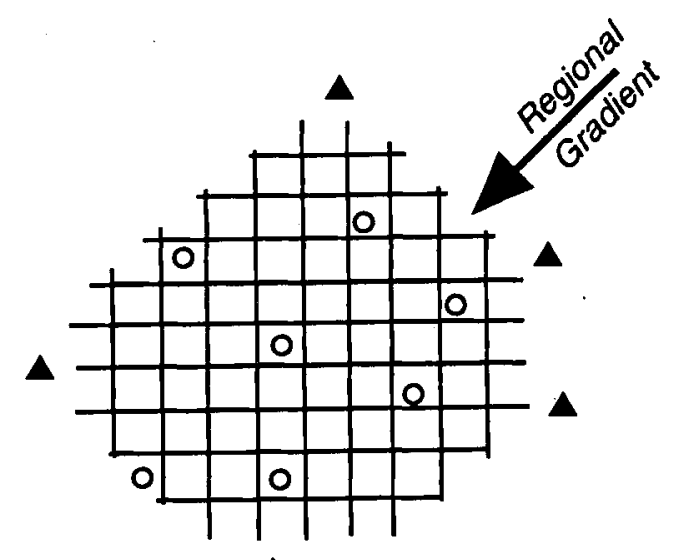

$\Delta$

WELL FIELD

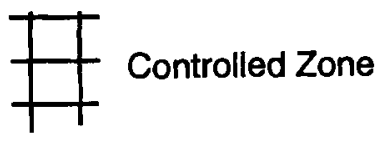

\section{Control Wells \\ o Control Points}

S9211013.15

FIGURE 3.2. Plan View of a Well Field for an Optimal Strategy to Control Drift within the Controlled Zone

This standard optimization function reduces the velocity magnitude only at the control points within the control area. If there is a need to control the direction as well, the minimization function can be modified accordingly.

Initial gradient-control investigations will use a two-dimensional homogeneous flow model. Once basic sensitivity studies have been conducted with this simplified model, the effects of heterogeneity at other scales and of partial penetration can be investigated with more complicated two- and three-dimensional models [e.g., the CFEST code (Gupta et al. 1987)].

\subsubsection{Sequenced Multiple-Well Injection-Withdrawal Experiment}

This approach involves an alternating sequence of injection and withdrawal through multiple wells. The multiple-well, sequenced injectionwithdrawal concept is illustrated in Figure 3.3. The diagram illustrates locations for the injection and withdrawal wells and plume shapes and 


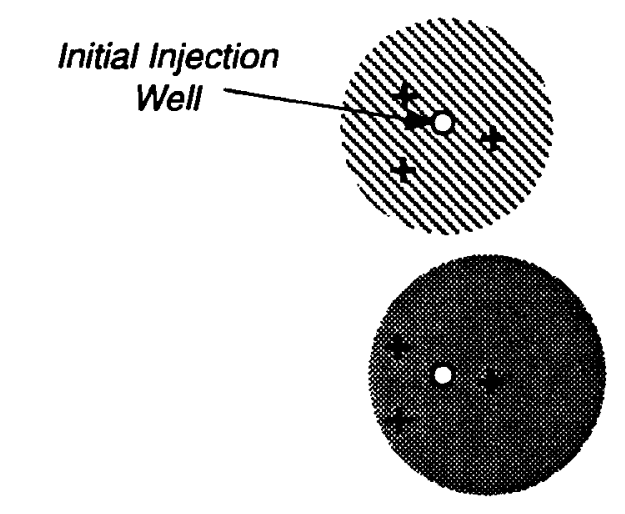

1. Plume at End of Initial Injection Phase

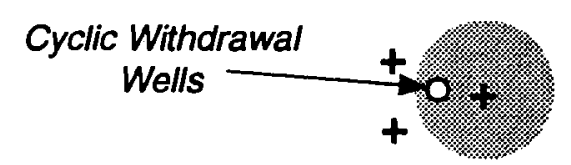

2. Plume at End of Initial Residence Phase

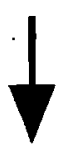

3. Plume at End of Cyclic Withdrawal Phase
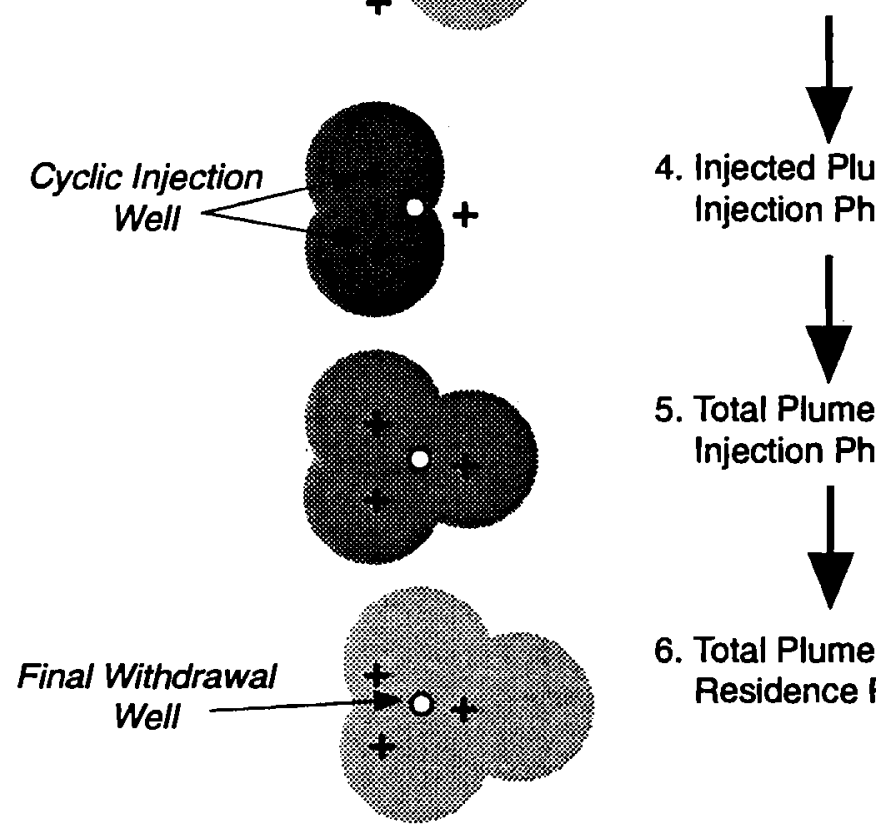

4. Injected Plume at End of Cyclic Injection Phase

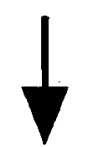

5. Total Plume at End of Cyclic Injection Phase

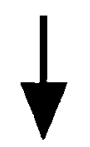

6. Total Plume at End of Cyclic Residence Phase

$\$ 9211013.16$

FIGURE 3.3. Conceptual Diagram of the Multiple-We11, Sequenced Injection-Withdrawal Experiment 
movements at various times during both the initial and cyclic phases of the experiment. With this concept, the residence time that would occur with natural gradient drift is increased, by injecting a plume upgradient (step 1 of Figure 3.3). The initial injection plume is then allowed to drift until it is centered over the downgradient withdrawal well (step 2 of Figure 3.3). The plume at the end of the cyclic withdrawal phase (step 3 of Figure 3.3) represents the volume of the aquifer that is continuously exposed to reagent or stimulated biological activity. Aquifer fluid that is withdrawn during step 3 is mixed with additional reagent to bring it back to initial injection concentrations before it is reinjected into the two upgradient wells, as illustrated in step 4. Steps 5 and 6 illustrate the plume at the beginning and end of the first cyclic drift cycle. At this point, the process begins again at step 3 (Figure 3.3).

This sequenced injection-withdrawal experiment is, in a sense, a discrete version of the recirculating tracer test. As such, it allows the supply of reagent for the abiotic experiment and nutrients for the biotic experiment to be supplemented in much the same way as would be possibie in a recirculating tracer test. On the other hand, it retains the advantage of the injection-withdrawal experiment of keeping all of the injection flow lines, and thus the reagent, within a well-controlled and finite region. The feasibility and possible advantages of this sequenced injection-withdrawa experiment over the gradient-control scheme discussed above can be evaluated through a sensitivity analysis using the two-dimensional homogeneous flow and transport model implemented in the CFESTT code (Gupta et a1. 1987).

\subsubsection{Heterogeneity and Uniform Dispersal of Reagent}

in Section 2.3.3, it was prstulated how various types of heterogerieity could affect the uniform dispersal of reagent throughout the aquifer volume (Figure 2.17) and thus affect our ability to interpret the results of the proposed single-we 17 experiment. In this section, an approach for investigating the relative importance of various types of heterogeneity is out 7 ined. The approach is to use prototype statistics on the Ringold outcrop that are being gathered in another project to generate detailed synthetic twodimensional data sets with appropriate length scales, shapes, and magnitudes 
of parameter contrasts over a hierarchy of transport scales (e.g., one-meter and tens-of-meters scales). Preliminary digital images taken as part of that project are shown in Figures 3.4 through 3.6, to illustrate the basic character and the various kinds and scales of heterogeneities typically found in the middle Ringold Formation.

The Ringold Formation is a massive fluvial deposit, as illustrated in Figure 3.6. Large rounded clasts of basalt and other imported rocks form a basic pore space that is filled with finer sediments ranging from fine gravels through sands and silts. Larger scales of heterogeneity (tens of meters long and centimeters to meters thick) in the form of coarse-grained clean sandbar depcsits (as illustrated in Figure 3.4), as well as fine-grained overbank

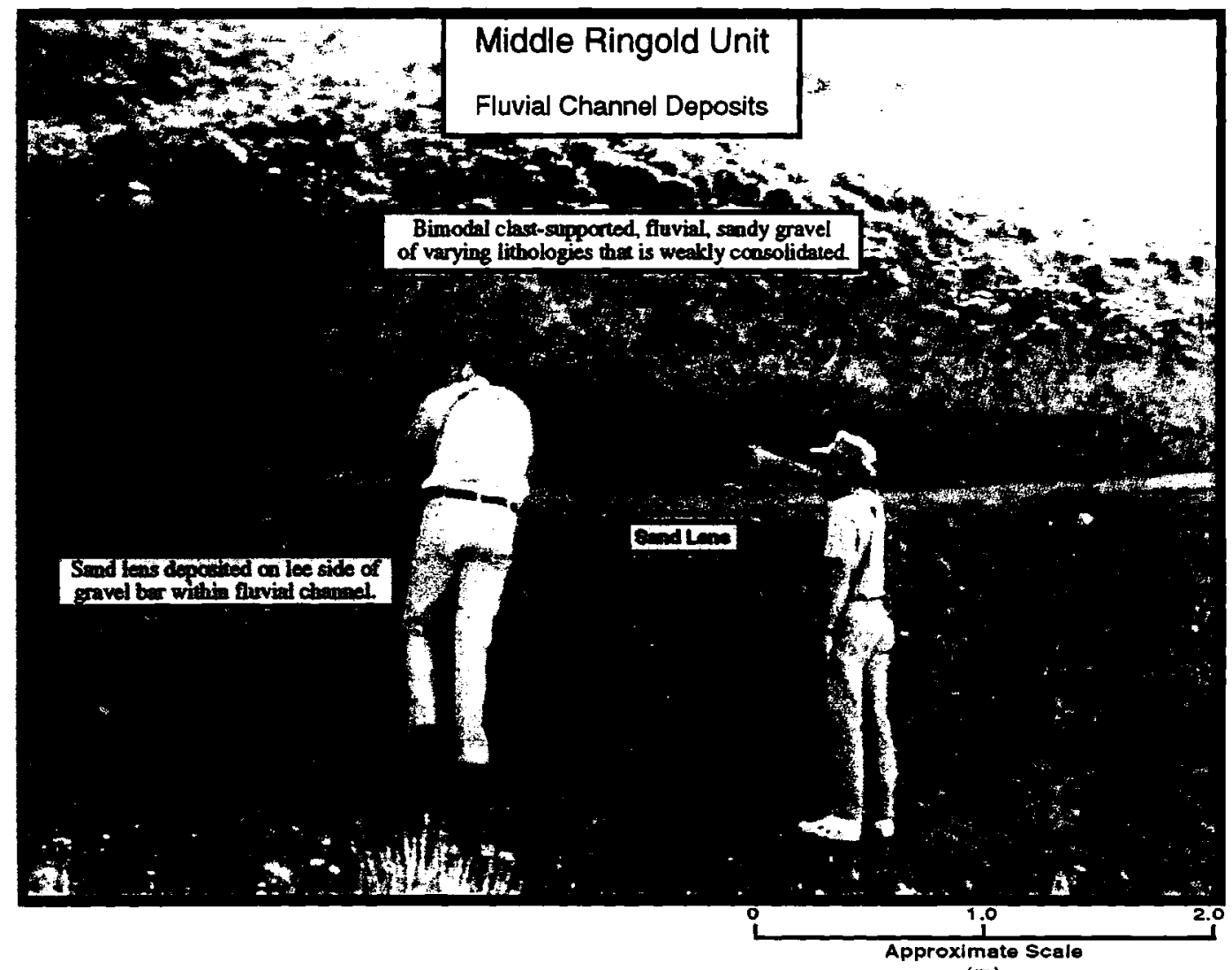

(m)

FIGURE 3.4. Digital Image of the Middle Ringold Outcrop Illustrating Heterogeneity in the Form of a Typical of a Sand Lens 
deposits, are observed. The large clasts for the most part are essentially impermeable; however, there are rip-up clasts consisting of overbank deposits (see Figure 3.5), as well as partially and completely weathered basalt clasts (Figure 3.6).

Based on the digital images, several bimodal realizations will be constructed. The pore space will be filled with homogeneous and heterogeneous gravels, sands, and silts. Some of these realizations will include finegrained clasts (i.e., rip-up or weathered basalt); others will include the larger-scale sandbar and overbank deposits. Flow and transport in these systems will be analyzed using the three-dimensional, finite-difference hydrologic flow code MGRID3D, which uses the multigrid solution method (Cole and Foote 1989) and the PNL-modified version of the AVST particle tracker. The analysis will attempt to identify those characteristics and scales of heterogeneity that could have a significant effect on the dispersal of reagent.

\subsection{SUMMARY OF RECOMMENDED RESEARCH ACTIVITIES}

The recommended research activities fall into two areas, field-site characterization and basic laboratory and computer-modeling studies.

Initiation of a three-phase site characterization and reagent-injection test plan is recommended as soon as a suitable site is chosen. In the first phase, the hydraulic, geochemical, and microbial properties of the site will be characterized in both an areal and a vertical sense. The results would then be used to select a limited vertical interval for the redox test. This limited vertical interval would then be characterized more comprehensively in tne second piase, using wells installed in the chosen test area. A variety of techniques, including tracer tests, would be used in this second phase. The third phase would be the actual injection of reagent. Specific techniques for use in monitoring the injection experiment and interpreting the results are recommended.

Recommended basic laboratory studies include additional study of dithionite, as well as such other potential abiotic reducing reagents as 


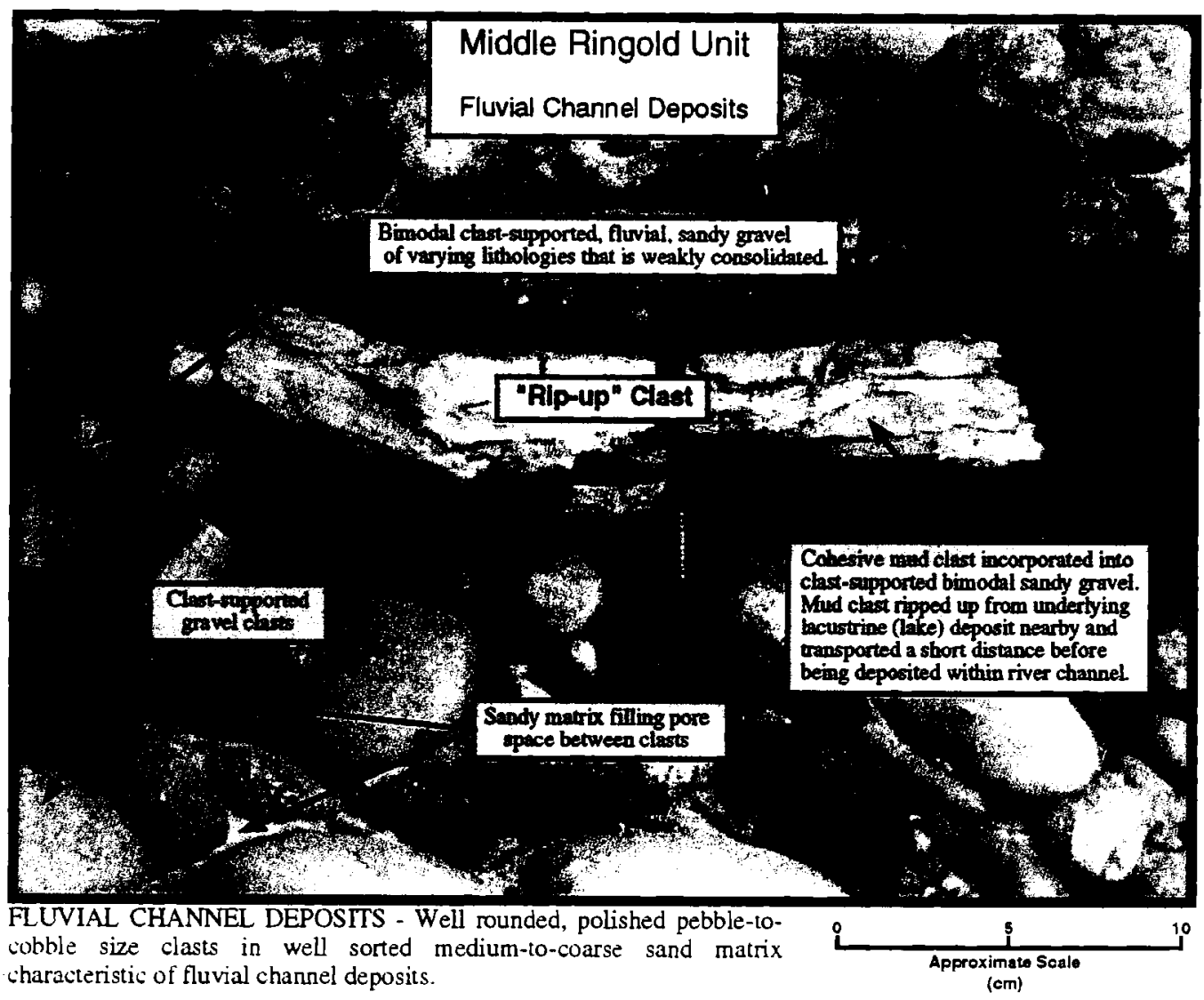

FIGURE 3.5. Close-up Digital Image of the Middle Ringold Outcrop Illustrating Its Bimodal Grain Size (i.e., large clasts and finergrained fill), as well as Heterogeneity in the Form of a Fine-Grained, Overbank Deposit, Rip-Up Clast

hydroxylamine, citrate, and hydrazine. These investigations would be carried out both in simple aqueous solutions and in aqueous solution-subsurface sediment mixtures. Microbial reduction experiments would include determination of the distribution and abundance of dissimilatory iron-reducing bacteria in sediments. Subsequently, the nutrient requirements and geochemical controls on these bacteria would be determined. Intermediate-scale tests of microbial reduction of site-specific sediments would be carried out before proceeding to the field test site. 


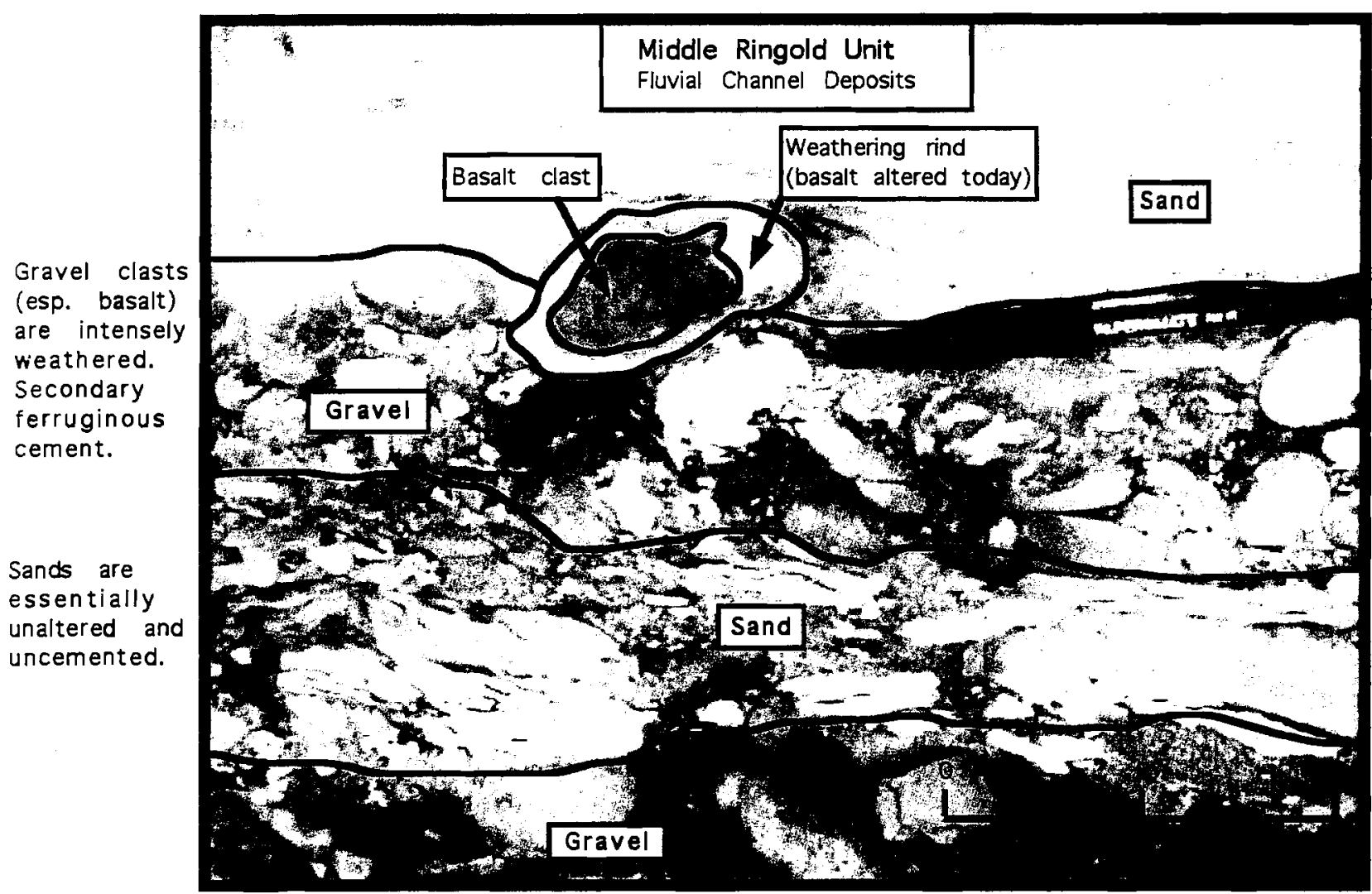

Alternating layers of weathered gravel and unaltered sand.

FIGURE 3.6. Close-up Digital Image of the Middle Ringold Outcrop Illustrating a Typical Sand Lens Heterogeneity (upper part of picture) and Smaller-Scale Heterogeneities in the Form of Weathered Basalt Clasts in Various Stages of Disintegration

Recommended computer simulation and visualization studies include modeling to improve the design of the in situ redox-manipulation experiment and to understand the effects of subsurface heterogeneity on reagent dispersal and recovery, and exploration of methods for achieving longer reagent residence times by means of gradient control. Both single- and multiple-well methods for gradient control should be investigated. 



\subsection{REFERENCES}

Abriola, L. M., and G. F. Pinder. 1982. "Calculation of Velocity in Three Space Dimensions from Hydraulic Head Measurements." Ground Water $20(2): 205-213$.

Amonette, J. E., and A. D. Scott. 1991. "Determination of Ferrous Iron in Non-Refractory Silicate Minerals--1. An Improved Semi-Micro Oxidimetric Method." Chemical Geology 92:329-338.

Anderson, M. P. 1987. "Field Studies in Groundwater Hydrology -- A New Era." Reviews of Geophysics 25:141-147.

Aral, M. M. 1989. "Waste Stabilization in Multilayer Aquifers by Optimal Hydraulic Control." Groundwater 27(4):517-523.

Barcelona, M. J., and T. R. Holm. 1991. "Oxidation-Reduction Capacities of Aquifer Solids." Environmental Sciences Technology 25:1565-1572.

Bluemling, P., and P. Hufschmied. 1989. "Fluid Logging in Deep Boreholes." NAGRA Bulletin, Special Edition, December 1989, pp. 24-38.

Borden, R. C., P. B. Bedient, M. D. Lee, C. H. Ward, and J. T. Wilson. 1986. "Transport of Dissolved Hydrocarbons Influenced by Oxygen-Limited Biodegradation 2. Field Applications." Water Resources Research 22:1983-1990.

Bouwer, H., and R. C. Rice. 1976. "A Slug Test for Determining Hydraulic Conductivity of Unconfined Aquifers with Completely or Partially Penetrating Wel1s." Water Resources Research 12(3):423-428.

Ba11, W. P., and P. V. Roberts. 1991a. "Long-Term Sorption of Halogenated Organic Chemicals by Aquifer Material. 1. Equilibrium." Environmental Science and Technology 25:1223-1237.

Ba11, W. P., and P. V. Roberts. 1991b. "Long-Term Sorption of Halogenated Organic Chemicals by Aquifer Material. 2. Intraparticle Diffusion." Environmental Science and Technology 25:1237-1249.

Cole, C. K., and H. r. Foote. 1990. "Pultigriu Methods iur Solving Multiscale Transport Problems." In Dynamics of Fluids in Hierarchical Porous Media, ed. J. H. Cushman, pp. 273-303. Academic Press, New York.

Cooper, H. H., Jr., J. D. Bredehoeft, and I. S. Papadopulos. 1967. "Response of a Finite-Diameter Well to an Instantaneous Change of Water." Water Resources Research 3(1):263-269.

Cotton, F. A., and G. Wilkinson. 1988. Advanced Inorganic Chemistry, 5 th edition. Wiley, New York. 
Creutz, C., and N. Sutin. 1974. "Kinetics of the Reactions of Sodium Dithionite with Dioxygen and Hydrogen Peroxide." Inorganic Chemistry $13: 2041-2043$.

Curtis, G. P., P. V. Roberts, and M. Reinhard. 1986. "A Natural Gradient Experiment on Solute Transport in a Sand Aquifer 4. Sorption of Organic Solutes and Its Influence on Mobility." Water Resources Research $22: 2059-2067$.

Drost, W., D. Klotz, A. Koch, H. Moser, F. Neumaier, and W. Rauert. 1968. "Point Dilution Methods of Investigating Groundwater Flow by Means of Radioisotopes." Water Resources Research 4(1):125-146.

Evans, J. C., P. J. Mitche11, and D. I. Dennison. 1988. Hanford Site Groundwater Monitoring for April through June 1987. PNL-6315-1, Pacific Northwest Laboratory, Richland, Washington.

Freeze, R. A., and J. A. Cherry. 1979. Groundwater. Prentice-Ha17, Englewood Cliffs, New Jersey.

Gan, H., J.W. Stucki, and G.W. Bailey. 1992. "Reduction of Structural Iron in Ferruginous Smectite by Free Radicals." Clays and Clay Minerals $40(6): 639-665$.

Gupta, S. K., C. R. Cole, C. T. Kincaid, and A. M. Monti. 1987. Coupled Fluid, Energy, and Solute Transport (CFEST) Model: Formulation and Users Manual. BMI/ONWI-660, Battel7e Project Management Division, Office of Nuclear Waste Isolation, Columbus, Ohio.

Halevy, E., H. Moser, 0. Zellhofer, and A. Zuber. 1966. "Borehole Dilution Techniques - A Critical Review." In Isotopes in Hydrology, pp. 531-564. International Atomic Energy Agency, Vienna, Austria.

Hess, A. E., and F. L. Paillet. 1989. "Characterizing Flow Paths and Permeability Distribution in Fractured-Rock Aquifers Using a Sensitive, Thermal Borehole Flowmeter." In Proceedings of the Conference on New Field Techniques for Quantifying the Physical and Chemical Properties of Heterogeneous Aquifers, pp. 445-461. National Water Well Association, Dublin, Ohio.

Kasza, G. L., M. J. Hartrian, F. N. Hodges, and D. C. Weekes. 1991. Ground Water Maps of the Hanford Site, June 1991. WHC-EP-0394-3, West inghouse Hanford Company, Richland, Washington.

Kear7, P. M., J. J. Dexter, and J. E. Price. 1988. Procedures, Analysis, and Comparison of Groundwater Velocity Measurement Methods for Unconfined Aquifers. UNC/GJ-TMC-3, UNC Geotech, Grand Junction, Colorado.

Komadel, P., and J. W. Stucki. 1988. "The Quantitative Assay of Minerals for $\mathrm{Fe}^{2+}$ and $\mathrm{Fe}^{3+}$ Using 1,10-phenanthrol ine--III. A Rapid Photochemical Method." Clays and Clay Minerals 36:379-381. 
Lovley, D. R., and E. J. P. Phillips. 1987. "Rapid Assay for Microbially Reducible Ferric Iron in Aquatic Sediments." Applied Environmental

Microbiology 53:1536-1540.

Lovley, D. R., E. J. P. Phillips, Y. A. Gorby, and E. R. Landa. 1991.

"Microbial Reduction of Uranium." Nature 350:413-416.

MacQuarrie, K. T., and E. A. Sudicky. 1990. "Simulation of Biodegradable Organic Contaminants in Groundwater 2. Plume Behavior in Uniform and Random Flow Fields." Water Resources Research 26:223-239.

Molz, F. J., and L. C. Be11. 1977. "Head Gradient Control in Aquifers Used for Fluid Storage." Water Resources Research 13(4):795-798.

Molz, F. J., and M. A. Widdowson. 1988. "Internal Inconsistencies in Dispersion-Dominated Models That Incorporate Chemical and Microbial Kinetics." Water Resources Research 24:615-619.

Molz, F. J., J. G. Melville, 0. Guven, R. D. Crocker, and K. T. Matteson. 1985. "Design and Performance of Single-Well Tracer Tests at the Mobile Site." Water Resources Research 21:1497-1502.

Molz, F. J., 0. Guven, J. G. Melville, R. D. Crocker, and K. T. Matteson. 1986a. "Performance, Analysis, and Simulation of a Two-Well Tracer Test at the Mobile Site." Water Resources Research 22:1031-1037.

Molz, F. J., M. A. Widdowson, and L. D. Benefield. 1986b. "Simulation of Microbial Growth Dynamics Coupled to Nutrient and Oxygen Transport in Porous Media." Water Resources Research 22:1207-1216.

Nealson, K. H., and C. R. Myers. 1992. "Microbial Reduction of Manganese and Iron: New Approaches to Carbon Cycling." Applied Environmental Microbiology $58: 439-443$.

Newcomer, D. R., and J. P. McDonald. 1990. Water-Table Elevations on the Hanford Site, June 1989. PNL-7282, Pacific Northwest Laboratory, Richland, Washington.

Novakowski, K. S. 1989. "Analysis of Pulse Interference Tests." Water Resources Research, 25(11):2377-2387.

PNL. 1991. Procedures for Ground-Water Investigations. PNL-6894, Pacific Northwest Laboratory, Richland, Washington.

Rehfeldt, K. R. 1989. "Application of the Borehole Flowmeter Method to Measure Spatially Variable Hydraulic Conductivity at the MADE Site." In Proceedings of the Conference on New Field Techniques for Quantifying the Physical and Chemical Properties of Heterogeneous Aquifers, pp. 419-443. National Water Well Association, Dublin, Ohio. 
Riley, R.G., and J. M. Zachara. 1992. Contaminants on DOE Lands and Selection of Contaminant Mixtures for Subsurface Seience Research. DOE/ER-0547T, U.S. Department of Energy, Washington, D.C.

Rinker, R. G., T. P. Gordon, D. M. Mason, R. R. Sakaida, and W. H. Corcoran. 1960. "Kinetics and Mechanism of the Air 0xidation of the Dithionite Ion $\left(\mathrm{S}_{2} \mathrm{O}_{4}{ }^{2-}\right)$ in Aqueous Solution." Journal of Physical Chemistry $64: 573-581$.

Roberts, P. V., M. N. Goltz, and D. M. Mackay. 1986. "A Natural Gradient Experiment on Solute Transport in a Sand Aquifer 3. Retardation Estimates and Mass Balance for Organic Solutes." Water Resources Research 22:2047-2058.

Scott, M. J., and J. J. Morgan. 1990. "Energetics and Conservative Properties of Redox Systems." In Chemical Modeling of Aqueous Systems II, ed. D. C. Melchior and R. L. Bassett, pp. 368-377. American Chemical Society, Washington, D.C.

Shafer, J. M., and L. W. Vail. 1987. "Screening Method for Contaminant Plume Control." Journal of Water Resources Planning and Management 113(3):336-352.

Spane, F. A., Jr. 1990. Description and Results of Tracer Tests Conducted for a Deep Fracture Zone with in Granitic Rock at the Leuggern Borehole, (Switzerland). NTB-90-05, NAGRA, Wettingen, Switzerland.

Spane, F. A., Jr. 1992. Applicability of Slug Interference Test under Hanford Site Test Conditions: Analytical Assessment and Field Test Evaluation. PNL-8070, Pacific Northwest Laboratory, Richland, Washington.

Spane, F. A., Jr., and R. B. Mercer. 1985. HEADCO: A Program for Converting Observed Water Levels and Pressure Measurements to Formation Pressure and Standard Hydraulic Head. RHO-BW-ST-71P, Rockwell Hanford Operations, Richland, Washington.

Stucki, J. W., D. C. Golden, and C. B. Roth. 1984. "Preparation and Handling of Dithionite-Reduced Smectite Suspensions." Clays and Clay Minerals 32:191-197.

Sudicky, E. A., S. L. Schellenberg, and K. T. MacQuarrie. 1990. "Assessment of the Behavior of Conservative and Biodegradable Solutes in Heterogeneous Porous itedia." In Dynamics or Fluids in Hierarchical Porous Media, ed.

J. H. Cushman, pp. 429-461. Academic Press, New York.

Taylor, K., S. Wheatcraft, J. Hess, J. Hayworth, and F. Molz. 1990.

"Evaluation of Methods for Determining the Vertical Distribution of Hydraulic Conductivity." Ground Water 28(1):88-98.

Thomas, J. M., and C. H. Ward. 1989. "In Situ Biorestoration of Organic Contaminants in the Subsurface." Environmental Science and Technology $23: 760-766$. 
Thurman, E. M., L. B. Barber, and D. LeBlanc. 1986. "Movement and Fate of Detergents in Groundwater: A Field Study." Journal of Contaminant Hydrology $1: 143-161$.

Tsang, C.-F. 1987. A Borehole Fluid Conductivity Logging Method for the Determination of Fracture Inflow Parameters. LBL-23096, Lawrence Berkeley Laboratory, Berkeley, California.

U.S. Department of Energy (DOE). 1989. Evaluation of Mid-to-Long Term Basic Research for Environmental Restoration. DOE/ER-0419, U.S. Department of Energy, Washington, D.C.

U.S. General Accounting Office $(G A 0)$. 1988a. Nuclear Waste Problems Associated with DOE's Inactive Waste Sites. GAO/RCED-88-169, U.S. Government Accounting Office, Washington, D.C.

U.S. General Accounting Office (GAO). 1988b. Nuclear Waste, Supplemental Information on Problems at DOE's Inactive Waste Sites. GAO/RCED-88-229FS, U.S. General Accounting Office, Washington, D.C.

Widdowson, M. A., F. J. Molz, and J. G. Melville. 1990. "An Analysis Technique for Multilevel and Partially Penetrating Slug Test Data." Ground Water 28(6):937-945.

Wilson, J. T., and C. H. Ward. 1987. "Opportunities for Bioreclamation of Aquifers Contaminated with Petroleum Hydrocarbons." Developments in Industrial Microbiology 27:109-116.

Young, S. C., and W. R. Waldrop. 1989. "An Electromagnetic Borehole Flowmeter for Measuring Hydraulic Conductivity Variability." In Proceedings of the Conference on New Field Techniques for Quantifying the Physical and Chemical Properties of Heterogeneous Aquifers, pp. 463-474. National Water Well Association, Dublin, Ohio. 

APPENDIX A

\section{TEST PLANS.}

This appendix contains the test plans for the three phases of site characterization associated with the in situ redox-manipulation experiment.

\section{A.1 PHASE 1 - AREAL SITE CHARACTERIZATION TEST PLAN}

Prior to the in situ redox-manipulation experiment, a detailed areal hydrogeologic characterization of the selected site will be completed. Information obtained from this initial site characterization is needed to support selection of both the candidate target depth interval and a control test area for conducting the in situ redox-manipulation experiment, as well as to decrease the level of uncertainty associated with the in situ redox test results. Specific objectives of the areal hydrogeologic characterization include

- determining the degree of heterogeneity of geologic materials in the subsurface,

- assessing the distribution of hydraulic properties vertically and laterally,

- determining the hydraulic gradient within and between selected geologic horizons, and

- characterizing the chemical composition of groundwater(s) at the field site.

The following sections present a discussion of identified hydrogeologic site characterization activities planned during Phase 1 of the proposed fieldscale, in situ redox-manipulation experiment. The discussion focuses on field methods that can be utilized to characterize the subsurface hydrogeologic framework within the site and the target depth interval that will be selected to demonstrate the in situ redox-manipulation experiment. 


\section{A.1.1. Test/Monitoring Well Requirements}

For the initial areal site characterization phase, a four-test/ monitoring-well array is envisioned. The test wells will be characterized sequentially, with each well having a retrievable multilevel monitoring system installed and in operation before drilling and characterization of the next test/monitoring well facility. The horizons monitored in the multilevel systems will be selected based on results obtained from the detailed borehole characterization activities. The characterization wells will be arrayed in a square pattern and will be oriented with wells sited both parallel and perpendicular to the known prevailing groundwater flow direction (e.g., Newcomer and McDoriald 1990; Kasza et al. 1991), so as to provide maximum hydraulic head and gradient information for the site. Distance between the characterization test/monitoring wells will be largely determined by the hydraulic properties obtained from the first completed test/monitoring well facility. Distance between the outer test/monitoring wells, however, is anticipated to range between 100 and 200 feet.

\section{A.1.2 Hydrogeologic Characterization Activities}

Hydrogeologic characterization activities within Phase 1 can be grouped into four major categories: 1) geologic property characterization, 2) hydrau1 ic property characterization, 3) hydrochemical content evaluation, and 4) hydraulic head determination. Geologic and hydraulic property characterization activities (items 1 and 2) will be mainly completed prior to or immediately after installation of the well screen; hydrochemical evaluation and hydraulic head determination activities (items 3 and 4 ) will be initiated primarily after installation of the multilevel monitoring system within each test we11. The activities associaied with the respective characterization categories are described in the report sections that follow. Procedures for the conduct of the identified characterization activities are contained in PNL (1991). 


\section{A.1.2.1 Geologic Property Characterization}

These activities focus on determining the distribution of geologic properties and geochemical composition of the subsurface hydrogeologic framework. Activities include geologic sampling and laboratory analysis, as well as selected borehole geophysical logging.

During the drilling of each test/monitoring well, geologic samples will be collected from the subsurface materials that have been penetrated. Samples will be collected by core-barrel or split-spoon retrieval methods every $5 \mathrm{ft}$ and after any major lithologic change is encountered. From the set of geologic samples collected, a suite of samples from selected depths will be submitted for laboratory analysis to define the geologic properties of the subsurface hydrogeologic framework. A minimum of five depth samples will be submitted for laboratory analysis for each test/monitoring well. In particular, samples will be selected for depth locations within and immediately adjacent to the target depth interval. Laboratory analyses will include sediment grain-size distribution, lithologic description, calcium-carbonate content, clay analysis [by X-ray diffraction (XRD)], mineralogical composition, moisture content, saturated (vertical) hydraulic conductivity, bulk density, and porosity.

When the well screen has been set, a suite of borehole geophysical logs will be conducted to provide information concerning the subsurface distribution of hydrogeologic properties (e.g., porosity) and units (i.e., sand versus clay). Information obtained from the borehole geophysical logs will be used to identify a candidate target depth interval and for comparison with results obtained from geologic and hydraulic property characterization activities. Appropriate burehole geophysical log surveys inclucie natural gamma, neutron-epithermal neutron, selected electrical methods (e.g., induction), density, and fluid temperature.

\section{A.1.2.2 Hydraulic Property Characterization}

For proper analysis of test results obtained from the in situ redoxmanipulation experiment, the variation of hydraulic conductivity (both laterally and vertically) will be assessed utilizing single- and multiple-well 
(i.e., interference) test techniques. Test methods will include standard hydrologic techniques, such as slug (single-we11) and constant-rate pumping tests, as well as newer slug or pulse-interference methods (e.g., Novakowski 1989; Spane 1992).

Results obtained at the various test/monitoring well' sites and by the various test methods will be compared to examine the lateral variation of hydraulic conductivity. Single-well test methods generally have a radius of influence that is restricted to the region immediately surrounding the point of investigation (i.e., the stress we11); in contrast, interference tests are more reflective of the hydraulic properties of the intervening test interval (i.e., between the stress well and the monitoring observation well). Comparing the results obtained from various test methods with different scales of investigation will provide information pertaining not only to the lateral variation of hydraulic conductivity, but also to horizontal anisotropy.

For evaluating the vertical distribution of hydraulic conductivity at individual test/monitoring well sites, a number of direct and indirect test methods are available. Direct test methods include the measurement of the vertical distribution of horizontal groundwater inflow into the open well section during pumping. The vertical distribution of horizontal groundwater inflow is normally measured using a specialized flow-sensing device, such as a packer impeller (Rehfeldt 1989), a thermal flow meter (Hess and Paillet 1989), or an electromagnetic flow meter (Young and Waldrop 1989). Indirect sensing techniques [e.g., fluid electrical conductivity, fluid temperature (Tsang 1987; Bluemling and Hufschmied 1989)] have also been used successfully in estimating horizontal inflow conditions in certain situations. Once the distribuiticn of hurizoniail groundwater inflow within hydrogeologic units along the well screen has been determined, the vertical profile of hydraulic conductivity can be obtained using standard analytical equations (i.e., the Thiem equation for steady-state conditions, the Theis or Cooper and Jacob equations for transient conditions).

Other test techniques that can be used to obtain the vertical distribution of horizontal hydraulic conductivity include multilevel slug tests, 
laboratory sediment grain-size analysis, selected borehole geophysical techniques, and tracer-dilution tests (Taylor et a1. 1990). Of these techniques, multilevel slug and tracer-dilution tests appear to provide the best opportunity for characterizing the vertical distribution of hydraulic conductivity. Tracer-dilution testing, however, will not be used for this purpose, but rather will be used to characterize the hydraulic gradient within selected intervals of the multilevel monitoring systems installed at each test/monitoring well facility.

Single-Well Tests. After the well screen has been installed and developed, a series of single-we11 tests will be conducted for each test wel1. The first test will investigate the entire well-screen section, utilizing a packer-flowmeter (e.g., impelier type) pumping test. For this test, groundwater will be pumped at a constant discharge rate using an electrical submersible pump. During pumping, the flowmeter will be positioned at specified depth intervals (e.g., every $5 \mathrm{ft}$ ) within the screened interval and the vertical flow rate will be measured. A vertical distribution of horizontal inflow rates versus time will be developed by subtracting the total vertical flow rate measured at a given depth setting from that observed at the adjacent overiying depth station. In this manner, the profile of horizontal groundwater inflow to the well can be obtained during the pumping test. The horizontal hydraulic property profile within the well section can then be developed using anatytical methods.

Based on the flowmeter/pumping test results, candidate zones will be identified that will be investigated in further multilevel slug tests. These slug tests are conducted by "instantaneously" applying a stress to the we 11 screen section isolated between the packers. Ona preferrad technique for applying the slug stress is to depress the fluid column within the well using gas supplied from a high-pressure gas cylinder, as described by Spane (1992). After the system has equilibrated to the fluid column depression, gas within the well above the fluid column is released rapidly, causing an instantaneous stress (i.e., slug withdrawal) to be applied to the isolated test interval. The pressure recovery of the test interval to this applied stress is then analyzed to estimate the horizontal hydraulic conductivity for the isolated 
test section. Methods used for analysis of the slug test response are dependent on well/test interval geometry and hydrologic test relationships. Accepted analytical methods for various geometric and hydrologic test relationships include those of Cooper et al. (1967), Bouwer and Rice (1976), and Widdowson et a1. (1990).

Based on the results obtained from the single-well tests and borehole geophysical surveys, zones will be selected for monitoring with a multilevel monitoring system; one of these zones will be the target depth interval. The actual number of monitoring zones selected will be dependent on specific site conditions; however, it is envisioned that a maximum of five zones will be monitored at each test/monitoring well.

Multiple-Well Interference Tests. Following completion of single-well testing and installation of multilevel monitoring systems within the four characterization test wells, multiple-well interference tests will be conducted. The tests are identical to the single-well tests (i.e., slug or pumping tests). The only difference is that the effects of the test are monitored not only at the stress well, but also in nearby observation wells. Results from multiple-well interference tests provide areal site characterization information not obtainable with single-well tests, including

- the average hydraulic properties of the test interval between the stress well and the point of observation,

- the lateral continuity of the test interval, and

- the degree of hydraulic communication with overlying and underlying hydrogeologic units.

The number and type of multiple-well tests to be conducted depend on results obtained from the single-well tests. If hydraulic conditions and distance spacings between the test/monitoring wells are favorable (i.e., transmissivity values greater than $100 \mathrm{ft}^{2} / \mathrm{d}$, storativity less than $10^{-2}$, and observation wells within approximately $100 \mathrm{ft}$ ), slug interference tests (e.g., Novakowski 1989; Spane 1992) will be conducted for each of the monitored horizons. Based on results obtained from this phase of testing, target depth intervals will be selected for more detailed constant-rate pumping interference tests. Results obtained from the multiple-well tests, supported by 
information from single-well tests, will then be used in selecting the target depth interval for the in situ redox-manipulation experiment.

\section{A.1.2.3 Hydrochemical Characterization of Well-Water Samples}

After installation of the multilevel monitoring systems at each wel1, representative groundwater samples will be collected from each monitored horizon (i.e., maximum of five monitor zones). Groundwater samples will be collected using submersible pumps. Unstable hydrochemical parameters, such as $\mathrm{pH}$, Eh, oxygen content, and alkalinity, will be measured in the field at the time of sample collection. Planned laboratory analyses include major inorganics, trace elements, specific electrical conductivity, $\mathrm{pH}$, and alkalinity. Hydrochemical information obtained from laboratory analyses will be used in designing the reagent(s) to be injected into the target depth interval during the in situ redox-manipulation experiment.

Samples for initial characterization of the site will be obtained from environmental monitoring wells being drilled close to the preferred location. Cores for characterization measurements of geochemical, microbiological, and hydraulic properties will be obtained during drilling. Geochemical measurements of cores will include cation exchange capacity, extractable iron, exchangeable ions, total chemical analysis, and mineralogy. Aqueous measurements for extracted pore waters will include major and trace cations and anions, redox-sensitive couples, Eh, $\mathrm{pH}$, dissolved oxygen, and organic and inorganic carbon. The response of the redox-sensitive elements to natural changes in aquifer redox status will be determined. Microbiological measurements will include identification and enumeration of specific physiological groups and their nutrient requirements. These groups wi1l include aerobes, nitrate-reducers, iron-reducers, sulfate-reducers, and methanogens. A matrix of various electron donors and electron acceptors will be employed to allow identification of the carbon substrates that may be best suited for in situ stimulation. Measurement of geohydrologic parameters will include grain-size analysis, porosity, density, and hydraulic conductivity. The degree of heterogeneity of all these properties will be evaluated. 


\section{A.1.2.4 Hydraulic Head Characterization}

Hydraulic head patterns within the test site will exert a profound influence on the conduct of the in situ redox-manipulation experiment. The focus of hydraulic head characterization activities is largely confined to determining the hydrau'ic gradient and groundwater flow direction. Determining the hydraulic gradient (change in head per unit of distance in a given direction) is of primary importance for planned reagent injection tests, since it is the natural driving force for the movement of fluids in the subsurface. Determination of groundwater flow direction is also important and is required for the proper siting of the injection well and the surrounding monitoring well network that will be used during the in situ redox-manipulation experiment. The hydraulic head properties within the test site will be characterized using standard hydraulic analysis of areal head information provided from the test/monitoring well facilities and through performance of tracer-dilution tests.

Areal Hydraulic Head Analysis. After installation of the multilevel monitoring systems within each test well facility, hydraulic head values will be calculated through conversion of downhole pressure measurements for the respective monitoring horizons. Fresh-water hydraulic head is the head parameter that is used in determining the horizontal hydraulic gradient and the lateral groundwater flow direction. The procedure for converting downhole pressure measurements to fresh-water head values is described by Spane and Mercer (1985). Hydraulic gradients and groundwater flow directions will be calculated for each monitoring horizon, based on analyzing the fresh-water head values using the test method described by Abriola and Pinder (1982). This technique relies on a procedure that delineates a best-fit plane through the areal hydraulic head values for individual hydrogeologic units. Hydraulic gradient and groundwater flow direction are then determined based on the delineated best-fit plane.

In addition to providing estimates of hydraulic gradient and groundwater flow direction, time-variant head responses for the respective monitored horizons will be evaluated to assess the dynamics of the groundwater flow system (i.e., the response to both natural and human-related stresses, such as 
natural recharge and discharge, or waste-water disposal). This evaluation will be of special significance in assessing any possible effects (e.g., Columbia River fluctuations) during the in situ redox-manipulation experiment. Hydraulic gradient and groundwater flow direction calculations and time-variant responses will also be compared between the various monitored horizons to assess possible hydrologic interrelationships within the site.

Tracer-Dilution Tests. Based on the results obtained. from the areal hydraulic head analysis, monitored horizons will be chosen for tracer-dilution testing. The tracer-dilution test method is an accepted technique for determining the lateral hydraulic gradient or groundwater flow velocity within the immediate vicinity of a borehole. Essential design elements of a tracerdilution test include

- establishing a known, constant tracer concentration within the test section,

- continuous mixing or circulation of the tracer solution within the borehole/test interval, and

- monitoring the decline of tracer concentration with time.

The decline in tracer concentration is then analyzed to ascertain the hydraulic gradient (if the hydraulic conductivity of the formation is known) or the test interval hydraulic conductivity (if the hydraulic gradient is known) using the following analytical expression:

$$
\ln \left(C / C_{0}\right)=-(Q t) / V
$$

where

$$
\begin{aligned}
& C=\text { concentration of the tracer in the test interval at time } t \\
& C_{0}=\text { initial concentration of the tracer at the start of the test } \\
& Q=\text { groundwater discharge through the test interval, such that } \\
& \qquad Q=-(K \mathrm{~A}) /(\mathrm{dh} / \mathrm{dL}) \\
& V=\text { isolated test interval volume. }
\end{aligned}
$$


Various aspects of tracer-dilution tests (e.g., test design, influencing factors) have been discussed in detail by a number of investigators (e.g., Halevy et a1. 1966; Freeze and Cherry 1979). Following completion of the tracer-ditution test, the tracer will be recovered from the formation by pumping, as a means of assessing the dispersivity within the test interval.

It is envisioned that tracer-dilution testing will be limited to the selected target-depth interval. Results obtained from the tracer-dilution tests conducted at the four test/monitoring wells will be compared with hydraulic gradient calculations obtained from areal fresh-water head analysis. Differences in hydraulic gradient calculations obtained with tracer-dilution techniques have been noted (e.g., Drost et a1. 1968; Kearl et a1. 1988). These differences have been attributed to distortions in the flow field due to increased (or decreased) permeability caused by the presence of the well. However, based on the expected moderate hydraulic conductivity of the target depth interval and on the method of well completion, little distortion of the flow field is anticipated.

\section{A.2 PHASE 2 - DETAILED SITE CHARACTERIZATION TEST PLAN}

The second phase will include the installation and testing of monitoring wells that will allow detailed site characterization within the test control area identified for the in situ redox-manipulation experiment. Most of the monitoring wells installed and characterized during Phase 2 will be part of the final test facility configuration for implementing the in situ redoxmanipulation experiment. Based on the results obtained during Phases 2 and 3 , additional monitoring wells will be needed to complete the in situ redoxmanipulation experiment. Test facilities inctalled during Phase 2 that can be used in the in situ redox-manipulation experiment include the central injection well [to be used for administering the redox-controlling reagent(s)] and wells within the network of surrounding monitoring wells that will be used for observing the effects of the reagent injection(s). Characterization activities within Phase 2 will be limited to the selected target depth interval, within the test control area. Characterization methods during Phase 2 will include some Phase 1 techniques. Tracer-dilution tests will be used to 
investigate the near-field hydraulic gradient and the flow transport characteristics of the target depth interval prior to the in situ redoxmanipulation experiment. Specific Phase 2 hydrogeologic characterization objectives include

- assessing the areal and vertical distribution of hydraulic properties within the test control area

- determining the degree of heterogeneity of geologic materials in the subsurface

- determining the hydraulic gradient and groundwater flow direction within the test horizon, and

- characterizing the chemical composition of groundwater(s) at the field site.

The following subsections present a discussion of hydrogeologic site characterization activities planned during Phase 2 in support of the in situ redox-manipulation experiment. The discussion focuses on the field methods that will be used to characterize the subsurface hydrogeologic framework within the target depth interval in the test control area.

\section{A.2.1 Test/Monitoring Well Requirements}

For the detailed site characterization phase, a seven-test/monitoringwell array is envisioned; two sets of three wells will be equidistant (i.e., at 120 degree spacings) around a central test well (see Figure A.1). (Note: one of the seven Phase 2 wells will be one of the Phase 1 characterization wells.) Distance spacing between the monitoring wells and the central test we 11 will be largely determined by the hydraulic property results obtained from Phase 1. Distance spacings between the test and monitoring wells, nowever, are expected to range between 10 and $15 \mathrm{fee} i$, and between 20 and 30 feet for the inner and outer concentric rings of wells, respectively. The individual test wells will be characterized sequentially with interwell tests being conducted after complete well facility installation. Each well will have a retrievable monitoring system (i.e., pressure and hydrochemical sensors). The target depth interval is expected to be thin (i.e., $10 \mathrm{ft}$ or 


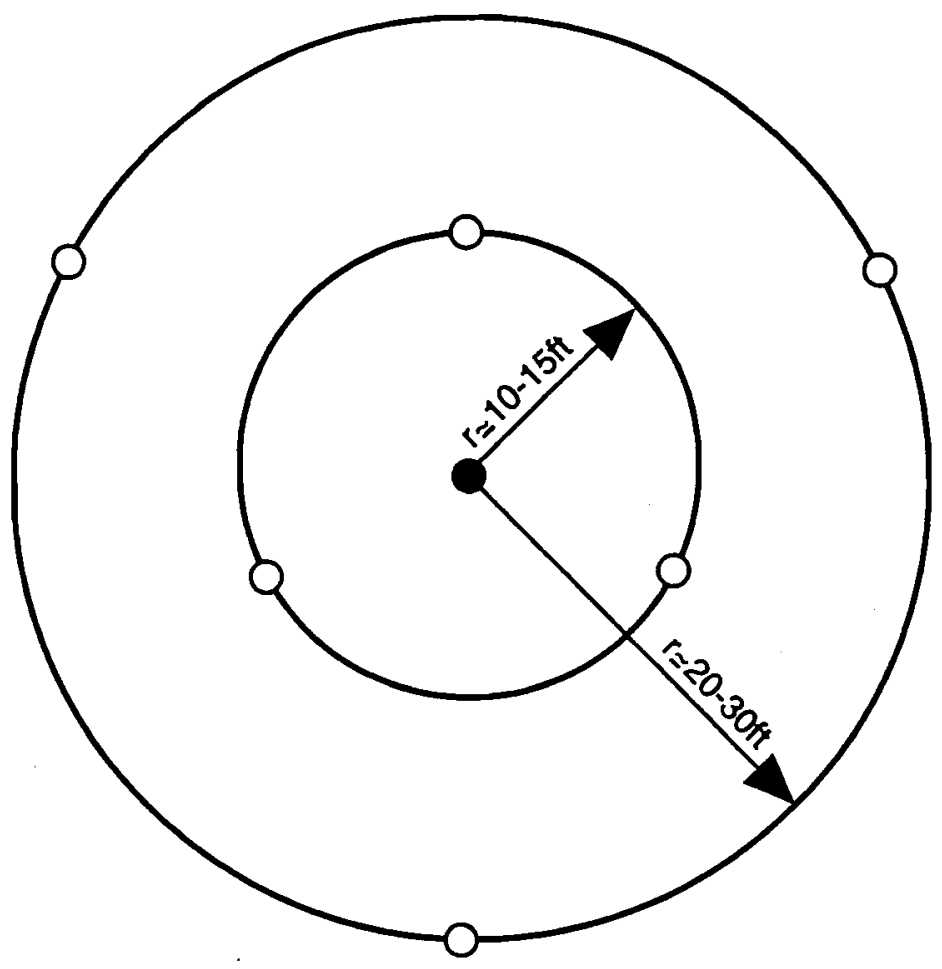

Tracer injection/withdrawal well

Monitoring well

S9211013.10

FIGURE A.1. Proposed Layout of Phase 2 Test/Monitoring We11 Sites, for a Test Control Area Having Low Hydraulic Head Gradients and Relatively Homogeneous Subsurface Conditions

less) and relatively homogeneous. If significant heterogeneity is evident within the target depth interval, a multiple-level monitoring system will be employed.

\section{A.2.2 Hydrogeologic Characterization Activities}

Hydrogeologic characterization activities during Phase 2 can be grouped into four major categories: 1) geologic property characterization, 2) hydraulic property characterization, 3) hydrochemical content evaluation, and 4) hydraulic head gradient determination. The activities associated with 
the respective characterization categories are described in the following subsections. Procedures for the characterization activities are contained in PNL (1991).

\section{A.2.2.1 Geologic Property Characterization}

These activities focus on determining the distribution of geologic properties and geochemical composition of the subsurface hydrogeologic framework. The activities are the same as described for Phase 1, including geologic sampling and laboratory analysis, and selected borehole geophysical logging.

Geologic Sampling/Analysis. During the drilling of each Phase 2 test/ monitoring well, geologic samples will be collected from the subsurface materials that have been penetrated. Methods will be the same as those used in Phase 1 (see Section A.1.2.1). Samples will be selected for depth locations within and immediately adjacent to the target depth interval. A minimum of five depth samples (a minimum of two of which will be from the target depth interval) will be submitted for laboratory analysis for each test/monitoring we11. Laboratory analyses will include sediment grain-size distribution, lithologic description, calcium-carbonate content, clay analys is (by XRD), mineralogical composition, moisture content, saturated (vertical) hydraulic conductivity, bulk density, and porosity.

Borehole Geophysical Surveys. When the well screen has been set, a suite of borehole geophysical logs will again be conducted to provide information concerning the subsurface distribution of hydrogeologic properties (e.g., porosity), boundary contacts, and lithologic homogeneity within the target depth interval (see Section A.1.2.1). Information obtained from the borehole geophysical logs will be used to identify possible heterogeneity within the target depth interval (i.e., both vertically at individual well sites and laterally between well sites in the test control area), and for comparison with results obtained from geologic and hydraulic property characterization activities. Borehole geophysical log surveys will include natural gamma, neutron-epithermal neutron, selected electrical methods (e.g., induction), density, and fluid temperature. 


\section{A.2.2.2 Hydraulic Property Characterization}

For proper analysis of test results obtained from the in situ redoxmanipulation experiment, the lateral variation of hydraulic properties must be assessed using single- and multiple-well (i.e., interference) test techniques. The test methods used in Phase 2 are the same as those used in Phase 1 , including standard hydrologic techniques, such as slug (single-well) and constant-rate pumping tests, as well as newer slug or pulse-interference methods (e.g., Novakowski 1989; Spane 1992). Results for the test well and monitoring well sites will be compared to examine lateral variation in hydraulic conductivity. The radius of influence of single-well test methods is generally restricted to the region immediately surrounding the point of investigation (i.e., the stress well); interference tests are more reflective of hydraulic properties within the intervening test interval (i.e., between the stress well and monitoring observation well). Comparing the results obtained from various test methods with different scales of investigation will provide information pertaining not only to the lateral variation of hydraulic conductivity, but also to horizontal anisotropy within the target depth interval.

If initial characterization results indicate a lack of homogeneity within the target depth interval in the control test area, then the vertical distribution of hydraulic conductivity at the test well and individual monitoring wells will be determined using several direct and indirect test methods, as described in Section A.1.2.2. Once the vertical distribution of horizontal groundwater inflow within the target depth interval along the well screen is determined, the vertical profile of hydraulic conductivity can be obtaineci using stanicrd anaiytical equations ii.e., the Thiem equation for steady-state conditions, the Theis or Cooper and Jacob equations for transient conditions).

Other test techniques that can be used to obtain the vertical distribution of horizontal hydraulic conductivity include multilevel slug tests, laboratory sediment grain-size analysis, selected borehole geophysical techniques, and tracer-dilution tests (Taylor et al. 1990), as discussed in Section A.1.2.2. Tracer-dilution testing, however, will not be used for this 
purpose, but rather will be used to characterize the hydraulic gradient at the test well and selected monitoring well locations within the test control area.

The test arrays shown in Figures A.1 and A.2 are designed for characterizing a test control area with relatively homogeneous subsurface conditions. The test/monitoring well configuration would be modified to accommodate heterogeneities discovered during Phase 2 site characterization.

The individual test/monitoring wells installed during Phase 2 will be characterized sequentially, with interwell tests being conducted after well facility installation is complete. Each well will have a retrievable monitoring system (i.e., pressure and hydrochemical sensors). It is expected that the target depth interval will be thin (i.e., $10 \mathrm{ft}$ or less) and relatively homogeneous. If significant heterogeneity is evident within the target depth interval, a multilevel monitoring system will be employed.

Following completion of single-well testing and installation of the monitoring systems within each of the six surrounding characterization/ monitoring wells, multiwe 11 interference tests will be conducted. The tests are identical to the single-well tests (i.e., slug or pumping tests). The only difference is that the effects of the test are monitored not only at the stress well, but also in nearby observation wells. Results from multiple-well interference tests provide areal site characterization information not obtainable with single-well tests, including

- the average hydraulic properties for the target depth interval within the region between the stress well and monitoring well locations,

- the lateral continuity of the target depth interval (i.e., presence of boundaries), - information concerning the horizontal anisotropy (i.e., $\mathrm{K}_{\mathrm{hx}} / \mathrm{K}_{\mathrm{hy}}$ ),
and

- the degree of hydraulic communication with overlying and underlying hydrogeologic units.

The number and type of multiple-well tests to be conducted depend on results obtained from the single-well tests. As a minimum, one constant-rate 


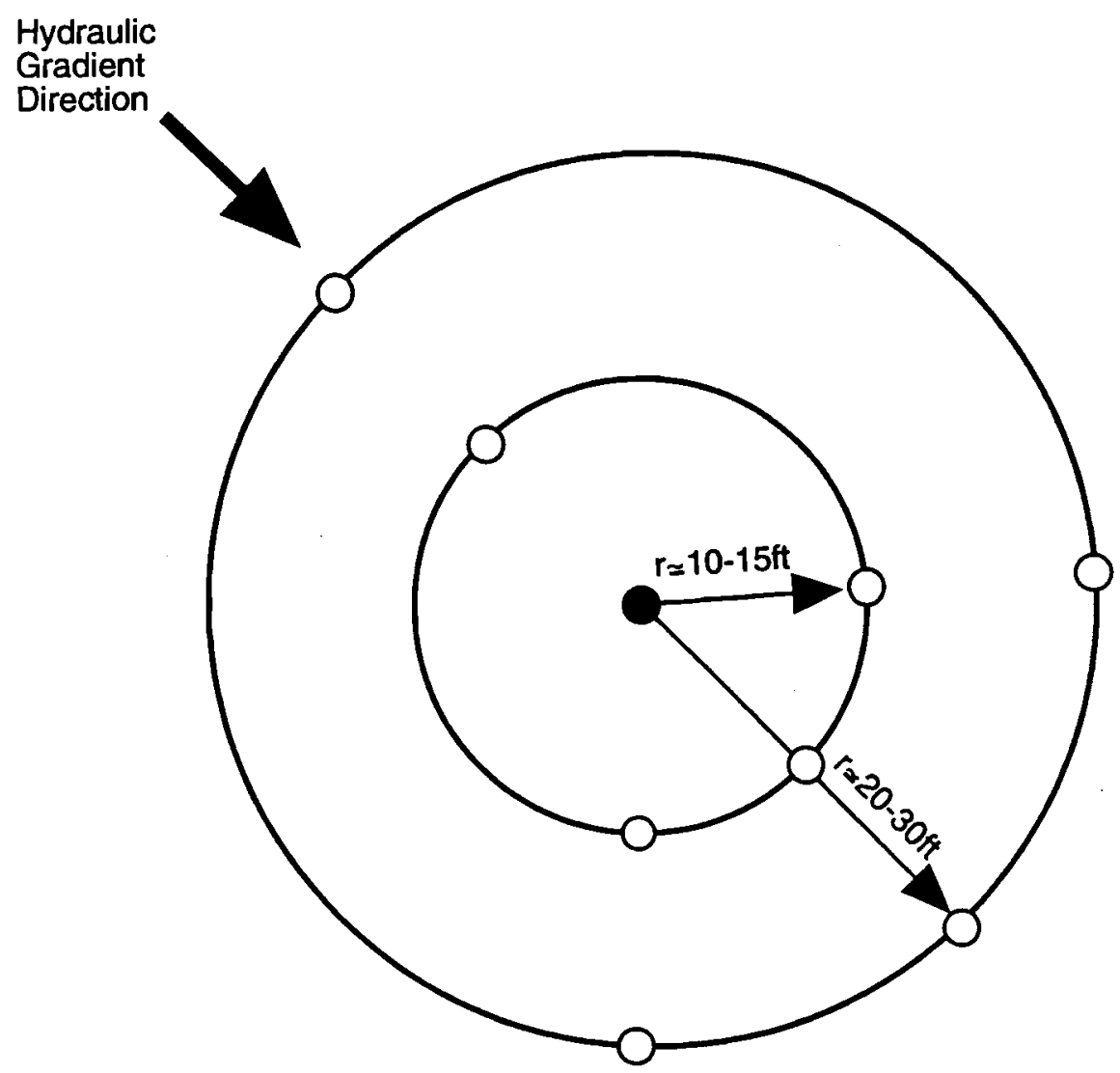

Tracer injection/withdrawal well

Monitoring well

S9211013.11

FIGURE A.2. Proposed Layout of Phase Test/Monitoring Well Sites, for a Test Control Area Having Moderate to High Hydraulic Head Gradients and Relatively Homogeneous Subsurface Conditions

pumping tast (using the central test well as the stress well) and one to four slug interference tests (using the central test well and possibly the three inner monitoring wells as the stress well) are envisioned. Information obtained from the Phase 2 multiple- and single-well tests will be the primary source for characterizing the target depth interval in the test control area, and will be used in the design of the tracer tests conducted during Phase 3 and the subsequent in situ redox-manipulation experiment. 
Information obtained from the single- and multiple-well tests will also be used for the design of hydraulic gradient control measures (should they be deemed necessary), which may be implemented during the in situ redoxmanipulation experiment. The objective of implementing such measures during the experiment is to allow the test control area to be exposed to the redoxcontroliing reagent continuously during the entire residence period following tracer injection.

\section{A.2.2.3 Hydrochemical Sampling and Analysis}

After installation of the monitoring systems at each well, representative groundwater samples will be collected from a maximum of three monitored horizons at several of the monitoring well locations. Because of the proximity of the well facilities, groundwater samples will not be required from each well facility for the hydrochemical characterization of the target depth interval. If the target depth interval is homogeneous and multilevel monitoring systems are not needed in the monitoring wells, sampling will be confined to the test well location. Groundwater samples will be collected using a submersible pump. Unstable hydrochemical parameters, such as pH, Eh, oxygen content, and alkalinity will be measured in the field at the time of sample collection. Planned laboratory analyses include major inorganics, trace elements, specific electrical conductivity, $\mathrm{pH}$, and alkalinity. Hydrochemical information obtained from laboratory analyses will be used in designing the reagent(s) to be injected into the target depth interval during the in situ redox-manipulation experiment.

Although complete hydrochemical characterization of groundwater samples for the target depth interval is planned for the test well only, samples from ali inonitoring well locations will be collected and archived. ihese samples. will be available for comparisons during hydrochemical sampling in Phase 3 that is designed to assess geochemical changes within the target depth interval caused by the in situ redox-manipulation experiment.

\section{A.2.2.4 Hydraulic Head Characterization}

Hydraulic head patterns within the test control area will exert a profound influence on how the in situ redox-manipulation experiment is 
conducted. The focus of site hydraulic head characterization activities is primarily on determining the hydraulic gradient and groundwater flow direction within the area of investigation. Determining the hydraulic gradient (change in head per unit of distance in a given direction) is of primary importance for reagent injection tests, since the gradient is the natural driving force for the movement of fluids in the subsurface. Groundwater flow direction determination is also important, because the optimum siting of the injection well and the surrounding monitoring well network is dependent on the direction of reagent/tracer migration during testing.

In contrast to Phase 1 characterization activities, Phase 2 characterization of hydraulic head properties within the target depth interval will depend primarily on results of tracer-dilution tests. Because of the closeness of the wells, areal hydraulic head based on actual head differences will be difficult to analyze, given standard measurement procedure accuracies and anticipated hydraulic gradient conditions ( $i . e ., \leq 10^{-3} \mathrm{ft} / \mathrm{ft}$ ). It is envisioned that a minimum of three tracer-dilution tests will be conducted, one at the central test well, and one each within the inner and outer rings of monitoring wells.

Areal Hydraulic Head Analysis. Even though it is unlikely that accurate hydraulic head gradient and groundwater flow direction determinations can be obtained through areal hydraulic head analysis, the effort will be made. Because of their wider distance spacing, the three monitoring wells in the outer ring offer the best chance for valid information.

After installation of the monitoring systems within each well facility, hydraulic head values will be calculated by conversion of downhole pressure measurements for the monitoring well locations, as described in Section A.1.2.4 for Areal Hydraulic Head Analysis.

In addition to providing estimates of hydraulic gradient and groundwater flow direction, time-variant head responses for the target depth interval will be evaluated to assess the dynamics of the groundwater flow system (i.e., the response to both natural and human-related stresses, such as natural recharge and discharge, waste-water disposal). This evaluation will be of special 
significance in assessing any possible effects (e.g., Columbia River fluctuations) during the in situ redox-manipulation experiment.

Tracer-Dilution Tests. Tracer-dilution testing will be the primary method for determining hydraulic gradient and groundwater flow direction within the test control area. It is envisioned that a minimum of three tracer-dilution tests will be conducted, one at the central test well, and one each within the inner and outer rings of monitoring wells.

The tracer-dilution test method is an accepted technique for determining the lateral hydraulic gradient or groundwater flow velocity within the immediate vicinity of a borehole. Essential design elements of a tracerdilution test were discussed in Section A.1.2.4, on Tracer-Dilution Tests.

Differences in hydraulic gradient calculations obtained with tracerdilution techniques have been noted (e.g., Drost et al. 1968; Kearl et al. 1988). These differences have been attributed to distortions in the flow field due to increased (or decreased) permeability caused by the presence of the well. However, based on the expected moderate hydraulic conductivity of the target depth interval and on the method of well completion, little distortion of the flow field is anticipated.

Although hydraulic gradient conditions can be directly determined from tracer-dilution test results, groundwater flow direction cannot. For estimating groundwater flow direction, tracer arrival time at surrounding monitoring wells will be detected. Groundwater velocity calculations (based on detected tracer arrival times) for two or more monitoring well locations can be used to define the groundwater flow direction within the test control area.

Phase 2 areal head analysis and tracer-dilution testing results will be compared with hydraulic gradient and groundwater flow direction determinations obtained over the entire test site during Phase 1. Close similarity is anticipated, although slight differences in the test control area attributed to localized hydrogeologic conditions would be expected. 


\section{A. 3 PHASE 3 TEST PLAN}

Phase 3 test activities will pertain directly to the performance of the in situ redox-manipulation experiment. In addition to the test itself, these test activities include conservative tracer test(s) for design guidance for the in situ redox-manipulation experiment and, following completion of the experiment, repeated hydraulic characterization tests to assess any physical and geochemical changes within the target depth interval that can be attributed to the reagents that were administered. The assessment of possible physical and geochemical changes wi11 require repeating selected characterization tests from Phase 2, as well as additional geologic and hydrochemical sampling within the target depth interva1. Details for the in situ redoxmanipulation experiment are not included in the description of the Phase 3 site characterization plan, but will be contained in a separate test plan document.

\section{A.3.1 Conservative Tracer Design Tests}

Prior to the in situ redox-manipulation experiment, a series of conservative tracer tests will provide additional information concerning local heterogeneity in the target depth interval and support the design of the redox test. The conservative tracer tests will be conducted in the same way as the in situ redox test. No additional test or monitoring wells are required for Phase 3 activities or the in situ redox-manipulation test. The we 11 network that will be used is as described for Phase 2. This includes the seven test/monitoring well array with two sets of three equidistant wells (i.e., 120 degree spacings) located around a central test we 11 (Figure A.1).

The conservative tracer tests wi1l be conducted as a single-wel1 injection/withdrawal test, using the central test we 11 as the tracer injection/withdrawal facility, and the surrounding monitoring wells to observe the migration of the injected tracer(s). The following are salient aspects of the single-well tracer injection/withdrawal tests:

- injection of the conservative tracer at a constant rate from the central test well,

- termination of tracer injection after the required volume of tracer has been injected, 
- a prescribed residence time for the tracer to interact with the hydrogeologic framework of the target depth interva],

- tracer monitoring at the surrounding monitoring wells

- withdrawal of the conservative tracer from the target depth interval by pumping at a constant rate from the central test wel1, and

- monitoring of tracer concentrations at the central test well and at the surrounding monitoring well locations.

A minimum of three single-well tracer tests are planned, with each successive test having a longer residence time (e.g., 1 week, 2 weeks, 3 weeks) after termination of tracer injection. Ideally, the three tracer injection tests could be combined in a single test phase, having only one pumping withdrawal period. However, complications can arise when tracer injection phases are combined in a single test, as a result of tracer interactions, analysis interferences, and the like (Spane 1990). For these reasons, each tracer selected will be completed as a separate trace injection/ withdrawal test.

Comparison of results obtained from the single-well tracer tests will provide information concerning dispersivity and local heterogeneities within the control test area. This information in turn will be used to select the optimum residence time for the in situ redox-manipulation experiment. If results from the single-well tracer tests indicate unfavorable responses in the surrounding monitoring well network, then a multiple-we11, non-recirculating withdrawal test will be conducted. For such a test, groundwater is pumped from the central test well at a constant rate. After the drawdown has stabilized (i.e., steady-state conditions have been achieved) at the monitoring well lozations, conservative trazers are released from selected monitorinc wells. The tracer concentrations are then monitored in the groundwater pumped from the central test we11. The tracer "break-through" patterns are then analyzed to obtain information (e.g., dispersivity, anisotropy) concerning the target depth interval in the interwell region. Information obtained from this test can then be used in the redesign of the in situ redox-manipulation experiment. 


\section{A.3.2 Assessment of In Situ Redox-Manipulation Experiment Effects}

After completion of the in situ redox-manipulation experiment, tests will be conducted to assess physical and geochemical changes within the target depth interval. Assessment of physical and geochemical changes attributed to the reagents that were administered'will require repeating selected characterization tests from Phase 2, as well as additional geologic and hydrochemical sampling within the target depth interval.

\section{A.3.2.1. Geologic Sampling/Analysis}

To assess possible physical and geochemical changes within the target depth interval, additional characterization boreholes will be required. The number and location of such additional boreholes depends on results obtained during the in situ redox-manipulation experiment; however, if redox reagents are detected within monitoring wells in the outer ring, a minimum of two additional characterization boreholes is envisioned. The additional characterization boreholes will be sited in the immediate area of existing monitoring wells. Geologic sampling and analyses for the target depth interval within the characterization boreholes will follow those described previously for Phase 2 monitoring wells.

\section{A.3.2.2 Hydraulic Property Characterization}

To evaluate possible changes to hydraulic properties within the target depth interval in the test area, selected tests conducted during Phase 2 and earlier stages of Phase 3 will be repeated. To minimize uncertainties due to test scale effects, the repeated tests will be conducted in identical fashion to the original tests. As a minimum, the following tests will be repeated:

- Multiple-Well Interference Test to assess hydraulic property changes in the interwell region (previously conducted during Phase 2),

- $\quad$ Single-We11 Slug Tests to assess hydraulic property changes in areas immediately surrounding the well locations (previously conducted during Phase 2), and

- Conservative Tracer Design Test (either the single-well injection/ withdrawal or multiple-wel1 non-recirculating withdrawal test) to assess changes to transport properties within the interwell test area (previously conducted during earlier stages of Phase 3 ). 
Hydraulic heads will be measured at various levels in the wells to define both vertical and horizontal gradients. Information on the regional gradient will be available from nearby wells.

\section{A.3.2.3 Hydrochemical Sampling/Analysis}

To assess possible hydrochemical changes within the target depth interval, additional groundwater sampling and analysis will be required. As a minimum, resampling and analyses should be performed for all wells within the control test area that exhibited the presence of reagents during the in situ redox-manipulation experiment. Analysis results will be compared with those obtained from archived samples collected before the in situ redox-manipulation experiment. Hydrochemical analyses for the target depth interval within the characterization boreholes will include those described for hydrochemical characterization in Phase 2.

\section{A.3.2.4 Geochemical and Microbiological Characterization of Core Samples}

To assess changes in the geochemical characteristics of the solid phases in the aquifer, particularly the redox status, cores for characterization measurements of geochemical, microbiological, and hydraulic properties will be obtained by drilling boreholes after the injection of the reagent. Geochemical measurements made on cores will include cation exchange capacity, extractable iron, exchangeable ions, total chemical analysis, ferrous/ferric iron ratio, and mineralogy. Aqueous measurements for extracted pore waters will include major and trace cations and anions, redox-sensitive couples, Eh, $\mathrm{pH}$, dissolved oxygen, and organic and inorganic carbon. The response of the redox-sensitive elements to any natural changes in aquifer redox status will be determined. Microbiological analyses will include identification and enumeration of specific physiological groups and a comparison to populations observed before the injection. These groups will include aerobes, nitratereducers, iron-reducers, sulfate-reducers, and methanogens. Measurement of geohydrologic parameters will include grain-size analysis, porosity, density, and hydraulic conductivity. The degree of heterogeneity of each of these properties will be evaluated. 
. 


\section{DISTRIBUTION}

No. of

Copies

$\underline{\text { OFFSITE }}$

12 DOE/Office of Scientific and Technical Information

25 U.S. Department of Energy 12800 Middlebrook Road Germantown, MD 20874

T. D. Anderson

EM-551

K. J. Angleberger

EM-442

S. B. Balone

J. E. Baublitz

J. 0. Boda

J. A. Coleman

S. P. Cowan

J. J. Fiore

D. W. Geiser

L. Harmon

M. T. Janaskie

R. A. Jump

I. M. Lankford

R. Levine

S.C.T. Lien

R. G. Lightner

S. A. Mann

W. C. Schutte

M. W. Shupe

C. H. Sink

L. H. Taylor

J. S. Walker

H. F. Walter

S. W. Warren

S. M. Wolf

2 U.S. Department of Energy Forrestal Building 1000 Independence Ave. SW Washington, DC 20585

W. Bixby

L. W. Smith

$E M-343$

$E M-442$

EM-542

$E M-60$

$E M-60$
No. of

Copies

2 U.S. Department of Energy Albuquerque Field office P.0. Box 5400

A1buquerque, NM 87115

D. H. Bandy

P. A. Saxman

T. Taylor

U.S. Department of Energy Amarillo Area Office

HGWY 60 FM 2373

Pantex Plant

Amari110, TX 79120

S. Webster

U.S. Department of Energy

Chicago Field Office

9800 S. Cass Ave.

Argonne, IL 60439

F. J. Wobber

U.S. Department of Energy 19901 Germantown Rd. Germantown, MD 20874

S. Hinschberger

U.S. Department of Energy

Idaho Field office

785 DOE Place

Idaho Falls, ID 83402

2

U.S. Department of Energy

Morgantown Energy Tech Ctr 3610 Collins Ferry Road

Morgantown, WV 26507-0880

T. Martin

C. Zeh 
PNL -10123

UC - 402,802

No. of

Copies

2 U.S. Department of Energy Nevada Field Office P.0. Box 98518 .

Las Vegas, NV 89193-8518

K. McWilliam

R. F. Smiecinski

2 U.S. Department of Energy Oak Ridge Field Office P.O. Box E

Oak Ridge, TN 37831

J. Moore

J. Sweeney

G. E. Staats

U.S. Department of Energy Pittsburgh Energy Tech Cntr P.0. Box 10940

Cochran's Mill Road

Pittsburgh, PA 15236-0940

2 U.S. Department of Energy Rocky Flats Office

DOE Building 116

Golden, C0 80402-0928

R. Tyler

S. Grace

R. Scott

U.S. Department of Energy

San Francisco Field Office 1333 Broadway

0akland, CA 94612

M. O'Rear

U.S. Department of Energy Savannah River Field office P.0. Box A

Aiken, SC 29808
No. of

Copies

6 Argonne National Laboratory 9700 S. Cass Ave. Argonne, IL 60439-4837

N. Beskid

J. C. Cunnane

J. Frank

J. E. Helt

D. Johnson

R. W. Peters

2 Ames Laboratory 329 Wilhelm Hall

Iowa State University

Ames, IA 50011

W. Haas

P. Wang

Dr. John Benemann

343 Carave 11 Dr.

Walnut Crek, CA 94598

S. Foge 1

Bioremediation Consultants, Inc.

55 Halcyon Road

Newton, MA 02159

2 Bradtec

1010 Huntcliff Tr., Suite 1350

Atlanta, GA 30350

N. Swift

M. Dunn

2 Brookhaven National Laboratory

Building 703-50 Rutherford

Upton, NY 11973

J. Heiser

P. Colombo 
PNL -10123

UC $-402,802$

No. of

Copies

3 Chem-Nuclear Geotech, Inc.

PO Box 14000

Grand Junction, CO 81502-2567

D. Emilia

S. J. Morrison

S. Schweissing

D. Kaback

Colorado Center for

Environmental Management

1536 Cole Blvd.

Bldg 4, Suite 180

Golden, CO 80401

R. Treat

Ebasco Services, Inc.

1201 Jadwin, Suite 202

Richland, WA 99352

5 EG\&G Idaho, Inc.

Idaho National Engineering $L a b$ P.0. Box 1625

Idaho Falls, ID 83415

K. Koller

K. M. Kostelnick

R. Kuhl

K. Merrill

P. Wichlacz

J. L. Peterson

EG\&G Rocky Flats, Inc.

Technology Development

P.0. Box 464

Golden, CO 80402

L. Rogers, RLS-11

EG\&G Energy Measurement, Inc.

P.0. Box 1912

Las Vegas, NV 89125

3 Fernald Environmental

Management Company of Ohio

P.0. Box 398704

Cincinnati, $\mathrm{OH}$ 45239-8704

K. Nuhfer

P. J. Pettit

D. E. Ridenour
No. of

Copies

C. Voss

Golder Associates, Inc.

4104 148th Ave.

Redmond, WA 98502

2 Lawrence Berkeley Laboratory

1 Cyclotron Rd.

Berkeley, CA 94720

$S$. Benson

G. Moridis

5 Lawrence Livermore National

Laboratory

P.0. Box 808

Livermore, CA 94550

D. Bishop

A. C. Heywood

R. B. Knapp

D. Rice

J. L. Yow

3 Los Alamos National Laboratory

Los Alamos, NM 87545

B. R. Erdal

D. Janecky

H. D. Murphy

3 Martin Marietta Energy Systems

HAZWRAP

P.0. Box 2003

Oak Ridge, TN 37831-7606

R. E. Adams

R. Snipes

R. Swatzell

Massachusetts Institute of Technology

Plasma Fusion Center

167 Albany Street, NW16-140

Cambridge, MA 02139

2 MSE Inc.

P.0. Box 4078

Butte, MT 59702

N. S. Egan

W. C. Goldberg 
PNL -10123

UC $-402,802$

No. of

Copies

12 Oak Ridge National Laboratory P.0. Box 2008

Oak Ridge, TN 37831-6273

J. Berry

B. Faison

D. Gates

S. E. Herbes

R. Jenkins

K. Kibbe

K. T. Klasson

J. Koger

A. Malinauskas

A. V. Palumbo

R. L. Siegrist

R. Swatzell

4 Sandia National Laboratories P.0. Box 5800

Albuquerque, NM 87185

D. Berry

E. R. Lindgren

J. Nelson

J. Rea

6 Westinghouse Savannah River Co.

Savannah River Site

Aiken, SC 29808

J. Bibler

T. Coleman

T. C. Hazen

B. Looney

J. Steele

W. Wilde

2 Stanford University

Stanford, CA 94305-4020

P. Kitanidis

P. McCarty

2 U.S. Air Force

Tynda7 7 AFB, FL 32403-6001

J. Spain

K. Voge1, HQ AFCESA/RAVW
No. of

Copies

3 U.S. Environmental Protection Agency

W. Martin Luther King Dr.

Cincinnati, $\mathrm{OH} 45268$

E. F. Barth

J. Martin

R. Parker

H. Pritchard

U.S. Environmental Protection Agency

1 Sabine Island Dr.

Gulf Breeze, FL 32561-5299

J. Barich ES-098

U.S. Environmental Protection Agency

Region 10

1200 Sixth Ave.

Seattle, WA 98101

R. Mink

University of Idaho

106 Morrill Hall

Moscow, ID 83843

D. E. Daniel

University of Texas

Austin, TX 78712-1076

\section{ONSITE}

9 DOE Richland Operations Office

D. A. Brown

K8 -50

J. K. Erickson

A5- 19

L. Erickson

R3 -74

R. D. Freeberg

A5 -19

J. D. Goodenough

A4- 19

J. M. Hennig

L. Mamiya

R3-80

R. K. Stewart

K8-50

D. E. Trader

A5- 19

K8-50 
No. of

Copies

U.S. Environmental Protection Agency

D. R. Sherwood

B5-01

\section{ICF Kaiser Hanford Company}

H. A. Dugger E6-64

10 Westinghouse Hanford Company
M. R. Adams
$\mathrm{H} 6-01$
H. Babad
R2 -78
J. D. Berger
$\mathrm{L} 0-18$
R. L. Gilchrist
$\mathrm{L} 5-63$
M. C. Hagood
H6-04
H. D. Harmon
$\mathrm{R} 2-52$
J. 0. Honeyman
$\mathrm{R} 2-52$
H. E. McGuire
B3 -63
E. C. Thornton
H6-06
D. D. Wodrich
$\mathrm{HO}-30$

38 Pacific Northwest Laboratory
J. E. Amonette
B. N. Bjornstad
$\mathrm{K} 6-81$
G. D. Black
T. M. Brouns
$\mathrm{K} 6-84$
K7 -28
D. A. Carrothers
P7 -35
C. R. Cole
$\mathrm{K} 6-86$
L. J. Criscenti
$\mathrm{K} 6-77$
$\mathrm{K} 6-81$
J. K. Fredrickson
$\mathrm{K} 4-06$
J. S. Fruchter
K6-96

No. of

Copies

$\begin{array}{ll}\text { M. A. Gerber } & \text { P8-38 } \\ \text { Y. Gorby } & \text { K4-06 } \\ \text { D. J. Holford } & \text { K6-77 } \\ \text { P. J. Mellinger } & \text { B } 1-40 \\ \text { R. W. Moss } & \text { P }-41 \\ \text { M. E. Peterson } & \text { K2-47 } \\ \text { M. J. Quadrel } & \text { L5-63 } \\ \text { J. A. Schramke } & \text { K6-81 } \\ \text { C. S. Simmons } & \text { K6-77 } \\ \text { R. S. Skeen } & \text { P7-41 } \\ \text { S. C. Slate } & \text { K1-19 } \\ \text { F. A. Spane } & \text { K6-96 } \\ \text { S. L. Stein } & \text { BSRC } \\ \text { T. O. Stevens } & \text { K4-06 } \\ \text { J. C. Templeton } & \text { K6-81 } \\ \text { J. S. Tixier } & \text { P7-34 } \\ \text { V. R. Vermeul } & \text { K6-96 } \\ \text { J. W. Virden } & \text { K2-44 } \\ \text { R. E. Wildung } & \text { P7-54 } \\ \text { M. D. Williams } & \text { K6-77 } \\ \text { S. B. Yabusaki } & \text { K6-77 } \\ \text { J. M. Zachara } & \text { K3-61 } \\ \text { Publishing Coordination } & \\ \text { Technical Report Files (5) }\end{array}$

Routing
R. M. Ecker
Sequim
M. J. Graham
K6-78
P. M. Irving
$\mathrm{K} 6-98$
S. A. Rawson
K6-04
P. C. Hays/
L. K. Grove (1ast)
$K 6-86$ 
